\title{
NATIONAL OCEANIC AND ATMOSPHERIC ADMINISTRATION AUTHORIZATION
}

Y 4. C 73/7:S. HRG. 103-865

National Dceanic and Atnospheric Ad...

\section{HEARING}

BEFORE THE

\section{COMMITTEE ON COMMERCE, SCIENCE, AND TRANSPORTATION \\ UNITED STATES SENATE \\ ONE HUNDRED THIRD CONGRESS \\ SECOND SESSION}

JUNE 15, 1994

Printed for the use of the Committee on Commerce, Science, and Transportation

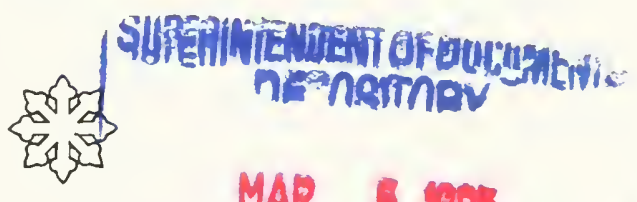

MAR 8 ings

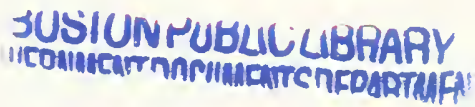

U.S. GOVERNMENT PRINTING OFFICE 



\section{NATIONAL OCEANIC AND ATMOSPHERIC ADMINISTRATION AUTHORIZATION}

Y 4. C 73/7: S. HRG. 103-865

Kational Dceanic and Atnospheric Ad...

\section{HEARING}

BEFORE THE

\section{COMMITTEE ON COMMERCE, SCIENCE, AND TRANSPORTATION \\ UNITED STATES SENATE \\ ONE HUNDRED THIRD CONGRESS}

SECOND SESSION

JUNE 15, 1994

Printed for the use of the Committee on Commerce, Science, and Transportation

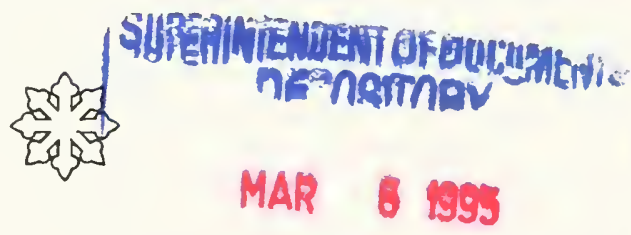

SUSIUNRUBLICLLBRARY

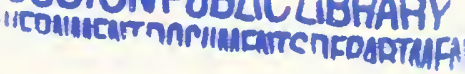

U.S. GOVERNMENT PRINTING OFFICE 


\section{COMMITTEE ON COMMERCE, SCIENCE, AND TRANSPORTATION}

ERNEST F. HOLLINGS, South Carolina, Chairman

DANIEL K. INOUYE, Hawaii

JOHN C. DANFORTH, Missouri

WENDELL H. FORD, Kentucky BOB PACKWOOD, Oregon

J. JAMES EXON, Nebraska

JOHN D. ROCKEFELLER IV, West Vinginia

JOHN F. KERRY, Massachusetts

JOHN B. BREAUX, Louisiana

LARRY PRESSLER, South Dakota

TED STEVENS, Alaska

JOHN MCCAIN, Arizona

CONRAD BURNS, Montana

RICHARD H. BRYAN, Nevada

CHARLES S. ROBB, Vinginia

SLADE GORTON, Washington

TRENT LOTT, Mississippi

BYRON L. DORGAN, North Dakota

KAY BAILEY HUTCHISON, Texas

HARLAN MATHEWS, Tennessee

KEVIN G. CuRTIN, Chief Counsel and Staff Director JONATHAN CHAMBERS, Republican Staff Director

(II) 


\section{O N T E N T S}

\section{LIST OF WITNESSES}

Baker, Hon. James D., Under Secretary of Commerce for Oceans and Atmoshere, National Oceanic and Atmospherica Administration .................... Prepared statement

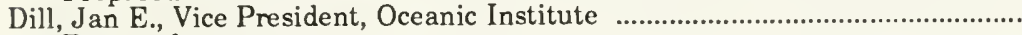
Prepared statement

Garrison, Rob, Executive Director, Nantucket Research and Education Foundation Prepared statement

Hallerman, Dr. Eric, Assistant Professor, Department of Fisheries and Wildlife Sciences, Virginian Polytechnic Institute and State University ................. Prepared statement

Sandifer, Dr. Paul A., Director, Marine Division, South Carolina Department of Natural Resources Prepared statement

\section{APPENDIX}

Environmental Defense Fund, prepared statement of the

Questions asked by, and answers thereto by Dr. Baker:

Senator Dorgan

Senator Gorton

Senator Inouye

Rampy, P.T., Coordinator, Treasure Coast Coalition, Inc., letter from, to Senator Hollings, dated June 17, 1994 



\title{
NATIONAL OCEANIC AND ATMOSPHERIC ADMINISTRATION AUTHORIZATION
}

\author{
WEDNESDAY, JUNE 15, 1994
}

\author{
U.S. SENATE, \\ Committee on Commerce, Science, and Transportation, \\ Washington, $D C$.
}

The committee met, pursuant to notice, at 10:10 a.m. in room SR-253, Russell Senate Office Building, Hon. John F. Kerry, presiding.

Staff members assigned to this hearing: Penelope D. Dalton, senior professional staff member, and Lila H. Helms, professional staff member; and John A. Moran, minority staff counsel.

\section{OPENING STATEMENT OF SENATOR KERRY}

Senator KERRY. The hearing will come to order. My apologies to everybody for the delay. I did not forget that we had a hearing, but unfortunately I was held up at the Foreign Relations foreign aid markup. We were talking about an amendment of mine so I could not break out of there, and I apologize to everybody for that fact.

We are meeting this morning to discuss NOAA's budget reflecting the fiscal priorities for 1995 , and in addition to that we will discuss proposals to strengthen the involvement of NOAA and the National Sea Grant College Program in marine aquaculture. So, I am delighted to welcome Dr. Jim Baker, Under Secretary for Oceans and Atmosphere, who will testify on behalf of NOAA. I appreciate your being here today, as you have been on many occasions.

I would like to welcome the other distinguished witnesses who will provide testimony regarding marine aquaculture: Dr. Paul Sandifer, director of the Marine Division from the South Carolina Department of Natural Resources, member of the National Research Council's Marine Board; Rob Garrison, executive director of the Nantucket Research and Education Foundation, a nonprofit organization based in Nantucket, MA; Jan Dill, vice president of the Oceanic Foundation, Honolulu; and finally, Dr. Eric Hallerman, assistant professor in the Department of Fisheries and Wildlife Sciences, Virginia Polytechnic and State University. And thank all of you for coming here today and sharing time with us.

On my way over here, I was discussing with my legislative director the impossible, almost nonsensical, constraints that we are operating under currently and how probably any one of us could identify serious pockets of waste or nonsensical programs within the $\$ 1.5$ trillion budge' we pass on, but how, nevertheless, annually under these generic caps, we seem to be cutting our own throats, reducing the capacity of Government to function. 
There are some in this country who cheer that notion out of knee-jerk reactions that no government is good government and somehow reducing any expenditures is a healthy trend. I could not disagree with them more strongly. And I think we are quickly reaching a point here in Washington where we are going to confront the essence of what we are doing here and why.

You have to invest in your future. You have to invest in your population. You certainly have to invest in protecting precious resources, particularly precious resources about which we know very little. Ecosystems are fragile. We are only on the bottom end of the learning curve in many respects. Notwithstanding that, we are struggling-struggling-to find the wherewithal to meet the mission, so to speak.

NOAA's mission is really reflective of one of the greatest challenges that we face today, to simultaneously conserve marine resources and protect coastal environments and develop coastal economies. And equally important is its mission to describe, monitor, and predict changes in the Earth's environment so that we can ensure and enhance sustainable economic opportunities. These are very complex, and I might add essential, tasks, and it is appropriate that the first Office of Sustainable Development has been established within NOAA recognizing those priorities.

We can juxtapose all of those priorities with the realities of what is happening out there. The groundfish fisheries of New England have collapsed, the salmon fishery of the Pacific Northwest has collapsed, both have alerted us here in this country to the immediate need to focus on development of sustainable marine resources and management programs. Also, if you spend the time, as too few do, and look at what is happening to bays, estuaries, rivers, and oceans all across the planet, the trend line is extraordinarily disturbing.

Nevertheless, we are cutting or struggling to simply keep up. And today we are going to talk a little bit about that. In order to carry out its missions, NOAA's strategic plan now identifies three broad priorities for fiscal year 1995. No. 1, the continued modernization of the Nation's weather service; No. 2, managing our marine resources, including maintaining critical management of our fisheries, recovering protected species, and maintaining and enhancing coastal ecosystems health management; and No. 3, investing in global change research.

I want to applaud NOAA for this strategic plan which makes sense. After years of underfunding I am glad to see that as to these priorities the budget is beginning to reflect the designation of a strategy, which it did not in the past. And there is a focus on cost effectiveness and on cooperation among agency programs.

An important part of carrying out NOAA's mandates is completing the fleet modernization plan. This is something we have talked about in this committee ever since I assumed the vice chairmanship of NOAA and have been at these hearings. I have been disturbed that notwithstanding appropriation there has been no expenditure, and the program has been in some disarray notwithstanding many years ago having heard about the urgent need for the revitalization of trie fleet. 
NOAA's plan was recently criticized in reports by the National Research Council and the General Accounting Office, I might add of which both examinations were invited by Dr. Baker. I have absolute confidence that he is going to use those reports to reach goals of efficiency and effectiveness, and so we look forward today to hearing precisely how that is going to happen.

We also want to hear about the next generation aircraft reconnaissance system that is going to be used for hurricane and severe storm forecasting. This program is every important since the highaltitude capability does not presently exist and more accurate forecasting reduces loss of life and property damage, and obviously cost to the Government.

The committee would emphasize that NOAA needs to continue focusing on coastal and ocean programs within the National Ocean Service and oceanic and atmospheric research efforts. With the reauthorization of the Coastal Zone Management Act coming before us, it is vitally important that there be adequate funding of NOS programs. Furthermore, it is essential that NOAA continue to maintain a strong role in coastal monitoring and research. And finally, the coastal ocean program is important because of its ability to cut across line offices and to address the critical ocean research needs.

I might just comment quickly on marine aquaculture which we will focus on somewhat this morning. We have called previously on NOAA to maintain its commitment to the aquaculture industry, and we believe very much that strong programs within NOAA for effective marine aquaculture management, research, and education, are now needed more than ever before. With fisheries and ports, Such as Gloucester and New Bedford in Massachusetts, the Northwest Pacific, and here up and down the east coast, under enormous stress, the whole concept of aquaculture looms with far greater urgency, and not just possibilities. The demand for fish product is going up, the capacity of the ocean to produce it is going down. And so we are in a clash with these trend lines and have a fundamental responsibility to future generations to try to deal better with these resources.

I would point out also that there are obviously constraints on aquaculture. Located near coastal waters or in coastal waters, aquaculture operations by definition have to operate in an extremely complex regime of coastal regulations. These regulations along with public concerns, environmental concerns about wastewater, water quality, concerns about genetic contamination of naturally occurring species, and conflicts with other coastal users loom as large issues. It is very clear from the Asian experience and from other people's efforts in this area that there is a great deal left for us to do to begin to take advantage of what marine aquaculture has to offer.

So, my final comment is that I think this committee provides one with a unique opportunity to consider what we are doing here in Washington, what we are doing to ourselves now versus what we ought to be doing for ourselves for the future. I am increasingly concerned that we are on a kind of automatic pilot in Washington that is ignoring the realities of what is happening around us. We are very busy cutting off our nose to spite our face in the interests 
of small bromides of political equations that in the long run do not make sense but in the short run they get you reelected.

This committee affords us an opportunity to really confront those trend lines and those political realities, and I hope we are going to begin to do it with a larger dose of reality than we currently have. Senator Packwood.

\section{OPENING STATEMENT OF SENATOR PACKWOOD}

Senator PACKWOOD. Mr. Chairman, thank you.

Dr. Baker, let me thank NOAA for holding the small town meetings on the Pacific coast over the past several weeks so the administration could find out directly from those involved as to the problems they face because of the salmon closure. John Bullard of your Office of Sustainable Development has done a very good job and I have had good reports. Are we happy about the closure? No. Have the meetings been worthwhile and helpful? Yes.

Now, let me address a couple of concerns I do have. I am miffed about a statement that appeared in the Oregonian paper. You have eliminated the Mitchell Act fish hatcheries, \$13.8 million, and the fish screens which is $\$ 4.7$ million, in your budget. The budget information that I received when I met with your people in February was that the Bonneville Power Administration was going to pay NOAA to run the hatcheries programs and, therefore, they were not in your budget.

Now, unfortunately, nobody told the Bonneville Power Administration about this, and it will take an act of Congress to shift that money. I understood what your people said when they came to see me, but then a story appears in the Oregonian that I agreed with their statement. And that is sort of like saying to the condemned man you are going to be hung tomorrow morning. He understands the statement. He does not necessarily agree with it, but he understands it.

If Bonneville is going to have to pay for this and you are saying we have to raise the rate for the ratepayers to pay for it, that is something we will fight and have fought in the past. But I think for NOAA to say "Well, do not worry, the problem has been taken care of, we have shifted it to somebody else's budget," is not quite an answer to our problem.

The salmon are disappearing and the hatcheries are vital. We have had them since 1938. The Federal Government has been putting up the money under the Mitchell Act from that time to now to make up for the fish that we knew we would kill with the dams.

So, I do not regard as adequate for NOAA to say to the Bonneville Power Administration that Bonneville is going to pay for it and that Bonneville will have to get an act of Congress to do it. Bonneville cannot shift the money around by themselves. NOAA just can't say it is no longer its problem or no longer the Department of Commerce's problem.

I want to know specifically where the funding is going to come from next year for the operation of the hatcheries, and to a lesser degree the fish screens which keep the salmon from getting swept into the irrigation pumps. Where is that money coming from? Is the administration going to push Bonneville today? Is the adminis- 
tration going to say to Bonneville that you demand this, or do we have to say no, we are not going to shift it there?

My second concern is the National Coastal Resources Research and Development Institute which NOAA says it is a good program but it is no longer in its mission. It does not seem to be in anybody's mission, not that I can find in the Department of Commerce anyplace. And I understand poor old Leon Panetta's problems and I understand budget limitations. He probably says to you, Dr. Baker, "I am sorry, you cannot have all the money you want. You figure it out how to get it down. Do not come back to me with more requests."

If NCRI is a good mission and it should be funded, but NOAA is not going to fund it and the Department of Commerce is apparently not going to fund it, who is going to fund it? What are your recommendations? Where do we get the funding?

If you could get answers for me Dr. Baker, I would appreciate it. And Mr. Chairman, I am going to go off to the Finance Committee now, and I appreciate your letting me make this statement.

Senator KERRY. Thank you very much, Senator Packwood.

Senator Stevens, do you have an opening statement?

Senator STEvens. No, Mr. Chairman, I would prefer to listen to my good friend, my southern neighbor from Washington and then ask some questions afterward. I have no statement.

Senator KERRY. Thank you very much, Senator Stevens.

Dr. Baker, thank you for being with us. We look forward to your testimony.

\section{STATEMENT OF HON. JAMES D. BAKER, UNDER SECRETARY OF COMMERCE FOR OCEANS AND ATMOSPHERE, NATIONAL OCEANIC AND ATMOSPHERIC ADMINISTRATION}

Dr. BAKER. Senator Kerry, thank you very much for the opportunity to talk to your committee.

I am very cognizant of the fact that one of the reasons we have a NOAA here today is because of this committee. Your support of NOAA over the years has been vital to the existence of the agency and to the achievement of its mission, and I want you to know that we recognize that, and it is a very important thing for us.

I am very pleased to appear before you today as we build our authorization plan for the 1995 budget. Our budget right now is about $\$ 1.9$ billion, and we have about 15,000 employees nationwide.

I would also like to thank you, Senator Kerry, and you, Senator Stevens, for your legislation to reauthorize the Magnuson Act, which is another very important driving force for our activities.

As you mentioned, Senator Kerry, we have restructured NOAA's budget from the previous organization-based structure to a structure that mirrors our strategic plan. This structure allows us for the first time to directly link NOAA's programs with agencywide budgets, goals, and objectives. You can find a more detailed outline of the strategic plan in my written testimony.

As far as environmental stewardship is concerned, our mission includes promoting global environmental stewardship in order to conserve and wisely manage the Nation's marine and coastal resources, and I would also like to thank you for your leadership on 
the Coastal Zone Management Act, which is another driving force for what we do.

I am also happy to announce that today the Marine Fisheries Service is upgrading the status of the California gray whale from endangered to fully recovered, an important success story from the Endangered Species Act. As you know, Secretary Babbitt and I announced yesterday a number of administrative changes in the Endangered Species Act which will make that act easier to manage and more responsive to all of the constituencies, including the endangered species.

Now, in terms of building sustainable fisheries, an important priority for us, one of the new things that is in our budget this year is fishery user fees. In 1995, our proposal that has come with the President's budget proposes an increase of fishery fees for living marine resources by $\$ 82$ million.

Four categories of fishery user fees are proposed. They are first sale value of U.S. commercial landings, first sale value of edible imported seafood, value of individual transferable harvest shares, and vessels to cover costs of special management measures that directly benefit specific fisheries and fish harvesters, for example, observers.

This proposal was developed after a series of meetings with representatives of Congress and industry constituent groups to develop a proposal which we believe is both fair and practical. Our guiding principle in developing these fees includes the idea that the fees be reasonable and not represent an onerous burden, and that revenues generated by the fees be used to benefit the people paying the fees. A specific proposal to generate revenues was submitted to Congress by the administration during the Magnuson Act reauthorization process.

A second part of our NOAA strategic plan is environmental assessment and prediction. That is, describing, monitoring, and predicting changes in the Earth's environment in order to ensure and enhance sustainable economic opportunities now and for the future.

In our 1995 budget, we are requesting about $\$ 1.1$ billion for advanced short-term forecast and warning services. Funds are requested to maintain ongoing forecast and warning operations, including the modernization and restructuring of the National Weather Service.

In the case of the next generation radar and the automated surface observing station procurements and new office construction, we are on the downside of the funding profile. The modernization associated restructuring initiative, the Advanced Weather Interactive Processing System-that is, the software-and the current series of our geostationary and polar satellites are on the upside of the funding profile.

Recently there has been some concern expressed regarding whether it is safe for humans to live near the next generation radars. The system that we have operates at levels that are thousands of times lower, in terms of radiation levels, than the 1992 American National Standards Institute and the Institute of Electric and Electronic Engineers' thresholds.

Now, in terms of cross-cut programs, NOAA in 1995 will share host responsibilities with NASA for the Vice President's Inter- 
agency Global Learning and Observations to Benefit the Environment, or GLOBE program. GLOBE will enhance global environmental awareness and increase scientific understanding of the Earth by working with the worldwide network of schools to collect environmental observations.

This program focuses on the environmental education of our human resources, and our budget contains about a $\$ 7$ million increase for this exciting program.

In terms of environmental technology, we have four distinct pilot programs that will focus our unique contributions to environmental technology efforts: marine biotechnology through the National Sea Grant College Program, weather, hydrologic, and marine observations and information systems; environmental hazards mitigation; and a worldwide environmental information network.

This committee has expressed interest in discussing proposals to strengthen marine aquaculture efforts of NOAA and the National Sea Grant College Program. In 1995, we request an increase of $\$ 1.1$ million to begin the process of accelerating the growth of U.S. marine aquaculture.

Globally, aquacuiture accounts for about 15 percent of fisheries production and about one-third of gross revenues, yet marine aquaculture and stock enhancement are almost insignificant in the United States. Assessments of the potential production from wild stocks and the demand for seafood clearly indicate an increasing dependance on aquaculture and stock enhancement in the future.

In addition, the National Sea Grant College Program sponsors research focused on exploring technological advances to cost-effective aquaculture in closed systems, developing computer monitoring in control systems, developing hatchery technology, and defining physiological, endocrinological, and nutritional controls on development, growth, and reproduction of aquacultural species. The United States is behind the rest of the world in the production of seafood by marine aquaculture.

You mentioned fleet replacement and modernization, an important topic for us. The majority of ships in our NOAA fleet are rapidly approaching the maximum age for cost-effective and productive operations. With the help of funds appropriated by Congress, NOAA has made substantial progress in modernizing its fleet of ships. The highest priority fleet problems have been targeted and actions are underway to solve these problems. Contracts have been awarded or are soon to be awarded for major repairs to existing ships, construction of one new oceanographic ship, and conversion of one of the Navy's T-AGOS ships.

The Marine Board of the National Academy of Sciences has just completed a review of the FRAM plan, which you mentioned. In response to the Marine Board review, we have established a review team consisting of the Deputy Assistant Administrators for the National Marine Fisheries Service, the National Ocean Service, and the Office of Atmospheric and Oceanic Research.

The team will assess the FRAM program in light of the Marine Board's recommendations, and propose appropriate revisions to the FRAM plan.

The House NOAA Authorization Act, H.R. 4008, proposes an evaluation of the role of the NOAA Corps within NOAA. We agree 
with the Marine Board that it is good management practice to review all components of our operations, and certainly the NOAA Corps is no exception. If a study is appropriate at this time, we believe that senior civilians within NOAA are the best people to conduct such a study. We believe that this group has a clear understanding of the strengths and weaknesses of the NOAA Corps, as well as how the corps may better serve NOAA.

With regard to aircraft, NOAA's high-altitude aircraft is expected to improve the accuracy of hurricane prediction by about 20 percent. In 1994, we began an aggressive procurement schedule for the new aircraft, and in April we provided industry with a draft statement of work and specification. The response received from industry representatives will be used to finalize the request for proposals, which will be disseminated in mid-July. We anticipate awarding the contract in 1995. The first operational flight of the new aircraft is scheduled for the 1996 hurricane season.

In conclusion, I would like again to stress the NOAA mission to promote global environmental stewardship and describe and predict changes in the Earth's environment. I share your view that we have a gloomy future if we do not address the problems that NOAA works on, and I thank the chairman and the members of this committee for the opportunity to testify, and look forward to working with you as we shape an authorization plan for the future of NOAA.

Thank you.

[The prepared statement of Dr. Baker follows:]

\section{Prepared Statement of Dr. D. James BaKer}

Mr. Chairman and Members of the Committee, I am pleased to appear before you today as we work together to build an authorization plan for the future of the $\mathrm{Na}$ tional Oceanic and Atmospheric Administration. NOAA has a budget of $\$ 1.9$ billion and almost 15,000 employees nationwide. In Massachusetts alone, NOAA employs 663 people and added almost $\$ 48$ million to the economy in the last fiscal year while working to protect the environmental resources needed for long-term sustainable development.

Twenty-four years ago, NOAA was established as a science-based agency with the responsibility of predicting changes in the oceanic and atmospheric environments and living marine resources and providing related data, information and services to the public, industry, the research community and other government agencies.

Many changes have taken place since 1970, and just recently NOA developed an aggressive strategic plan to serve as our guide for the present and our map to the future. This is the first comprehensive attempt to unify NOAA programs toward agency-wide goals and objectives and allows us to address the public's needs more efficiently. Our vision for the year 2005 , as contained in the Strategic Plan, is a world in which societal and economic decisions will be strongly coupled with an increasingly comprehensive understanding of the environment. To achieve this vision, NOAA's base program capabilities and our proposed future efforts are now structured around two major areas-Environmental Stewardship and Environmental Assessment and Prediction-as well as the supporting cross-cut and infrastructure programs.

We have restructured NOAA's budget-from the previous, organization-based structure-to the current structure which mirrors the Strategic Plan. This new structure allows us for the first time to directly link NOAA's programs with agencywide goals and objectives. It is revitalizing our agency by giving us the flexibility to apply our resources across traditional NOAA program elements, allowing us to implement more cost-effective techniques and to become more responsive to users.

The Department of Commerce has organized its FY 1995 budget request into five themes. NOAA programs are included in two of these themes, one on Environmental Stewardship and Assessment and the other on Civilian Technology. The formulation process for NOAA's budget was both highly interactive and positive. NOAA was engaged fully with the Department of Commerce and the Office of Management and 
Budget in discussing all of the issues, and received good support throughout the process.

The implementation of this plan is already beginning to unify the agency and help us to rethink our operations. This plan furthers our commitment to an environmental strategy that promotes sustainable development and proves environmental protection and economic growth can-and must-go hand in hand.

\section{ENVIRONMENTAL STEWARDSHIP}

NOAA's mission includes promoting global environmental stewardship in order to conserve and wisely manage the Nation's marine and coastal resources. This area of our plan consists of four elements-Build Sustainable Fisheries, Recover Protected Species, Coastal Ecosystems Health and Modernize Navigation and Positioning Services.

\section{Build Sustainable Fisheries}

One of NOAA's most significant goals for the next decade is to build sustainable fisheries by refocusing policies and fishery management planning on increased scientific information, rather than letting controversy and confusion drive the decision making. To achieve this NOAA will conduct programs to assess the status of fishery resources, advance fishery predictions, manage for economic growth and promote a healthy fishing industry, ensure adequate compliance, reduce bycatch and accelerate the growth of U.S. aquaculture. Work is conducted on these programs mostly by the National Marine Fisheries Service (NMFS) with support from Sea Grant and others.

In FY 1995, \$259 million is requested to Build Sustainable U.S. Fisheries. Increases of $\$ 40.6$ million are proposed to maintain ongoing operations and to develop fishery management plans to address more effectively the desperate situation facing the Nation's fisheries. We will continue financial support for the eight Regional Fishery Management Councils, and increase funding for the Fishery Reinvestment Program to assist the fishing industry during periods of stock rebuilding.

In FY 1995, NOAA proposes to increase fisheries fees for living marine resources by $\$ 82$ million. Four categories of fisheries user fees are proposed in the Administra. tion's amendments to-the Magnuson Act. They are: expansion of permit fees beyond administrative costs; a levy on the first sale value of fish; a levy on the value of the fish harvested under individual transferable harvest shares; and fees to cover costs of special management measures that directly benefit specific fisheries and fish harvesters (e.g., observers). This proposal was developed after a series of meetings with representatives of Congress and industry-constituent groups to develop a proposal which is both fair and practical. Our guiding principles.in developing these fees include the idea that the fees be reasonable and not represent an onerous burden and that revenues generated by the fees be used to benefit the people paying the fees.

The income from these fees will be used to offset the cost of proposed increases for living marine resource programs, including developing and implementing ambitious fishery management plans addressing such problems as uncontrolled access in fisheries, overcapitalization, overfishing, controversial allocation decisions between various fishing groups, and incidental catch. This effort will provide a significant step in the sustainable development of the fisheries industry. Establishing fees is an important factor in the investment for our living marine resource programs in FY 1995 and the future.

\section{Recover Protected Species}

NOAA strives to be a leader in preserving marine biodiversity by balancing exploitation of natural resources with management of protected species. NOAA's primary challenge is to bring about the recovery of protected species to optimal levels so that we no longer must require extreme conservative protective measures under the Marine Mammal Protection Act and the Endangered Species Act. To achieve this goal NOAA will reduce the impact of human activity on protected species, assess the status of protected species, implement conservation/recovery plans and avoid future listings.

For FY 1995, NOAA requests a total of $\$ 50.6$, million, a net increase of $\$ 19.2$ million over the FY 1995 base, to continue to fulfill the statutory responsibilities of the Endangered Species Act and the Marine Mammal Protection Act.

\section{Coastal Ecosystems Health}

No other area in the United States is as vital to our economy and ecology as the coast, and no other area in the United States is as threatened. Coastal counties occupy only 16 percent of U.S. land area but contain more than 50 percent of the U.S. population. NOAA will work with other State and federal agencies to ensure that 
economic development in U.S. coastal ecosystems is managed in ways that maintain biodiversity and long term productivity for sustained use. To achieve this goal: NOAA will integrate operations for coastal ecosystem management by creating partnerships with states and other federal agencies; NOAA will enhance cross-disciplinary ecosystem assessment of coastal resources; NOAA will develop a comprehensive national monitoring program for coastal ecosystems, working together with coastal states and the EPA to implement the National Coastal Monitoring Act; NOAA will increase scientific understanding of the importance of ecosystem functioning and develop a means for valuing ecological resources; and NOAA will provide a strong information base for informed public policy decision making based on sound science.

A total of $\$ 167.8$ million (including $\$ 7.8$ million from the Coastal Zone Management Fund) is requested for FY 1995. NOAA's new Center for Coastal Ecosystem Health, now being established, is an important element in this equation. Full funding for CZMA grants is included in our request. In FY 1995, we have requested increases of $\$ 3.0$ million for improved management of the Nation's marine sanctuaries, and $\$ 2.4$ million for habitat conservation.

\section{Modernize Navigation and Positioning Services}

In FY 1995, proposed funding for Modernization of Navigation and Positioning Services is $\$ 76.4$ million. NOAA's traditional mission of preparing nautical and aeronautical charts and information for navigation safety can be traced back nearly two centuries to the Nation's oldest scientific agency. Today NOAA is working to modernize its navigation and positioning services to provide accurate and timely marine, coastal and aeronautical data in conventional map and chart formats, as well as providing digital products in near real time. Revolutionary technologies, specifically powerful, low-cost computers and the Global Positioning System (GPS) are forcing changes in these services that are unprecedented. These efforts will lead to an increase in the efficiency and safety of marine and air transportation for purposes of offshore engineering, coastal zone management, military operations, and recreational activities.

\section{ENVIRONMENTAL ASSESSMENT AND PREDICTION}

The second major part of the NOAA strategic plan is Environmental Assessment and Prediction-describing, monitoring and predicting changes in the Earth's environment in order to ensure and enhance sustainable economic opportunities now and for the future. This includes improved short-term weather forecast and warning products, reliable seasonal to interannual climate forecasts, science-based policy advice on decadal to centennial environmental changes, and leveraging of available resources to accomplish more by converging government programs and avoiding duplication.

\section{Advance Short-Term Warning and Forecast Services}

By early in the next century, NOAA will have significantly improved short-term warning and forecast products and services for a broad spectrum of environmental events-such as tornadoes, hurricanes, floods, tsunamis and geomagnetic storms. This will be accomplished by completing the weather service modernization, applying thee lessons learned from the modernization effort, and conducting research and development activities to better understand and predict the environment. Achieving these goals will improve public safety and the economic productivity of the Nation.

In FY 1995, $\$ 1.091$ billion is requested to maintain ongoing forecast and warning operations, continue the weather service modernization, maintain satellite continuity, strengthen NOAA's environmental observing, research, and prediction systems in all areas of the environment, and improve dissemination of products and services. Weaknesses in any of these components will decrease the quality of all forecasts and warnings and hence the long-term benefits to the Nation.

Completion of the weather service modernization is a high priority of the Administration. Modernization has already saved lives and averted damage. The modernization has demonstrated its success through the dramatic increase in storm warning time as well as the significant decrease in false alarms. For example, accurate predictions of the tracks of hurricanes Andrew, Hugo and Iniki reduced thee potential loss of human life and saved money by better constraining evacuation areas.

Implement Seasonal to Interannual Climate Forecasts

Changes in the seasons are the most obvious natural climate cycle. Winters are cold; summers are hot. But the degree to which each winter and each summer differs from the norm creates opportunities and problems for society. To benefit from the opportunities and mitigate the problems, society requires routine, opcrational 
climate forecasts. The science of climate prediction has advanced rapidly over the last decade. However, to date, climate prediction has been done on an experimental basis only. NOAA plans to provide reliable one-year lead time forecasts of global climate variability, especially El Niño and the consequent precipitation and surface temperature distributions. This will enable Americans to respond to the forecasts so as to increase economic advantage and to mitigate against economic losses and social disruption. There are four program goals that are necessary to implement seasonal to interannual climate forecasts. They are: predictions, observing and data systems, process research, and socio-economic and educational dimensions.

In FY 1995, NOAA requests a total of $\$ 94.4$ million for the Seasonal and Interannual Climate initiative. Included in this initiative is $\$ 38.6$ million for the President's U.S. Global Change Research Program (USGCRP), reflecting an increase of $\$ 14.7$ million, which directly supports NOAA's seasonal-to-interannual activities.

\section{Predict and Assess Decadal to Centennial Change}

Our planet is naturally a place of change, often with severe impacts on society. The Sahelian drought and the Midwestern Dust Bowl are examples of decadal change, while the Little Ice Age of the 17th century exemplifies the high-impact climatic fluctuations have on the centennial time scale. Such natural climatic swings will undoubtedly be a part of our future. Human activities can now induce additional changes with equally large impacts. Human-induced changes observed on decadal time scales are already evident. Atmospheric pollution, the thinning ozone layer and greenhouse gasses are a few of the man-made problems which could greatly affect the future of our glpbal climate. NOAA is committed to providing sciencebased advice to policy makers by detecting and assessing decadal to centennial changes in the global environment-with special emphasis on climate change and greenhouse warming, ozone layer depletion and air quality improvement. To address these long-term changes, NOAA requests $\$ 94.1$ million for the Decadal to Centennial initiative.

\section{CROSSCUT PROGRAMS}

NOAA's efforts to provide leadership in environmental stewardship and environmental prediction and assessment would be incomplete without the successful pursuit of programs of technology and education that cross agency lines to tap external resources, expertise and experience NOAA's cross-cut programs aim to build effective bridges to other Department of Commerce bureaus, federal agencies and private sector partners to leverage limited resources in support of mission objectives.

In FY 1995, NOAA will share host responsibilities with NASA for the Vice-President's interagency Global Learning and Observations to Benefit the Environment (GLOBE) Program. GLOBE will enhance global environmental awareness and increase scientific understanding of the Earth by working with the worldwide network of schools to collect environmental observations. This program focuses on the environmental education of our human resources, and our budget contains a $\$ 7.0$ million increase for this exciting program.

\section{Education and Human Resources}

A strong education and human resources agenda will contribute to a national goal of ensuring and enhancing economic opportunity for the American people by fostering a scientifically literate public. A good example of this is the new GLOBE program, a vice-presidential initiative that teaches sound science practices to students while at the same time using their observations to further our knowledge of the Earth. To make the long-term commitment required to provide the highest quality environmental stewardship and predictions, NOAA must increase the pool of capable scientists and technicians available for public service. To attract and develop the best talent in a highly competitive market, NOAA must be recognized as an agency where talent and,, individual differences are respected and rewarded.

\section{Environmental Technology}

Few areas show the link between the environment and the economy more clearly than environmental techndlogies. This segment of the economy has been projected to grow as large as $\$ 600$ billion by the turn of the century, creating high skill/high wage jobs for American workers. For NOAA, the end challenge is to ensure that the environmental technologies are in place worldwide to protect the environment and to maintain and rebuild the world's natural atmospheric and oceanic resource base. Four distinct pilot programs will focus NOAA's unique contribution to environmental technology efforts: Marine Biotechnology through the National Sea Grant College Program and the National Marine Fisheries Service; Weather, Hydrologic 
and Marine Observations and Information Systems; Environmental Hazards Mitigation; and a World-Wide Environmental Information Network.

Globally, aquaculture accounts for about 15 percent of fisheries production and about one-third of gross revenues. Stock enhancement in coastal waters using aquaculture techniques supports valuable fisheries in some counties such as Japan and Norway. Dwindling domestic and world wild/natural production, static or incremental increases in consumption, and increased population have resulted in increasing demand and imports of cultured products. Yet marine aquaculture and stock enhancement are almost insignificant in the United States-.

The Committee has expressed interest in discussing proposals to strengthen the marine aquaculture ef forts of NOAA, including NMFS programs aimed at enhancement and development of an environmentally sound industry, and the National Sea Grant College Program. In FY 1995, NOAA requests an increase of $\$ 1.25$ million to begin the process of accelerating the growth of U.S. marine aquaculture. Assessments of the potential production from wild stocks, population growth and demand for seafood, clearly indicate an increasing dependence on aquaculture-based food production and a need for stock enhancement in the future. As enunciated in its strategic plan, NOAA will coordinate agency aquaculture activities, identify over-exploited species and candidates for commercial culture; foster the development and transfer of environmentally sound, cost-effective intensive commercial aquaculture systems and advance fisheries enhancement programs through technology development involving new hatchery rearing techniques, genetic improvements, development of feeds with improved conversion rates, and comprehensive health management. In addition, the National Sea Grant College Program sponsors research focused on exploring technological approaches to cost-effective aquaculture in closed systems, developing computer monitoring and control systems, developing hatchery technology, and defining physiological endocrinological and nutritional controls on development, growth, and reproduction of aquacultural species. A cohesive NOAA program, relying primarily on NMFS and Sea Grant, will provide the impetus for U.S. aquaculture production to meet the seafood demands of the 21 st century, and allow the United, States to assert its leadership role in environmental stewardship.

\section{Environmental Systems Convergence / Dual Use}

Today, due to increasing budget pressures, especially in the Department of Defense, there is an opportunity for NOAA to address this challenge with relatively modest investments by leveraging significant existing investments other agencies have already made. This leveraging involves both a dual use of some assets and a convergence of others (such as environmental satellites and the transfer of T-AGOS vessels from the Navy to NOAA), resulting in a more efficient national infrastructure. Convergence of the Nation's civil and military polar-orbiting environmental satellites is a good example. As you are probably aware, a Presidential Decision Directive was recently signed dircting the convergence of NOAA and DOD's polar-orbiting satellites, with the inclusion of NASA's Earth Observing System platform. The Presidential Decision Directive (PDD) will allow the government to reduce the cost of acquiring and operating polar-orbiting environmental satellites systems, while continuing to satisfy U.S. operational requirements for data from these systems. The PDD directs the Departments of Commerce and Defense and the National Aeronautics and Space Administration (NASA) to create an IPO for the converged polar-orbiting operational satellite system by October 1,1994 . The IPO will be responsible for the management, acquisition, and operation of the converged system. The IPO will be under the direction of a System Program Director (SPD) who will report to a Triagency-Executive Committee (EXCOM) at the Under Secretary-level. The EXCOM will act as the Board of Directors for the program to provide policy guidance; ensure sustained agency support; and approve the management plan, budget, acquisition strategy, operations concept, and baselines (e.g., cost, schedule and performance, etc.) requirements.

\section{Environmental Information}

NOAA is in the process of initiating a long-term, agency-wide program to improve its dissemination of information products and services and to integrate its data into new products. The improved dissemination will take full advantage of connection to the Nation's emerging National Information Infrastructure.

\section{Global Partnerships for Fulfilling the Goals of the Earth Summit (UNCED)}

In 1992, the United States along with other members of the international community made commitments at the Earth Summit to take actions toward environmentally sustainable development. NOAA's principal contribution to the international aspect of implementation of the commitments made in Rio will be in the area of cooperative programs, involving cost effective advancement of NOAA's mis- 
sion through technical assistance and training related to our areas of expertisesuch as global climate change, coastal zone management and biodiversity.

\section{INFRASTRUCTURE PORTFOLIO}

NOAA's plan for the future requires investment in its infrastructure to enable the agency to carry out its programs efficiently, effectively and reliably.

\section{Fleet Replacement and Modernization}

The majority of ships in the NOAA fleet are rapidly approaching the maximum age for cost effective and productive operations. With the help of the funds appropriated by Congress, NOAA has made substantial progress in modernizing its flect of ships. The highest priority fleet problems have been targeted and actions are underway to solve these problems. Contracts have been awarded or are soon to be awarded for major repairs to existing ships, construction of a new oceanographic ship, and conversion of a Navy T-AGOS ship, chartering, and contracts for hydrographic surveys.

As with any program this size, there is a need for continuing review. A central theme in all the reviews that have been conducted to date has been the recommendation for NOAA to investigate other sources for ship support including charter with the private sector and further cooperation with UNOLS. Some FRAM funding has been used for charter and cooperative work with UNOLS. A contract for hy. drographic survey services will be awarded shortly, and a charter contract for a fisheries research ship will be awarded late in 1994.

The latest review of the FRAM Plan was by the Marine Board of the National Academy of Sciences. In response to the Marine Board review, NOAA has established a FRAM review team consisting of the Deputy Assistant Administrators for the National Marine Fisheries Service, the National Ocean Survey, and the Office of Oceanic and Atmospheric Research. The team will assess the FRAM program in light of the Marine Board's recommendations and propose appropriate revisions to the FRAM plan. In the interim NOAA will continue to pursue chartering and other outsourcing opportunities aggressively as requirements and resources allow. We will keep Congress apprised as this review continues and our new FRAM plan evolves.

Underlying all of NOAA's operating programs are the capital assets without which our observations, assessments, predictions and stewardship responsibilities would be impossible. In FY 1995, $\$ 41.0$ million are required to maintain our capital assets. This is comprised of $\$ 23.1$ million for Fleet Replacement and Modernization for critical maintenance, repair, and chartering, and $\$ 17.9$ million for Environmental Compliance and Facilities.

H.R 4008, the NOAA Authorization Act of 1994, as ordered reported by the House Merchant Marine and Fisheries Committee has called for a study of the role of the NOAA Corps in supporting NOAA missions. We are prepared to review all components of our operations and the NOAA Corps is no exception. If a study is appropriate at this time, we believe that senior civilians within NOAA are the best people to conduct such a study. NOAA's senior civilians have a clear understanding of both the strengths and weaknesses of the NOAA Corps as well as how the Corps may better serve NOAA.

With regard to aircraft, the initial operating capability of NOAA's high altitude aircraft is expected to provide a 20 percent improvement in the accuracy of landfall predictions resulting in the saving of lives, a reduction in property damage, and the elimination of costs associated with unnecessary evacuations. In FY 1994, NOAA began an aggressive procurement process for the new aircraft, and in April provided industry with our draft statement of work and specifications. The response received from industry wlll be used to finalize the Request for Proposals (RFP) and specifications. We anticipate award of the aircraft contract in early calendar 1995. The first operation flight of the new aircraft is scheduled for the 1996 hurricane season.

The new high altitude aitcraft will eventually provide three capabilities: hurricane surveillance, hurricane reconnaissance $\mathrm{N}$ and hurricane and tropospheric research. In prior testimony, NOAA has referred to the aircraft missions as hurricane reconnaissance and hurricane research. As specific requirements for this plane were being developed, the reconnaissance mission was divided into two categories. The National Hurricane Center's highest priority requirements are now referred to as hurricane surveillance, and those of next priority are now labeled hurricane reconnaissance. As funds become available, hurricane reconnaissance capability in support of the National Hurricane Center and hurricane research capability in support of the Hurricane Research Center will be added to the aircraft. Lastly, the aircraft's capability will be expanded to include tropospheric research. 
Facilities / Environmental Compliance

NOAA occupies an extensive inventory of 443 staffed facilities in every state and territory with more than 1000 buildings and a widespread number of activities. The challenge here is to ensure that these are in the right condition, configuration and location to support fully NOAA's missions. Cleanup of major environmental prob. lems at various NOAA sites is also a priority. While there are not a large number of such contaminated locations, each requires intensive attention.

\section{Environmental Satellites}

NOAA's core missions to observe, predict and assess the environment demand a robust environmental satellite system. The agency's satellite program is a critical area of NOAA's supporting infrastructure. Over the last 30 years, satellites have proven to be an efficient means of collecting vast quantities of essential environmental data.

\section{CONCLUSION}

In closing, I would again like to stress the NOAA mission to promote global environmental stewardship and to describe and predict changes in the Earth's environment. I thank the Chairman and the Members of the Committee for this opportunity to testify before you and look forward to working with you as we shape an authorization plan for the future of NOAA. Together we can prove that economic progress and environmental stewardship are not mutually exclusive.

Senator KerRy. Thank you very much, Dr. Baker.

Let me begin, if I may, with some questions on just some details regarding the budget, if we can for a minute.

If you look, the budget that you have presented us is reflective of the strategic plan and the unification of the agency, if you will, but if you break that out and kind of look at it measured against the line items of each of last year's agencies, you effectively have a very similar amount allocated in each case, with the exception of a modest increase for NMFS. So, if you could say to me where your greatest expectation is for the costsavings that you are planning on getting, where would that be?

Dr. BAKER. Let me address that question in a general way first. We feel that the strategic plan is a very important thing for us to do, because it allows us to show where we think the agency should be going and how we should try to address national priorities, but it is not enough for us to say what we should do. We have to build a very strong constituency.

I think we have a strong constituency in Congress. We need to build that same constituency in the administration and in the public, and to the extent that such a constituency has been built for the Weather Service and satellites, we see that reflected in a continuing support for Weather Service modernization.

I believe we have to do the same thing for our coastal and fisheries efforts, and one of the reasons for our strategic plan was to identify fisheries and coastal issues as very important for our agency to take on.

Now, we were successful in convincing the Department of Commerce and the administration and OMB that we should have an increase in the National Marine Fisheries Service, and we have about a $\$ 50$ million increase in our budget. I believe that is the first increase that has been proposed by the administration in a long time. That came about, I believe, largely because we in NOAA, working with you, have identified this as a very high priority.

I think we have to continue to do that and to continue to push both the fishery and the coastal issues the way that the constituency has been built for the modernization of the Weather Service 
and the satellites. I think if we can do that we will have a broad constituency and we can begin to get the funding that we need for these important national priorities.

Senator KERRY. Well, is it your sense that the reorganization is really a reorganization, then, more directed at this strategic goal, and less concerned with trying to find savings where you can?

Dr. BAKER. Well, we are an agency that has had to find savings in a very big way over the past 12 years. During the 4 years of the Reagan administration and the first couple of years of the Bush administration, NOAA was an agency whose budget barely increased. It only increased because of the additions that Congress put in, but the administration basically level-funded or decreased the budget for the agency.

Because of that, and because of the fact that our responsibilities did not change over that period, we have had to go in and make major costsavings with regard to the way we do business.

Senator KERRY. In fact, is it not fair to say your responsibilities increased?

Dr. BAKER. Absolutely.

Senator KERRY. While simultaneously your funding decreased.

Dr. BAKER. That is right, so we have that problem.

Senator KERRY. Well, share with the committee specifically how that has affected the NOAA mission. Can you give us concrete examples of impact?

Dr. BAKER. I can give you a couple of examples. We can look at trying to enforce the Coastal Zone Management Act, or enforcement of the provisions of the Fisheries Management Act. If we look at the coastal zone, we have one enforcement agent for every 1,300 miles of coast. We spend less on fisheries than the State of Texas spends on fisheries, for example. We have entire marine sanctuaries where we are trying to manage and operate and enforce the regulations with one or two people.

We have a continual push for new marine sanctuaries, but we do not have adequate support to really manage the marine sanctuaries, and I could go down probably a list of 50 programs and show you how we have a responsibility which we think is important, but we have not had adequate support to do the job.

Senator KerRY. Well, I would like you to do that. I would like you to submit that to the committee, if you would. I do not want to burden you with more work, but I think it is important to begin laying the record of what is happening here, and so I would find it extremely helpful for the committee's future work and advocacy efforts with the administration if you would do that.

Dr. BAKER. We will do that.

[The information referred to follows:]

Brief Description of Significant NOAA Statutory Authiorities

(The following are not necessarily NOAA identified priorities but are Congressionally identified responsibilities.)

Authorizes the Secretary of Transportation to reimburse NOAA from the Airport and Airway Trust Fund for the cost of providing the Federal Aviation Administration with aviation weather reporting services. 


\begin{tabular}{|c|c|c|}
\hline & Authorization level & 1994 enacted \\
\hline 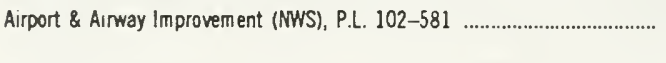 & $\begin{array}{l}37,800 \text { FY } 1994 \ldots \ldots \ldots \ldots . . . \\
39,000 \text { FY } 1995 \ldots \ldots \ldots \ldots . .\end{array}$ & 135,596 \\
\hline
\end{tabular}

IIn Operations, Research, and Facilities.

\section{ANADRONOUS FISH CONSERVATION ACTT}

Authorizes the Secretaries of Commerce and the Interior to enter into cooperative agreements with states and other non-Federal entities for conserving, developing and enhancing the Nation's anadromous fisheries resources, including fish in the Great Lakes and Lake Champlain that return up rivers to spawn, and for controlling the sea lamprey. An emergency striped bass research study is authorized to determine the causes of population decline in striped bass stocks.

\begin{tabular}{l|c|c}
\hline & Authorization level & 1994 emacted \\
\hline Anadromous Fish Conservation Act of 1965, P.L 102-130 .......................... & 8,000 FY 1990-95 ............ & 2.108 \\
\hline
\end{tabular}

\section{ATLANTIC TUNAS CONVENTION ACT}

The Act implements the International for the Conservation of Atlantic Tunas by authorizing the Secretaries of Commerce and State, among other things, to appoint U.S. commissioners, establish an advisory committee, conduct research, and promulgate regulations and otherwise enforce the Act.

\begin{tabular}{c|c|c}
\hline & Authorization level & l994 enacted \\
\hline Atlantic Tunas, P.L. 101-627 .............................................................. & 2,000 FY 1989-93 ........... & 0 \\
\hline
\end{tabular}

\section{ATLANTIC STRIPED BASS CONSERVATION ACT}

Provides Federal assistance for the development, implementation and enforcement of interstate policy on conservation and management of Atlantic Striped Bass. The Atlantic States Marine Fisheries Commission monitors the enforcement of the Interstate Fisheries Plan for Striped Bass and reports to the Secretaries of Commerce and the Interior on the effectiveness of enforcement. If it is determined that the Plan is not being enforced effectively in a State's waters, the Secretary of Commerce must declare a moratorium on fishing in those waters and may assess civil penalties for moratorium violations.

\begin{tabular}{l|c|c}
\hline & Authorization level & 1994 enacted \\
\hline Striped Bass Act of 1991, P.L. 102-130 Study ....................................... & 1,000 FY 1992-94 ........... & 250 \\
\hline
\end{tabular}

\section{CENTRAL, WESTERN, AND SOUTH PACIFIC FISHERIES DEVELOPMENT ACT}

The Act authorizes the Secretary of Commerce to carry out a program for the development of the tuna and other fisheries resources of the Central, Western, and South Pacific Ocean. Consultation and cooperation is authorized with the Secretaries of the Interior and State, the State of Hawaii and other affected states, the governments of American Samoa and Guam, the Office of the High Commissioner of the Trust Territory of the Pacific Islands, the Commonwealth of the Northern Mariana Islands, educational institutions, the commercial fishing industry, and all appropriate member nations of any South Pacific regional fishery agency.

\begin{tabular}{l|c|c}
\hline & Authorization level & 1994 enacted \\
\hline Central, Western \& So. Pacific Fisheries Dev., P.L 101-627 ..................... & 5,000 FY 1988-95 ............. & 0 \\
\hline
\end{tabular}

\section{COASTAL ZONE MANAGEMENT ACT}

The Act authorizes a Federal program of financial and technical assistant to coastal States and local governments for the purpose of managing the use and development of coastal areas of the various coastal States, including enumerated trust territories and U.S. possessions. The Secretary of Commerce is authorized to make grants to coastal States for administering Federally-approved coastal zone management programs. Such programs may be made for: redevelopment of deteriorating and underutilized urban waterfronts and ports and the provision of access of public 
beaches; nonpoint pollution control; estuarine research; off-shore energy development; facilities and services reguired as a result of Outer Continental Shelf energy activity; and developing and administering coordinated coastal zone planning.

\begin{tabular}{|c|c|c|}
\hline & Authorization level & 1994 enacted \\
\hline \multicolumn{3}{|l|}{ CZMA Reauthorization of 1990, P.L. 101-508: } \\
\hline Sec. 305 coastal state grants & 750 - FY $1990-93 \ldots \ldots \ldots \ldots$ & •. \\
\hline 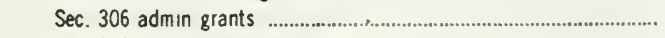 & 67,930 FY $1994 \ldots \ldots \ldots \ldots$ & \\
\hline Sec. $306 \mathrm{~A}$ resource mgmt grants .......... & $90,090-F Y 1995$ & \\
\hline Sec. $309 \mathrm{CZ}$ enhancement grants .... & $\begin{array}{l}\text { Total for } 305,306,306 \mathrm{~A} \\
\text { and } 309 .\end{array}$ & 41,500 \\
\hline \multirow[t]{2}{*}{ Sec. 308 gen. admin } & 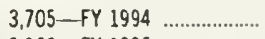 & 4,300 \\
\hline & 5,962 FY $1995 \ldots \ldots \ldots \ldots$ & \\
\hline \multirow[t]{2}{*}{ 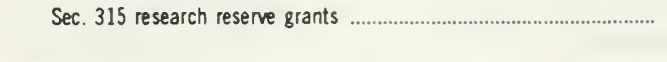 } & 6,847 FY $1994 \ldots \ldots \ldots \ldots \ldots$ & 3,214 \\
\hline & $7,155-F Y 1995 \ldots \ldots \ldots$ & \\
\hline 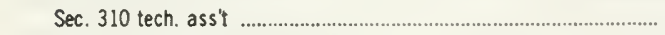 & 10,000 -FY $1990-95$. & \\
\hline Sec. 6217 - Coastal Nonpoint pollution ......... & $12,000-F Y 1993-95 \ldots . .$. & 4,000 \\
\hline
\end{tabular}

ENDANGERED SPECIES ACT

The Act provides for the management, conservation and recovery of endangered or threatened species of fish and wildlife. It also provides for the listing of species determined by the Secretaries of the Interior or Commerce to be endangered or threatened. Cooperative agreements may be entered into with any State which establishes and maintains an adequate and active conservation program for listed species. The Act calls for independent study on the status and conservation needs of sea turtles.

\begin{tabular}{c|c|c}
\hline & Authorization level & 1994 enacted \\
\hline Endangered Species Act of 1973, P.L 93-205 ................................ & $6,750 \ldots$ FY $1992 \ldots \ldots \ldots \ldots \ldots . \ldots . \ldots . \ldots$ & 8,625 \\
\hline
\end{tabular}

\section{INTERJURISDICTIONAL FISHERIES ACT}

The Act provides for: (1) grants to states in support of the management of interjurisdictional fisheries; (2) disaster assistance funds to restore fishery resources affected by natural or undetermined causes; and (3) development of interstate fishery management plans by the Atlantic States, Gulf States and Pacific Marine Fisheries Commissions.

\begin{tabular}{|c|c|c|}
\hline & Authorization level & 1994 enacted \\
\hline Interjurisdictional Fisheries Act, P.L. 103-238: & & \\
\hline 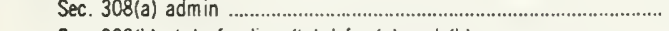 & $5,000-F Y 1994 \ldots \ldots \ldots \ldots \ldots$ & \\
\hline 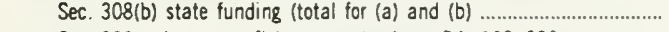 & $2,500-F Y 1989-95 \ldots \ldots \ldots \ldots$ & 3,156 \\
\hline Sec. 308(c) interstate fishery mgmt. plans, P.L 103-206. & $600-F Y 1994-95$ & 295 \\
\hline
\end{tabular}

\section{MAGNUSON FISHERY CONSERVATION AND MANAGEMENT ACT}

The Act provides for the conservation and management of the Nation's fishery resources; promotes domestic commercial and recreational fishing; provides for fishery management plans that will achieve and maintain the optimum yield from each fishery; establishes regional fishery management councils to prepare, monitor, and revise such plans; and encourages the development of fisheries which are underutilized by U.S. fishermen.

\begin{tabular}{|c|c|c|}
\hline & Authorization level & 1994 enacted \\
\hline Magnuson Fisheries Conservation and Management Act, P.L. 101-627 ....... & $102,000 \ldots . . . . .$. & 103,218 \\
\hline
\end{tabular}

\section{MARINE MAMMAL PROTECTION ACT}

Provides for long-term management and research programs for marine mammals. Places a moratorium on the taking or importing of marine mammals and marine mammal products, with limited exceptions. The Department of Commerce is responsible for whales, porpoise, seals and sea lions. The Department of the Interior is responsible for all other marine mammals. 


\begin{tabular}{l|r|r|}
\hline & Authorization level & 1994 enacted \\
\hline Marine Mammal Protection, P.L 100-711 ................................................. & $14,331-$ FY $1993 \ldots \ldots \ldots . . .$. & 20,542 \\
\hline
\end{tabular}

\section{MARINE PROTECTION, RESEARCH, AND SANCTUARIES ACT}

Title I of the Act provides for the regulation of dumping and transportation for dumping of material, including sewage sludge, into ocean waters. EPA shares responsibility for administration with the Army Corps of Engineers, which regulates dumping of dredged material; the Coast Guard, which has responsibility for surveillance of dumpers; and NOAA, which is responsible for monitoring the environment at and around dumpsites.

Title II provides for a comprehensive monitoring and research program on the effects of ocean dumping and a comprehensive continuing research program on the possible long-term effects of pollution, overfishing, and other activities on the ocean ecosystem. The programs are undertaken by NOAA in coordination with EPA and the Coast Guard.

Title III authorizes the Secretary of Commerce to designate as national marine sanctuaries those areas of the marine environment that are deemed of national significance due to their conservation, recreational, ecological or aesthetic values. Currently, 13 sanctuaries have been designated. Directs the Secretary to conduct research and educational programs regarding the resources of the sanctuaries and enhancement of public awareness, understanding and wise use of the marine environment; and conduct enforcement activities that are necessary and reasonable to carry out Title III.

\begin{tabular}{l|c|c}
\hline & Authorization level & 1994 enacted \\
\hline Marine Prot. Research \& Sanctuaries, P.L. 102-587 Title III .................. & 12,500 -FY $1994 \ldots \ldots \ldots \ldots \ldots .$. & 9,000 \\
& 15,000 FY $1995 \ldots \ldots \ldots \ldots \ldots$. & \\
\hline
\end{tabular}

\section{NATIONAL OCEAN SURVEY}

Authorizes the Coast and Geodetic Survey, whose functions were subsequently transferred to the National Ocean Survey within NOAA, to provide charts and related information for safe navigation of marine and air commerce.

Provides authority to conduct hydrographic and topographic surveys, tide and current observations, geodetic control surveys, field surveys for aeronautical charts, and geophysical measurements and investigations for determining variations in latitude and longitude.

\begin{tabular}{l|c|c}
\hline & Authorization level & 1994 enacted \\
\hline Mapping, Charting \& Geodesy ….............................................................. & 51,087 FY $1994 \ldots \ldots \ldots \ldots . . .$. & 49,454 \\
\hline
\end{tabular}

\section{NATIONAL SEA GRANT COLLEGE PROGRAM ACT}

Authorizes the awarding of grants and contracts to initiate and support programs at Sea Grant colleges and other institutions for research, education, and advisory services in variols fields related to the development of marine resources.

\begin{tabular}{|c|c|c|}
\hline & Authorization level & 1994 enacted \\
\hline $\begin{array}{l}\text { Sea Grant, P.L. 102-186, sec 205: contracts \& grants, sec } 208 \text { fellow- } \\
\text { ships; sec } 3 \text { internat'I cooperation. }\end{array}$ & $\begin{array}{l}49,443-F Y 1994 \ldots \ldots \ldots \ldots . . \\
51,261-F Y 1995 \ldots \ldots \ldots \ldots . . .\end{array}$ & 37,600 \\
\hline 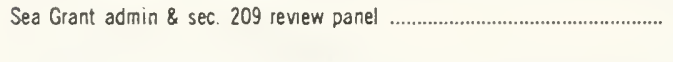 & 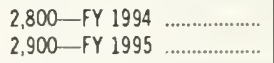 & 2,800 \\
\hline 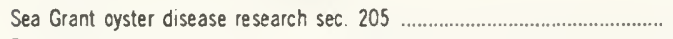 & $3,000-F Y 1993-95 \ldots \ldots \ldots$ & 0 \\
\hline Zebra mussel research & 3,375-FY 1991-95 ............ & 2,800 \\
\hline
\end{tabular}

\section{SOUTH PACIFIC TUNA ACT}

Implements the Treaty on Fisheries Between the Governments of Certain Pacific Island States and the Government of the United States; establishes a mechanism for regional fishing licenses, providing fishing opportunities for the U.S. distant water tuna fleet; and requires vessel operators to carry observers and report catch information to the Secretary of Commerce. 


\begin{tabular}{l|c|c}
\hline & Authorization level & 1994 enacted \\
\hline South Pacific Tuna, P.L. 102-523, admınistrative exp ............................... & $350-$ FY 1992-2002 ........... & 0 \\
\hline
\end{tabular}

NOAA 1994 PRIORITY REQUEST

The following lists NOAA Priorities as included in the President's Request and Congressional Action for FY 1994:

[In thousands of dollars]

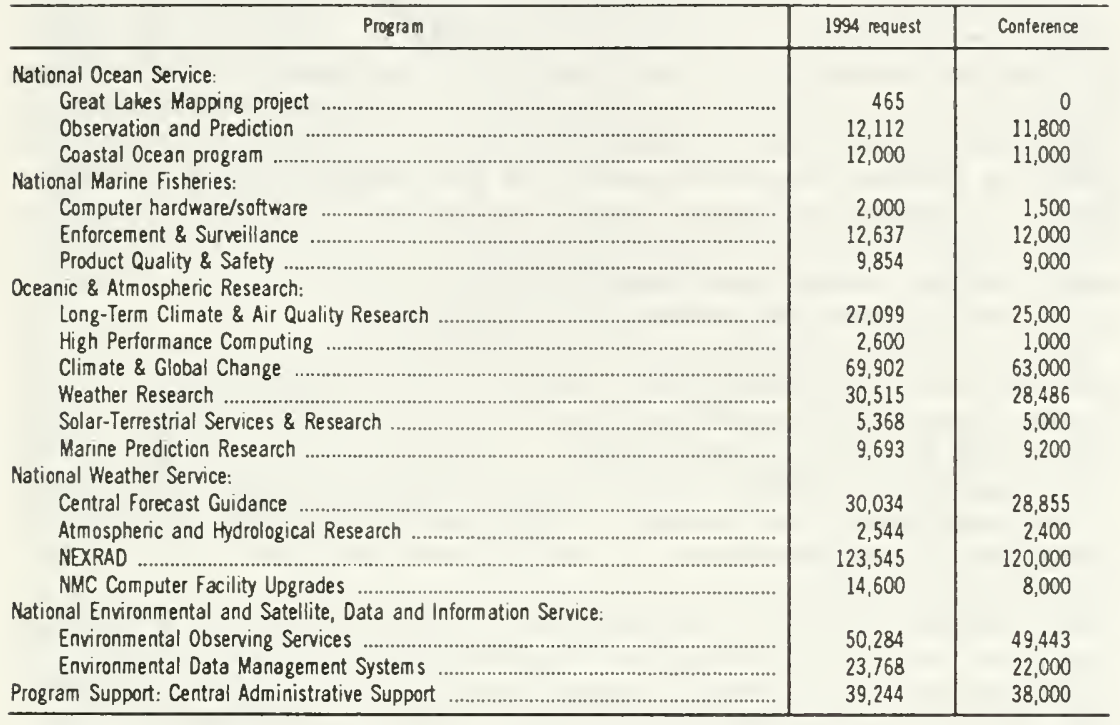

Senator KERRY. With respect to aircraft procurement, your testimony suggested that the new high-altitude aircraft eventually will provide three capabilities, hurricane surveillance, hurricane reconnaissance, and hurricane and tropospheric research.

The $\$ 43$ million in funding was for hurricane reconnaissance as set out in the 1994 appropriations report, but now you are saying that the money is only sufficient for hurricane surveillance, which is a lower level of capacity. Can you tell us what the distinction is, and why it exists between the original-

Dr. BAKER. This is an interesting issue with the aircraft, and I want to be completely up front with you about the issue associated with the aircraft. We are working very hard to get the aircraft in place, but I think it is important to recognize two things.

One is, we are working hard and we think we will get this aircraft procured in a time which is shorter than most aircraft procurements. Also I think it is fair to say that the aircraft was added to our budget last year, and we did not expect that to happen quite so soon, and because of that we had to work very hard and very fast to make sure that we had the requirements in place so that we could move ahead with the procurement, given the fact that we had the opportunity to have the aircraft in place.

It is something that we want, do not get me wrong. The current budget that has been estimated for the aircraft allows us to do what we call hurricane surveillance. This is the initial capability. This is drop wind sonde mission around the periphery of the storm, 
an immediate improvement in storm track predictions. This will be the major improvement from the information that comes from the aircraft for storm track predictions, which is the major item for hurricanes.

Now, by adding additional information to do what we call reconnaissance, we can fly into the eye of the hurricane and we can get additional information which helps us understand hurricanes.

If we also have information to let us look at high-altitude atmospheric properties, such as upper troposphere chemistry and physics, this will allow us to learn more about hurricanes. It will allow us to learn more about the development and the achievement of hurricanes-how they actually develop and become full stormswhich is another important aspect of the prediction of hurricanes. But the immediate aspect of hurricane forecast is to have the information that is necessary for us to predict the track of a fully developed hurricane, and that capacity is built into the initial capacity of the aircraft as it is currently being proposed.

Senator KERRY. Well, I want to understand what you mean when you say it is additionally being built in. The original report of the Senate last year suggested that the funding was for reconnaissance, but now you are saying that it is only for surveillance. What is the difference? What in the $\$ 43$ million for the aircraft, or for the requirements, has created a difference between the original expectation of reconnaissance for $\$ 43$ million, and now it is surveillance for $\$ 43$ million.

Dr. BAKER. The way we have used these words-and I think it has been confusing to me also. We have tried to use this term "reconnaissance" as a general term, which really includes two parts. One, is that the highest priority part of the reconnaissance is surveillance; the second is reconnaissance.

Senator KERRY. So, the $\$ 43$ million would cover both missions.

Dr. BAKER. The $\$ 43$ million, as I understand it, does not include the additional instrumentation which we would say was necessary for a full reconnaissance. However, it does provide the information we need for the first part of reconnaissance, which is what we call surveillance, or the information that we need for storm track predictions. That is the drop wind sonde mission around the periphery of the storm. That is the first, initial part of reconnaissance which is crucial.

Senator KERRY. Now, with respect to the fishery user fees, when your staff kindly came up and met with us prior to this hearing and the budget being put together, we discussed this.

I think they got an instantaneous reaction from me, and I know a similar one from the chairman of the full committee, Senator Hollings, and others, that there is obviously a certain immediate down side.

There is a certain ability for the public to feel pretty cynical about emergency efforts to deal with the problems of our fisheries on the one hand and a welcome and well-needed, and I must say remarkable, effective response by your Department and others to deal with that problem, on the other hand by providing $\$ 30$ million in emergency assistance. Only a few months later, though, the Department decides that these same people are going to have to ante up and pay for the use of the fisheries and in effect sort of dumps 
a burden back on them. This diminishes the value of what they have just been given, and I think there is going to be a lot of resistance to that.

I think it is going to be very difficult. I think you maybe even know that, but I would like to discuss that a little bit. What do you think the implications are if this fee is not adopted this year, and how do you respond to what I just said about the duplicity of giving on the one hand and taking with the other?

Dr. BAKER. Let me try to answer both these questions. I think these are very key issues as we look at the problem of how we deal with marine fisheries, the need to conserve the resources, and the need to understand the resource that we have, and even as we go into marine aquaculture.

Marine fisheries is one of the few natural resources that we have as a nation that does not have any fees associated with it. And there have been a number of public opinion polls asking about whether, in fact, it would make sense for commercial fishermen to pay some fees on the collection of natural resources.

And the recent polls have been really quite positive from the public saying yes, that would make sense. I have a recent one, I do not have it with me but we could certainly provide it for you, that shows about 75 percent of the public said that this would be a reasonable thing to be considered.

So, I think we have a recognition nationally that we have a natural resource and that some fee structure associated with that, because of the need to establish conservation rules and to understand the resources, is a sensible thing.

We also have in our administration, and I think we have seen in other administrations, a very strong push for user fees in general on issues. And this is a point that OMB has made to us. It is certainly not the first OMB that has made such a point.

When they suggested that to us we sat down with a number of the constituent groups to find out if this was something that we could in fact discuss and lay on the table. And we discovered that it was something that certainly we could bring up and discuss.

Now, we have a proposed amendment which takes into account many of those discussions. Part of the arrangement here is that there would be an alleviation of fees for those areas that were in particular distress. I do not have the details on that.

Senator KERRY. Would it be an alleviation or an exemption?

Dr. BA.KER. It is not a complete exemption, but it is at least a partial alleviation for those areas in distress. And we have also, I believe, built in, that we would particularly help those areas that have a fishery management conservation plan in place. Those are two points that we think are very important. So, we are trying to address the problem that you raised about the taking with one hand and giving away with the other.

Senator KERRY. Do you contemplate the distinction between commercial fishermen and recreational users?

Dr. BAKER. It applies only to recreational fishermen if they sell their catch. That would be the only fee on recreational fishermen.

Senator KERRY. The only fee on recreational. So, in effect the fee would be more on commercial than on recreational.

Dr. BAKER. It is on sales. 
Senator KERRY. Well, that also disturbs me. So, if you are a sports fisherman with a huge craft zonking out of one of your southern ports or Nantucket or wherever, gas guzzling away and dumping into the ocean and so forth, and pulling out $x$ number of tuna or fill fish or whatever you do not pay a fee. But if you are going out there to earn a living under extraordinarily difficult circumstances you do pay a fee.

That does not seem to make a lot of sense to me.

Dr. BAKER. That is a good point.

Senator KERRY. Well, I think we have to think this out a little further.

One last question before I turn to Senator Stevens. Fleet modernization-we have been going through this for a long time now, and I can remember sitting here a number of years ago, when I was told what the dire needs of the fleet are and how it is setting back our tracking and monitoring capacity and so forth.

You have a 22-ship fleet approaching 30 years of service. None have had midlife modernization. Only six have been partially rehabilitated.

Increasing levels of down time are indicated in the records because of the backlog of deferred maintenance, unreliable shipboard systems, and these modernization efforts finally began 2 years ago. And you have in your full testimony given us some indication of the improvements in the past 3 years, but it is hard for me to understand.

I mean, I know we have a backlog here. We have a lot of people who work on ships who are out of work. We have a lot of shipyards clamoring for work. We have a backlog of money in the pipeline, and the administration is requesting a $\$ 54$ million decrease this year.

So, again, I am a little puzzled by the expression of priorities, or even the management of the process.

Dr. BAKER. Well, Senator Kerry, we appreciate your interest in the FRAM plan and your support has been very important to us, and what you point out is absolutely correct. We have an old fleet that is decaying. We are in the process of trying to keep some of those ships alive with repair to extend. We have a situation which is not a good situation right now with the fleet.

I was personally involved in reviewing the early stages of the NOAA plan, I think it was in 1990 or 1991 when Dr. Knauss sent that plan to outside reviewers, and I was not convinced myself at the time that the plan was a viable plan although I understood the problems faced by the fleet.

When I took this job as NOAA Administrator, one of the first things I did was to try to understand from all of the various involved groups what are the issues associated with having a FRAM plan that can be fully acceptable inside and outside the agency that gets us from where we are today to a fully modernized fleet that meets our needs.

Now, since the time that the FRAM plan was started, there have been some changes. For example, there are ways to meet the charting and mapping objectives that NOAA has in the National Ocean Service that do not necessarily involve NOAA ships. You can do this with lasers, for example, carried by aircraft. 
It turns out that many outside private companies have the technology and the equipment to do surveying so that we could do chartering of that surveying and get a better job with better equipment than we could with our in-house equipment.

We have been offered now, in the last couple of years, several of the Navy's T-AGOS vessels to see if we could actually use those. And so we have on our plate a number of new opportunities. We have two or three very critical reports about where we stand with the plan. And it seemed to me, having been involved in the procurement of many large systems in the past, that it would make sense for us to at least spend a year trying to understand and put together a plan that I can come up here and be fully enthusiastic about, and a plan that you would agree is a sensible plan.

And so we did not try to put in additional funds for the construction of vessels this year. We have a temporary slow down in the plan while we try to put together-a very sensible plan.

Now, I have a lot of experience in oceanographic ships. I have spent a lot of my time sitting around the ward room of various ships talking to expert captains about what it is that makes a good oceanographic ship, and I am talking about fishery research vessels, mapping and charting vessels, and oceanographic research. And there are many ways that we can solve the problems.

I believe that the answer is going to be a strong use of these Navy vessels that we have because these are wonderful ships. They can be used, and they come to us at zero cost. You cannot beat a ship at zero cost. We built a whole oceanographic research fleet in the United States with zero cost vessels after World War II.

We have a need for fisheries research vessels to replace the ones we have. We have an opportunity to do a certain amount of charting from existing private vessels, but we are going to have to have some new ones. And we are going to have to solve the problem of how we do mapping and charting with new technology as well as from our ships and small launches.

Now, this has to be put together into a credible plan. We do not have a credible plan for you right now, and that is the reason that we have the budget proposed. This is a very high priority for us and we are working very hard on it.

Senator KERRY. Well, that sounds good. If there is a plan emerging and it is more sensible and more technologically state-of-theart, that makes sense obviously, and I do not think that we can complain about the fact that you are trying to conceivably save money or provide for a greater efficiency.

But I take it then that there is even the potential that some of the fleet may be deemed unnecessary or scrapped. Is that accurate?

Dr. BAKER. That is certainly on the table; yes.

Senator KERRY. What is the timeframe on our having a sense of this?

Dr. BAKER. Months, a few months.

Senator KERRY. Senator Stevens.

Senator STEvens. Thank you very much, Mr. Chairman.

Dr. Baker, I just left the Senate surgeon and he said it would be wise if I just went to bed, but there are too many other things on my plate today. I hope you will just bear with me as I try to be brief with the voice I have got. 
As I understand the budget request, and I am not critical of that budget, Dr. Baker, it is about $\$ 126$ million less than last year if we take into account there is about a $\$ 38$ million reduction and $\$ 88$ million in new fees. The chairman has already remarked about that.

One of the problems about the fees is that, even if we gave you the authority to put them into effect, I doubt seriously you could be collecting those fees by the close of fiscal year 1995. So, I think we have a strain on the budget to start with. We have to think about where that cut is going to fall.

You have eliminated from the budget a series of small items that really pertain to my State of Alaska. These include the Beluga Whale Program and some of the programs that deal with the Fishing Vessel Obligation Guarantee Program. That eliminated \$459 million. And the National Undersea Research Program has been cut rather severely, as a matter of fact.

So, there is some readjustment, and as a new director you have the obligation to try to readjust your money. I want to work with you to the maximum extent possible to do that.

But let me just ask a couple of direct questions. We established an observer training center in Anchorage because of the cost to Alaska's young people to go down to Washington State to get the training for being a fishery observer. I was able to get the city of Anchorage to provide the facility for that center free of charge. We got the University of Alaska at Anchorage to provide financial support for that training program. If you look at the cost of the program training observers in Alaska, it was about $\$ 150,000$.

That program has been eliminated and those same people are going to have to be trained down in Seattle. It is going to cost at least twice as much. I do not understand the sense of that kind of a change, frankly, and I urge you to take a look at it.

We worked long and hard to set up that training program. If our young people from Alaska go down to Seattle, they have to find a place to live. Most of them live somewhere around in the south central area part of Alaska or have friends there they can stay with while they are going to school to get their training. They can't do that in Washington.

I think it makes a lot of sense to try and save as much money as possible on that Observer Training Program. I would hope you would consider funding that training center in Anchorage.

In terms of the Oil Spill Recovery Institute coming out of the Exxon Valdez disaster, the Oil Pollution Act of 1990 authorized $\$ 23$ million to establish an institute to continue the baseline studies to see what if any permanent harm was caused to the Prince William Sound by the oilspill.

Again, this budget does not provide any money that is authorized for that activity, but there are funds in the Oil Spill Liability Fund that could be transferred to carry out the authorization in OPA to establish this institute. This is not bricks and mortar, Dr. Baker. It allows a group of highly capable experts in many disciplines to continue the work to determine what the long-term impact was of that spill.

I urge you, if you cannot get the money through this budget and it is obvious that you cannot, to join us in trying to see if we can 
get money out of that liability fund. I think this committee will join you to do that, because this committee joined me in establishing the institute.

I do have a number of problems with the budget request. Let us talk about the fees for a minute, Mr. Chairman. Up my way you could not be a sports fisherman and sell your fish. If you sell your fish you are a commercial fisherman and you have to get a commercial fishing tag.

I do not understand allowing sports fishermen to sell their fish. I think we ought to address that question right off. A sports fisherman that catches more than they need is not a sportsman as far as I am concerned. They ought to have more catch and release discipline as far as these sportsmen are concerned. There is no reason to allow sportsmen into commercial activity. I think we should address that here in terms of what we are going to do.

If a person sells fish they are commercial and I would require that person to have a commercial license. And in an area of controlled access or quotas, which is in almost every area, recreational fishermen have got to get in line. It may well be they have no right to catch the fish they are catching. So, I think we ought to give some good study to that.

But what bothers me is the 2-percent fee. I think the 1-percent fee is in trouble from the start with the committee. The 2-percent fee applies in fisheries that have the individual fishery quotas put into effect, and to my knowledge that is basically Alaska. Is that right?

Dr. BAKER. No. There are several of the ITQ programs. We have an Atlantic Surf Clam Program, which is an ITQ. Do we have others? I think there are three all together.

Senator STEvens. And that is a 3 percent which I understand includes the 1-percent fee.

Dr. BAKER. It is in addition, Senator. It is in addition I understand-3 percent does not include the 1 percent in the current proposal.

Senator STEvens. Oh, I understood it was the 3 percent was inclusive of the 1 percent across the board. Is that not true? It is 3 percent on ITQ/FQ? I stand corrected and I thank you.

But we have had some discussions about this before. I do not know how it is in New England and elsewhere in the country, but in Alaska there is an established method of distributing the catch. The fish tickets are actually reported and given to individual fishermen. They report that as their income.

The crew opposes taht new system vigorously, especially, if we imposed a tax on them for the ITQ/IFQ. I am sure you know the boat owners, the boat operators wanted the IFQ/ITQ. And it appears to me that you are making the crew oppose the ITQ/IFQ system pay for the system.

And with a crew of eight, the boat would get a share. The captain gets a larger share, and the other seven split the balance. And by definition in most instances that is more than one-half of the value of the catch, and yet they-the crew-are going to be paying for the IFQ. That does not set very well.

I have just come back from Alaska, and the people who have the individual fish tickets do not think they should pay a tax, and that 
is what would be paid. The fee would be paid on the value of the first sale, as I understand. They would paying that tax as the person who sold the fish because of the program that they opposed.

I suggest to you we ought to find some other way to collect that tax from the people who wanted the ITQ/IFQ's and not put it on the crew that share the fish under a fishing system where it is their direct income. You know that there are joint ventures. You have gone through that I assume, Dr. Baker. Is this not aimed at Washington State?

Dr. BAKER. I do not know the details of how they operate their programs in Washington State, so I cannot say. But I can look into it.

Senator STEvens. Well, I am hopeful we can find some way to go into these fees in depth and get some consensus as to how we can make them work.

I do not know about the rest of my colleagues. I went home and I said to my constituents that want these ITQ/IFQ programs, they cost money to implement and the Federal Budget is in a deficit. If you want these programs, you are going to have to find a way to pay for them. And I think our fishermen are ready to find a way to pay for them, but I do think the fees have to be fair. An automatic 3 percent on the first sale for ITQ's/IFQ's is going to hit the wrong people in my judgment. I would urge you to think that one through.

Dr. BAKER. Senator, I appreciate your concerns there. We have similar concerns and we would like to work with the committee to try to find some way of having a system that is fair. I can say we had to lay a proposal on the table so we had something to work from, but it is our feeling we want to address exactly the problems which you have just raised here.

Senator STEvens. Well, why do we not get away from these fishing fees and go to fishing licenses? Most of these vessels are investor owned, and I think that there ought to be some way to have a Federal license for that boat to be involved in fishing in Federal waters. That is much different than saying that you are going to have a tax on the people earning a living.

I feel the same way the chairman does about that. The bulk of the tax you propose will fall on people who are crew of the vessels. I am told Alaska will pay over 50 percent of the $\$ 70$ million, and of that more than one-half of the value is the value of the individual fish tickets that go to the individual deckhands. I do not think that is fair.

I think the boat owners ought to be paying for a license. If we need more money, let us get a Federal fishing license. Have you considered that?

Dr. BAKER. I do not know if that particular point has come or not. But, as I say, we needed to lay a proposal on the table and we are certainly willing to discuss a lot of different options about how we could address the problem.

Senator STEvens. Mr. Chairman, I think we ought to sort of have a consensus meeting. Dr. Baker has got a real problem, if my figures are right. He is more than $\$ 200$ million short right now, before he starts. And there is just no way the committee is going to 
put into effect the fees. And I do not think we are going to accept some of the cuts.

Now, somehow or another, we have got to figure out a way to cross that bridge.

Senator KerRY. Senator, I could not agree with you more. You are right on target. I think it is a starting point. The concept is on the table. We know we have to find some money. We are going to have to think this through. And I think, if we can spend some time, as we will, working on it, we will see what we can come up with. But this really underscores the dilemma that I was talking about up front, and I do not know anybody yet who thinks we are operating with that $\$ 82$ million in hand.

Senator STEVENS. I have just got three specific issues, Dr. Baker, on the charts. I note that you are predicting an increase in feesfrom the charts-I think it is $\$ 13$ million overall. I think that includes aeronautical as well as nautical charts. But on the nautical charts, you are canceling 127 charts in areas where there are too few sold-not closing down the place of sale, but closing down the charts.

Our examination shows that the area where it is being discontinued is the Pacific Northwest and Alaska; 39 in Alaska, 17 in Washington, and 9 in Oregon. The reason that there are so few sold is that there are not that many new boatmen in that area and there is not a high demand. But the new people who come in, they have got to have those charts.

Now, I just cannot understand-how are we going to get charts to replace those 39 maps for Alaska? How will we get them in Alas$\mathrm{ka}$ ?

Dr. BAKER. I think you have identified a weak point of our budget here in that charting. It is something we are going to have to go back and look at. We need to try to find some money, and I am not convinced that is the best way for us to save money, and I think you made a very good point there.

Senator STEvens. Thank you, Doctor. And, again, I would like to help you replace that money with something else. I have got some ideas on that, too.

Second, is the Yukon chum salmon decline. I am going to go up in August again to visit some of those villages that are really suffering because of that disaster there. There was a freeze in 1988. It was a Presidentially declared disaster. None of us thought one little bit about what was going to happen to the salmon fry that were in the Yukon. It was one real deep freeze.

It is obvious that we lost that run. We have made disaster relief available, as the chairman noted, in the overfished areas of the Northeast. But, in the Yukon area where these people have been suffering, and have suffered considerably, because of the total collapse of the chum salmon run due to natural causes, I do not think we have done anything to help.

I tried last year to get a commitment in this bill, and we were unable to get it. Now we have got the chum run coming in again, and the State has announced that chum fishing before the chum enter the Yukon will be cut in half. We are trying to preserve that run. But I see nothing in your program which addresses the Yukon chum or Yukon salmon supply. 
Can you take another look at that one?

Dr. BAKER. We will do that.

[The information referred to follows:]

NMFS does not have regulatory authority over inshore salmon runs. According to the Alaska Department of Fish and Game (ADF\&G), which manages the Yukon River chum salmon fishery, preliminary information indicates the number of chum salmon returning to the Yukon Rover is much stronger than the number that returned in 1993. ADF\&G has opened the Yukon River to commercial chum salmon fishery, based on the strength of the summer chum salmon runs.

NMFS implemented an emergency rule that establishes a cap of 42,000 salmon in the Bering Sea groundfish trawl fishery. If trawling during the period August 15December causes this cap to be reached, an area in the Catcher Vessel Operational Area, which is known to be an important area of chum salmon, will be closed. Al. though the continent of origin for the chum salmon by-catches occurring in the trawl fisheries is not well understood, NMFS took this action as a conservative measure to protect depressed chum salmon stocks.

Senator STEVENS. That has been put into the negotiations by the Canadians on the Canadian Salmon Treaty. I do believe we have got a terrible problem. Chum salmon provides the only income those people have. And if the chum run does not return this year, it is really a human disaster.

Last, we have got a real problem at the Pribiloff Islands. Your NOAA personnel have been meeting with representatives of St. George and St. Paul, looking to clean up the areas that were used by the National Marine Fisheries Service when the service ran those islands. We do have a fund that was created under the Department of Defense, which is the Defense Restoration Fund, using defense dollars to restore lands that were contaminated by defense activities in previous years which are no longer military reservations.

We do not have a similar fund here to deal with the cleanup on the Pribiloffs. It is not in your budget. There is a substantial amount of contaminated waste that was left on those islands by the National Marine Fisheries Service. The standards of activity in those days were different than now. Looking back, we see that mistakes were made. But now the problem is that the people of St. George and St. Paul are being asked to pay for the cost of that cleanup.

I think you ought to have a National Marine Fisheries Service Restoration Fund for the areas where your people have been active. You were at other places, I am sure, where you had similar activities. And I would urge you to find some way to focus on the cost of the cleanup of the Pribiloffs.

Has that been brought to your attention at all?

Dr. BAKER. Yes, it has, Senator. In fact, one of the first visits that we organized was to have Bob Fagin, the head of our Office of Administration, go to the Pribiloffs and take a team up there. This is the highest priority for us right now in our environmental compliance. In fact, we have a request of $\$ 6$ million in the 1995 budget for Pribiloff cleanup. We are working closely with the EPA and the Superfund rules to see how we can in fact develop a total budget for the complete cleanup and how we can get it accomplished.

Because, as you know, we can only work for a very short time up there in the islands and actually get things done each year. And 
we want to make sure that we are moving smartly toward really getting things cleaned up.

As I said, this is the highest priority for our environmental compliance, and we do have $\$ 6$ million in the budget this year for that.

Senator STEvens. Good. I did not see it identified for that. So, if it is, I apologize.

Dr. BAKER. It is in there. It may be in one more book of detail, but we have identified that. And it is our highest priority. We have identified that early on.

Senator STEvens. Mr. Chairman, the only thing that you raised, and I do not have any question prepared on it, is the marine aquaculture initiatives that are going to be pursued now by NOAA. I know Senator Akaka has got a bill that we are working with him on. I do not know what the jurisdictional arrangement will be between the committees, but I think it is highly important for us to look to aquaculture and to include methods of enhancement of natural runs.

Are you looking at it from that point of view?

Dr. BAKER. That is certainly one of the aspects of our total aquaculture interest; that is right. And it is an important thing for us.

Senator STEvENS. I know the fight that is going on, and I do not know if the chairman has heard about it. But the Canadians want to charge fees on our boats that go through Canadian waters from Washington to Alaska to fish. We have got an impasse with the Canadians now over the salmon issues.

In my judgment, the problem is supply. We should not have to get into these fights with our neighbors over how to ration a declining supply. We have the capability to enhance the supply of fish in the Pacific Northwest dramatically in a short period of time if we dedicate ourselves to it. And I do not think that it is part of your program. That bothers me.

Would you say you have an emphasis on enhancement of natural fish runs?

Dr. BAKER. I would say that we are still working on that. We have an overall aquaculture plan. Enhancement has been-certainly in the papers I have seen-mentioned as a part of that. It is not one of the highest priorities, but it certainly has been mentioned there. But I take into account what you have just said.

And let me just say about the Canadians that Ambassador Colson is ready to meet the Canadians. It may be that what the Canadians are trying to do violates international law. So, this is a point which we are taking very seriously.

Senator STEVENS. As a former maritime lawyer, I can tell you that there is no question that they are going to violate international law if they do it. And I think the only reason they did that was to get your attention and to make this salmon treaty a political issue and not just a negotiating issue within the confines of the treaty.

I do not know if you are familiar with what we did back in the days when Alaska was sort of a rambunctious State. I personally helped get the money to restock the Great Lakes with Alaska salmon. The Chileans are using the fortified eggs from one Alaskan hatchery, and Chile expanded their fishery in one year at an astounding rate. Yet we seem to be unwilling to do that. 
We cannot get access even to the fish and wildlife areas of southeastern Alaska to enhance rivers which are barren because the salmon were destroyed by high seas fishing. We cannot get access to the park areas to restore those runs. And I think there are similar situations in the Pacific Northwest that you are much more familiar with than I am.

But the other nations of the world are looking to enhancement and we are not. I think we ought to have a real task force working on how to enhance natural fish runs. It would be much cheaper than the aquaculture. We proved that in the Great Lakes, Doctor. They had a whole series of hatcheries that they are going to put in there. And we took the fortified eggs over there and put them in the Great Lakes and it worked just fine.

Dr. BAKER. That is a good point.

Senator STEVENS. I would urge you to give us a chance to show you the science we have developed in Alaska and let you utilize it both in Canada and the Pacific Northwest. I made that offer before, by the way. We offered to strip all of the Kings that are caught in southeastern Alaska, put them in the hatchery until the eggs are fortified, and transport down to put them in the Columbia. People said, you Alaskans do not know what you are talking about.

All I can tell you is that it works. We have restored innumerable streams that are under our control. But we cannot get to the streams that are under Federal control. And I think you are the person that could do that for us. You are certainly the person to convince Oregon and Washington to pursue some of the activities that have been so successful in Alaska.

I would hope that we can deal with a surplus rather than a shortage of fish.

Dr. BAKER. Senator, let me just say you have also been very successful in Alaska in having the stock of Bowhead whales recover. And I would like to thank you and Earl Comstock for the work that was done for the International Whaling Commission, because we were able to get an increased quota of Bowhead whales for the Alaska Eskimos up around Point Barrow, in those 10 villages. And that is because that stock has been carefully monitored and understood and watched by the Alaskans. That is, I think, an important success story for an endangered species.

Senator STEvens. Thank you.

This committee authorized the Alaska Eskimo Whaling Commission. You and your predecessors have worked with the Eskimo people to understand the Bowhead whale issue. We established a counting program and a taking program which was very restricted, until the Bowhead was totally understood. But I think that shows, as Senator Packwood said, the values of having people in the area involved. That program is a great example of how to restore endangered species.

I think you can restore the Pacific Northwest salmon in the same way if you had a commission in which the people of the area participated with your agency people to select the means of enhancement that would be most successful in the shortest period of time.

I thank you for that.

Senator KERRY. Let me interrupt, if I can here, because I know Senator Lott has to leave and he has been waiting. 
Senator LOTT. Thank you, Mr. Chairman.

I have run out of time, so I am just going to have to ask three questions very quickly.

First, Dr. Baker, thank you for being here. We appreciate your testimony and we look forward to working with you.

I do want to point out, as you know, these fisheries management councils have a very important role and, in many instances, do good work. We have vacancies, however, on the Gulf of Mexico Fisheries Management Council that have been there for quite some time. I wrote a letter on February 25 to Secretary Brown, again on May 6 to Secretary Brown, and again on June 1 about these vacancies. I have not had an acknowledgement to any of them, and the vacancies continue to be there.

If you would, I would like you to check into this matter, and I would appreciate the courtesy of a response. More importantly, we would like for those vacancies to be filled.

Dr. BAKER. We will do that, Senator.

[The information referred to follows:]

The appointments to the Management Councils for 1994-95 were announced July $1,1994$.

Senator LOTT. I do not want to beat a dead horse even more, but the fees you are talking about obviously cause major problems. In the Gulf of Mexico, our commercial fishermen are quite often very small operators - a husband and wife on a shrimp boat. They have already had to deal with the turtle-excluder device and invasion of imports and all kinds of problems. If you are talking about an additional fee, I think that they would be very, very unhappy with that prospect, as well as other commercial fisheries-not just shrimp, but commercial fishers in the gulf.

My question to you, though, is: Approximately how much would you anticipate getting from this fee? Do you have an amount in mind? Maybe you have already answered that question.

Dr. BAKER. Well, we are hoping to get as close to $\$ 82$ million as we can get.

Senator LOTT. And if you do not get that, of course, then you have got an additional shortfall on top of what is already anticipated.

Dr. BAKER. That is correct.

Senator LOTT. What would that $\$ 82$ million go far?

Dr. BAKER. That would go for directly paying for NMFS programs related to conservation and management of fisheries-a oneto-one correspondence there.

Senator LOTT. Just so the record will be clear, give me a couple of examples. Are you talking about the observer program? Are you talking about the charting of species where they are or what?

Dr. BAKER. An example would be enforcement of ITQ's. As we establish an ITQ fee, we have to know exactly how much is landed and how that is divided up. It has to be followed exactly. The fees would be used for that, for example.

Senator LOTT. The reason I ask this question is I need to be able to tell a fisherman in the Gulf of Mexico what he or she is getting out of it. And they do not think they get a whole lot of NMFS for the most part now. They may get more than they anticipate, but you are talking about very small operators or even medium-sized 
operators that would have a lot of questions about how much they really get out of these programs.

Dr. BAKER. Well, I think we are working our way toward trying to have accepted regional plans for fishery management, and that is what the fisheries management councils do. The implementation of the plans that the council develops requires funds. That is one of the places that we spend the money.

Senator LOTT. Jumping to one other area, on this bill that has already been referred to, 1288 , I believe, on the aquaculture research. Catfish are very, very important now in the economy of my State. And we had some problems with the legislation, but I understand that some of those have been taken care of, and the Catfish Farmers of America do endorse now this bill, 1288.

According to the analysis we have here, one of the things it does is provide additional disaster assistance for aquaculture producers. Could you tell me just a little bit about what that entails?

Dr. BAKER. Let me just see if we have some additional information. I do not have anything right here on that. We will have to get back to you on that. We are currently finishing our study of the Akaka bill and doing our comments on that. So, we will have to get back to you on that.

Senator LOTT. I would like to get your response for the record, particularly on how you would get this additional disaster assistance and how it would be available to the aquaculture industry.

Dr. BAKER. We will do that.

[The information referred to follows:]

I am unaware of the source of the analysis you referred to. NOAA does not have, nor proposes to create, any aquaculture disaster assistance program. It is my understanding that members of the aquaculture industry have approached DOA with the desire to make the current agriculture disaster assistance program available to their industry. While I am not familiar with the mechanics of the agriculture disaster assistance program, it suffices to state that NOAA supports DOA's willingness to extend this support to the aquaculture industry, particularly the marine aquaculture industry. It is NOAA's desire to promote the development of the commercial marine aquaculture industry and providing disaster assistance through DOA would support this objective. We look forward to working with DOA in the development of a national aquaculture program which draws on existing resources, expertise, and programs within the Federal Government.

Senator LoTT. Thank you very much, Dr. Baker.

Thank you, Mr. Chairman.

Dr. BAKER. Thank you.

Senator KERRY. I think Senator Stevens has underscored a number of points we need to continue working on, and we will do that.

If I could ask the second panel to come forward, and if it would do so expeditiously. Folks, thank you for your patience and thanks for being here. I would ask each of you if you would adhere to the rules of giving a 5-minute summary. Your text will be placed in the record in full. If you leave something out of your oral testimony, there is a chance during the Q\&A to really have a dialog and you can extend your remarks then. But I would like to try to make the presumption that the staff can read your prepared testimony and there is no need to really read the whole thing to us. So, if you would summarize, that would be terrific. Why do not we start with Jan Dill and work across. 


\section{STATEMENT OF JAN E. DILL, VICE PRESIDENT, OCEANIC INSTITUTE}

Mr. Dill. Thank you, Mr. Chairman, for the opportunity of appearing. My name is Jan Dill. I am vice president of the Oceanic Institute located in Honolulu, HI. OI is a private, nonprofit, applied aquaculture and marine biology research facility dedicated to the development of commercially viable and environmentally responsible aquaculture technologies. Our organization is composed of 150 researchers and technicians and support staff, and we have been working in the area of marine biology and aquaculture since 1960 . We are here to urge the reauthorization of NOAA.

We also urge that this reauthorization would take into account NOAA's role in supporting the development of marine and brackish water aquaculture in the United States. We view NOAA's role in marine aquaculture as an important part of a much needed and coordinated national aquaculture development strategy. This role is complementary to the functions and responsibilities of other Federal agencies, as outlined in S. 1288, the Akaka bill, presently under consideration in the Senate and supported by the entire domestic aquaculture industry.

Presently, the Institute is working on three important NOAAsupported projects that demonstrate the opportunity the agency has to work with institutions such as the Institute in the area of marine aquaculture. First is in the area of technology transfer. NOAA has funded the Institute in the development of the Asian Interchange Program. This effort has had great success in allowing U.S. growers access to important technologies and techniques used in foreign commercial aquaculture. This technology transfer to the United States has had practical and very positive impact on domestic production.

NOAA can and should play a leadership role in continuing a process of education and technology transfer for the benefit of the U.S. private industry. Hawaii is uniquely placed, geographically and culturally, to work with NOAA to expand this capability for the United States. The development of new, commercially viable, environmentally benign marine finfish culture technologies is central to the growth of the U.S. industry. NOAA has supported the Institute in the development of such technologies, specifically the culture of Coryphaena hippurus, the mahimahi fish, and pompano, known locally at papio. Both technologies offer great economic benefit for domestic producers and are examples of how NOAA can successfully collaborate in marine aquaculture development.

Finally, since 1988 OI has worked in the development of responsible stock enhancement of important recreational and commercial fisheries in Hawaii. This also is a NOAA-supported effort. Mr. Chairman, the State of Hawaii estimates that since 1900 close to 90 percent of the standing stocks of some of our in-shore fisheries have been depleted for a variety of reasons. Mr. Chairman, the situation is not unique to Hawaii. Whatever the reasons, it is now perfectly clear that enhancement of such marine and brackish water species can work.

The State of Hawaii and the Oceanic Institute through its NOAA-funded project, have developed a stock-enhancement tech- 
nology that is practical, ecologically responsible, and successful in reestablishing depleted and stressed stocks. In our tag and release trials of mullet, for example, we have demonstrated that a depleted population can be reestablished. Both commercial and recreational fisheries in Hawaii are benefitting from this development. The American Fisheries Society has gone on record in full support of the approach taken by this NOAA-supported program. We encourage NOAA's continuing and increasing support for such responsible enhancement efforts on a national level.

In closing, Mr. Chairman, we would encourage NOAA's continuing support for the development of marine aquaculture in the United States and its continuing collaboration with the many fine institutions having the capacity to augment NOAA's in-house resources. In these endeavors, we urge NOAA to work closely with the private sector in developing its priorities.

Thank you for the opportunity to present our views.

[The prepared statement of Mr. Dill follows:]

\section{Prepared Statement of Jan E. Dill}

Thank you, chairman and members of the committee, for allowing us to present testimony on draft legislation to reauthorize the National Oceanic and Atmospheric Administration. We also support bill S. 1288 authored by Senator Daniel K. Akaka to provide for the coordination and implementation of a national aquaculture policy for the private sector by the Secretary of Agriculture, to establish an Aquaculture Commercialization Research Program.

The Oceanic Institute $(O I)$ is a nonprofit, applied research organization concerned with practical oceanographic and aquaculture technologies, domestically and abroad. OI has conducted research in the field of applied aquaculture technology for over three decades.

Our Stock Enhancement of Marine Fish in the State of Hawaii (SEMFISH), Mahimahi Aquaculture Development and Asian Interchange programs are funded by the National Oceanic and Atmospheric Administration. In 1988, in response to a decline in Hawaii's coastal fisheries, OI established the SEMFISH program to examine the feasibility of enhancing coastal fish populations through stocking programs. SEMFISH technology can be applied to the enhancement and revitalization of inshore and nearshore fisheries worldwide. OI scientists are currently employing this new science to replenish Pacific threadfin, identified as the top priority species for stock enhancement in Hawaii. The Asian Interchange Program (AIP) was established at OI in 1989 to give key membres of the U.S. aquaculture industry and research community an opportunity to participate in discussions with their counterparts in Asia. AlP has completed four international aquaculture information exchange efforts to date that respond directly to areas of key concern to the U.S. aquaculture industry. The purpose of the Mahimahi Aquaculture Development Project is to advance the technology of mahimahi aquaculture to the point of commercial feasibility. Our work through these programs makes OI a logical candidate to act as an extension of the National Oceanic and Atmospheric Administration in Hawaii, to assist the agency in their mission to manage and protect our fisheries and the ocean environment.

The United States has always been a leader in the field of agriculture technology. Now is the perfect time to apply this leadership to the burgeoning aquaculture industry, domestically and globally. Tremendous commercial opportunities are available from aquaculture ventures, and the United States has the technology and expertise to be in the forefront of the industry using methods that are environmentally sustainable.

In the last 20 years, the world aquaculture industry has more than doubled its contribution to global fisheries. Aquaculture provides approximately 15 percent of world fisheries' supplies, and the value of 1990 harvests totaled approximately $\$ 30$ billion. Aquaculture in the United States has grown 20 percent annually through the 1980's to become the fastest growing segment of U.S. agriculture. The industry currently provides about 17 percent of the domestic seafood supply.

Hawaii's aquaculture industry has two components: the commercial production sector and the research and technology transfer (service) sector (i.e., research, training, professional conferences, degree education, and consulting activities). In 1993 
Hawaii's total aquaculture industry value was estimated at $\$ 25$ million. The wholesale product value in the commercial product sector was estimated at $\$ 8$ million and the service sector at $\$ 17$ million. Aquaculture farms now produce about 3 percent of the seafood consumed in Hawaii and 13 percent of the value of all local fisheries products.

Hawaii's diverse tropical and subtropical climate, suitable lands, nearshore ocean areas, and abundant supplies of fresh, brackish, and warm salt waters, combined with its location on the Pacific Rim, give it an unmatched advantage in the fish farming industry. More than 35 different marine species are farmed in Hawaii including mahimahi (dolphin fish), shrimp, tiaapia, mullet, and catfish.

Aquaculture research, technology transfer, and training are other areas providing growth to the industry. OI has transferred its technology to Egypt, Taiwan, Indonesia, and Ecuador; and has trained people form Oman, Belize, Turkey, Brazil, Burma, China, India, France, French Polynesia, and the continental United States. This transfer of knowledge benefits the industry, and will help to alleviate the world food problem.

Another aspect of marine aquaculture that needs encouragement is the use of aquaculture as a vehicle to teach science, math, and economics. Pilot programs at the Oceanic Institute and other institutions have demonstrated that the multidisciplinary aspects of aquaculture are ideal for education purposes. One of these programs is Future Farmers of America. OI was instrumental in developing the curriculum being used by Future Farmers of America in U.S. schools. While the goal of such programs may be to develop qualified personnel for the aquaculture industry, often students actually become interested in careers in other science fields. The "hands-on" nature of aquaculture can give students confidence in subjects they traditionally avoid but are necessary for science and math careers. Aquaculture involves biology, chemistry, physics, math, and economics.

The aquaculture industry needs continued research and development in the area of technology. For example, the industry must be supported by cost-effective aquatic feed. Out of the 4.6 million metric tons of feed to be produced by the year 2000 , 1.2 million metric tons of the total will consist of fish meal (a very costly and limited ingredient). Using new technology currently being developed, it is estimated that between 500,000 and 1 million metric tons of the fish meal component in aquatic feed may be replaced by plant proteins. The opportunity exists for American farmers to produce plant protein such as soy and wheat to replace costly fish meal in aquatic feed. Producing aquatic feed has tremendoud commercial potential. In 1990 aquaculture feed production in the United States totaled 400,000 tons with a value of approximately $\$ 120$ million. World aquaculture feed production totaled 2.7 million tons with a value of $\$ 1.7$ billion.

The success of aquaculture is dependent on the same components necessary for commercial agriculture. These components include adequate supplies of quality seed, feeds, feeding regimes, tight production management, prudent financing, health programs, and good marketing/distribution. All these factors are in place for traditional sustainable and profitable modern food production industries. The successful U.S. pultry and swine industry include high health chick and piglet or "seed" supplies. Tomato, potato, and rice farmers have in place tight production management and health programs.

In sharp contrast, world marine aquaculture to date has been primitive. The vast majority of production is dependent upon the capture of wild animals, unsophisticated breeding practices, limited disease programs, and common property water use in fragile coastal estuaries. Nonetheless, marine aquaculture continues to grow. For example, marine shrimp farming has grown into a $\$ 4$ billion worldwide industry, with production centered in Thailand, Indonesia, India, the Philippines, China, and Ecuador.

However, the picture of the shrimp farming industry is far from rosy. Short-term profitability has sacrificed long-term sustainability though environmentally unsound farming practices. In 1993, world shrimp farming revenues were down dramatically from the previous year. Disease and environmental problems have translated into a $\$ 1.2$ billion loss in exports for China alone. Approximately 40,000 hectares in Thailand and 15,000 hectares in Latin America have been abandoned because of similar problems related to deteriorating seed supply, disease, and environmental conditions.

Fortunately, aquaculture entrepreneurs in the United States have learned from the mistakes made by other countries and have taken the proper steps to maintain healthy animals and environments. The leadership the United States has maintained in world agriculture can be transferred to aquaculture production. The window of opportunity for U.S. leadership in the industry is open. The technologies for moving the United States into this position are being developed and can continue 
to be developed with Federal research programs such as those provided to the shrimp industry. In contrast to the rest of the world, the United States invested \$25 million over the past several years in research and development technologies, products, and services essential to profitable and sustainable shrimp farming. This has resulted in a 140-percent increase in production in the U.S. shrimp farming industry. This increase was achieved despite comparative disadvantages inherent to the United States like competing uses of scarce coastal resources. This example, can be duplicated in other types of marine aquaculture involving fish, feeds, and other products such as pharmaceutical. The United States should continue to develop these technologies, products, and services, and transfer these technologies to other end-users around the world.

We appreciate the opportunity to testify on behalf of this important legislation.

Senator KERRY. Thank you very much, Mr. Dill. Thanks for keeping your views tight like that. I appreciate it. Dr. Sandifer.

\section{STATEMENT OF DR. PAUL A. SANDIFER, DIRECTOR, MARINE DIVISION, SOUTH CAROLINA DEPARTMENT OF NATURAL RE- SOURCES}

Dr. SANDIFER. Thank you, Mr. Chairman.

My name is Paul Sandifer and I am director of the Marine Resources Division of the South Carolina Department of Natural Resources. Our facilities include the Waddell Mariculture Center, which is among the most significant marine aquaculture experiment stations in the country, and personally I have over 20 years' experience in research, development, extension, and education related to marine aquaculture.

Today in the United States fresh-water aquaculture accounts for nearly three-quarters of total U.S. aquaculture production. Thus, coastal aquaculture itself is rather small, yet most people consider it quite vital since the importation of marine products make up such a huge portion of our fisheries deficit.

Two years ago a committee of the prestigious National Research Council concluded that a number of benefits would accrue to the United States via the development of a "economically viable, technologically advanced and environmentally sensitive healthy marine aquaculture industry"-and all of that is included in their report. However, despite the importance of marine aquaculture to the $\mathrm{Na}$ tion, Federal efforts to nurture aquaculture development have largely failed to keep pace with needs.

Nevertheless, the good news from a recent survey of coastal State aquaculture coordinators was that, despite its many problems, marine aquaculture is alive and broadly distributed, with some activities taking place in more than 80 percent of coastal States and territories. The bad news is that coastal aquaculture clearly is not well. Only 31 percent of the States reported moderate growth, 42 percent reported very slow growth, and 27 percent reported no growth at all. If something is not done to improve its growth rate, marine aquaculture is going to remain a very small industry in this country for years to come.

The most significant impediments, identified in this survey, to marine aquaculture development were permitting, No. 1; burdensome regulations, No. 2; competing users of land and water, No. 3; then inadequate financial resources and lack of financial incentives. According to the survey respondents, the most important thing government could do to enhance aquaculture development was, right off the bat, simplify permitting. And, second, provide fi- 
nancial incentives, technical information and marketing assistance, and third, establish a friendly regulatory environment and consistent public policy.

So, what specifically should NOAA do? First, the regulatory and permitting structures that govern marine aquaculture need to be reexamined with a view toward simplification without loss of environmental protection. The Joint Subcommittee on Aquaculture, or JSA, should be charged with designing a streamlined planning and permitting process for marine aquaculture that emphasizes local, State, and Federal coordination. NOAA could provide some of the leadership and funding to make this possible.

Second, NOAA itself should play a much more proactive role in the development of marine aquaculture. While the U.S. Department of Agriculture is the overall lead Federal agency for aquaculture, the NRC committee recommended that NOAA take on specific responsibilities for marine aquaculture. For example, the National Sea Grant Program should be charged with leadership in support of research and extension programs on marine aquaculture related topics. Among the candidate research areas identified were environmentally safe technology, methods, and systems for culturing marine species.

The committee further identified the National Marine Fisheries Service as the agency to take the lead regarding the potential use of aquaculture to enhance marine fishery stocks. The committee suggested that NMFS develop a comprehensive national policy to direct marine stocking efforts and consider the potential roles of the private sector in marine stock enhancement. This is extremely important since fully 73 percent of the coastal States foresee one or more roles for private aquaculture in enhancement of coastal recreational and commercial fisheries.

The 1993 NOAA strategic plan reflects the NRC committee's recommendations. Acceleration of the growth of U.S. aquaculture was included as one of seven strategic actions that NOAA should take to build sustainable marine fisheries. In addition, a recent workshop concluded that NOAA should become the advocate for ocean aquaculture, should develop policy and cost-effective technologies to support aquaculture in Federal waters, and investigate uses of aquaculture for creating habitat in offshore areas.

What remains now is for these recommendations and the NOAA strategic plans to actually be put into action, and this will require that NOAA place a much higher priority on marine aquaculture programs and funding than it has previously. The NRC committee recommended a $\$ 12$ million national $R \& D$ initiative for marine aquaculture; NOAA would be a good place to start with some of this funding.

In conclusion, marine aquaculture is an effective tool to restore depleted species, help rebuild and enhance coastal habitats, produce high-quality seafood to meet escalating consumer demand and reduce reliance on imports, protect water quality, and create jobs and economic development opportunities. NOAA is the principal marine agency in this country, and its authorization legislation and its appropriations should clearly spell out marine aquaculture development as one of its priority missions, and one that 
cuts across its fisheries, habitat, and environmental stewardship responsibilities.

Thank you, Mr. Chairman.

[The prepared statement of Dr. Sandifer follows:]

\section{Prepared Statement of Paul A. Sandifer, Ph.D}

Mr. Chairman and members of the Committee, I am pleased to be here today to testify on behalf of marine aquaculture and the importance of Federal support for this industry. My name is Paul Sandifer, and I am director of the Marine Resources Division of the South Carolina Wildlife and Marine Resources Department. The Marine Resources Division's facilities include its headquarters at Fort Johnson on Charleston Harbor and the Waddell Mariculture Center, which is among the most significant marine aquaculture experiment stations in the country. The state of South Carolina has a rich history of leadership in the development of marine aquaculture, beginning in the 1940's with efforts of the late Dr. G. Robert Lunz at the Bears Bluff Laboratories, and today marine aquaculture remains very important to us. Personally, my background includes more than 2 decades of active participation in research, development, extension and education related to marine aquaculture in SC. Recently, I was privileged to serve as a member of the Committee on Assessment of Technology and Opportunities for Marine Aquaculture in the United States of the Marine Board, which is a standing board of the National Research Council, National Academy of Science.

My purposes today are to underline the importance of marine aquaculture to the United States, describe some of the major factors inhibiting its development, emphasize the necessity for close industry-government-university ties for its enhancement, and provide some recommendations as to how the Federal government in general and the National Oceanic and Atmospheric Administration in particular might improve the climate for expansion of marine aquaculture here.

\section{WHY IS MARINE AOUACULTURE IMPORTANT}

Today the United States imports over 60 percent of its fish and shellfish, and these imports of fishery products-some $\$ 9$ billion worth per year-are the largest contributor to the US trade deficit among agricultural products, and the second largest, after petroleum, among all natural resource products. Annually, foreign-grown aquaculture products constitute some $\$ 800$ million of the fisheries products consumed in this country.

On a world-wide basis, commercial fisheries stocks are threatened by overfishing, and catches of many species have leveled off, are declining, or in some cases have essentially disappeared. Neither the world's oceans nor our 200 -mile exclusive economic zone can continue to produce more and more fisheries products, and many fishery scientists think that humans have already reached, and are perhaps exceeding, the potential yield from the oceans. This is where aquaculture comes in-it can produce additional seafood, with resultant positive impacts on wild stocks and our country's huge trade deficit.

\section{WHAT IS THE SITUATION IN THE US TODAY}

In the US, aquaculture production has increased an average of 20 percent by weight annually since 1980, and it is the fastest growing segment of US agriculture. However, freshwater aquaculture still accounts for roughly three-quarters of total US aquaculture production. Of the approximately 25 percent contributed by marine and estuarine aquaculture, some 80 percent comes from oyster culture, with the remaining 20 percent made up principally of clams, mussels, salmon and shrimp. Thus, coastal aquaculture in the US is a relatively small industry. Yet many people consider it vital, since most of the huge deficit in fishery products comes from importation of marine, not freshwater, seafood. To put it another way, most of the fishery products that consumers want come from salt waters.

Two years ago, a committee of the Marine Board of the prestigious National Research Council concluded that a number of benefits would accrue to the US via the development of "an economically viable, technologically advanced, and environmentally sensitive healthy marine aquaculture industry." According to this committee's report, 1 these benefits would include "providing wholesome seafood to replace

${ }^{1}$ National Research Council, 1992. Marine Aquaculture, Opportunities for Growth. Report of the Committee on Assessment of Technology and Opportunities for Marine Aquaculture in the 
declining harvests of wild fish, products for export to improve the nation's balance of trade, enhancement of commercial and recreational fisheries and fisheries that are overfished or otherwise threatened, economic opportunities for rural communities, and new jobs for skilled workers, particularly in coastal communities where some traditional fisheries are at maximum sustainable yield or in decline." The committee concluded that "the advancement of the science and technology base in marine aquaculture will also provide benefits to other industries, such as biotechnology and pharmaceuticals."

Despite the current and projected future importance of marine aquaculture to the nation, Federal efforts to nurture aquaculture development have failed to keep pace with the needs of fish farmers. Major problems include:

(a) lack of credit;

(b) very limited research, development and extension programs;

(c) diffused legal jurisdiction and numerous legal questions concerning property rights, use of public resources, etc.;

(d) inconsistent interpretations among Federal agencies;

(e) lack of management information;

(f) lack of supportive government policies;

(g) lack of therapeutic compounds for treatment of diseases; and

(h) lack of reliable supplies of seed and brood stock.

Many areas of the US coastline are suitable for aquaculture, but most are subject to land-use or water-use policies and regulations that do not adequately consider the potential for aquaculture and, in fact, may hamper its development.

A recent survey of aquaculture coordinators in all coastal states and territories presented some interesting findings. ${ }^{2}$ The good news was that marine aquaculture is alive and broadly distributed in the US. Some activities-from shellfish culture to intensive fish or shrimp farming-were reported in more than 80 percent of the coastal states and territories. An important strength of US coastal aquaculture is its diversity-more than 50 species are involved. However, only a relatively few products such as oysters, clams, mussels, salmon, shrimp and striped bass are produced in significant quantities at this time.

The bad news from the survey was, that while coastal aquaculture is alive in this country, it clearly is not well. Only 31 percent of the states reported moderate growth of marine aquaculture, while 42 percent reported very slow growth and 27 percent no growth. Marine aquaculture in the US is small now; if something isn't done to improve its growth rate, marine aquaculture in the US will remain small for years to come.

The most significant impediments to marine aquaculture development identified in this survey were, in decreasing order of importance:

(a) permitting;

(b) burdensome regulations;

(c) competing uses of land and water;

(d) inadequate financial resources; and

(e) lack of financial incentives;

A potential growth area for the future identified in the survey and in the NRC study is utilization of marine aquaculture to support coastal recreational fisheries. Fully 73 percent of the coastal states and territories surveyed foresaw one or more roles for private aquaculture in this arena.

According to state aquaculture coordinators, the most important things government can do to assist in the development of marine aquaculture are:

(a) simplify permitting;

(b) provide financial incentives;

(c) provide technical information;

(d) establish a friendly regulatory environment;

(e) provide marketing assistance; and

(f) establish a consistent public policy.

\section{SUGGESTIONS FOR COMMITTEE CONSIDERATION}

To conclude my remarks, I would like to offer several suggestions for the Committee to consider as it deliberates the reauthorization of the programs and activities of the National Oceanic and Atmospheric Administration. These are based in large part, but not completely, on the recommendations of the NRC's Committee on As-

United States. Marine Board, Commission on Engineering and Technical Systems, National Research Council. National Academy Press, Washington, DC. 290 pp.

2 Sandifer, P.A. 1994. U.S. coastal aquaculture: flirting with opportunity. Water Farming Journal $8(4): 3-6,9-16$. 
sessment of Technology and Opportunities for Marine Aquaculture in the United States.

First, the regulatory and permitting structures that govern marine aquaculture at federal, state and municipal levels need to be reexamined, with complementary views toward simplification and environmental protection. The Joint Subcommittee on Aquaculture (JSA) should be charged with designing a streamlined planning and permitting process for marine aquaculture activities emphasizing joint local, state and federal coordination. A major accomplishment in the early days of the JSA was its contract with the Aspen Corporation to analyze the regulatory structure for aquaculture. The reports submitted to the JSA in 1983 were substantive and thorough; unfortunately, due to lack of appropriations, no actions were taken and the reports are now far out of date. Similar studies should be undertaken as soon as possible, but with a specific action plan in mind to streamline the regulatory maze. At least one state has already adopted an effective one-stop permitting process for aquaculture, and this should be examined as a possible model. Funding for the JSA to undertake this activity could be provided, at least in part, by NOAA.

Second, the Congress should designate marine aquaculture as a recognized use under the Federal Coastal Zone Management Act. The JSA should be given the responsibility for promoting the inclusion of marine aquaculture in the Coastal Zone Management Act. In addition, Congress should review and revise the Lacey Act, taking into account the requirements of modern aquaculture businesses.

Third, NOAA should play a more proactive role in the advancement of marine aquaculture in the US. While the US Department of Agriculture is clearly the lead agency for aquaculture, the NRC committee recommended that NOAA take on specific leadership responsibilities for marine aquaculture. For example, the Committee stated that the National Sea Grant College Program should "be charged with leadership in support of research and extension programs on marine-aquaculture related topics * **" Candidate research areas identified included the following:

(a) environmentally safe technology, methods, and systems for culturing marine species in the marine environment;

(b) marine aquaculture technology that is synergistic with other uses of the sea;

(c) life history and developmental biology of candidate species;

(d) the socioeconomic dynamics of the marine aquaculture industry (e.g., effects on local employment practices);

(e) methods for addressing and resolving conflicts between marine aquaculture and other competing users of the marine environment;

(f) comparative studies of state practices regarding the regulation and promotion of marine aquaculture; and

(g) alternative institutional and policy structures for managing marine aquaculture in other countries.

The report further identified the National Marine Fisheries Service (NMFS) as the agency to take the lead regarding the potential use of aquaculture to produce fish and shellfish for enhancement of marine fishery stocks. In this role, the committee suggested that NMFS develop a comprehensive national policy to direct marine stocking efforts and consider the potential roles of the private sector in marine stock enhancement.

The recent NOAA Strategic Plan ${ }^{3}$ reflects these recommendations. Acceleration of the growth of US aquaculture was included in the Plan as one of seven strategic actions NOAA should take to build sustainable marine fisheries. The plan further states that NOAA will specifically:

"Foster the development of environmentally acceptable, cost-effective intensive commercial aquaculture systems" and

"Advance NOAA's fisheries enhancement programs through the development of new hatchery rearing systems and the tailoring of candidate species for those systems, using biotechnology and other specific approaches. High priority areas include programs to develop technology for culturing currently over-exploited species and those in danger of over-exploitation, better broodstocks, improved hatchery techniques, enhanced growth of high-value species, improved disease resistance and treatment, imrroved control of reproduction, techniques for the identification of cultured stocks in the oceans, and understanding better the genetic consequences of enhancement."

Similarly, a recent workshop on aquaculture in the southeastern US 4 concluded that NOAA should become the advocate for ocean aquaculture and develop policy and cost-effective technologies to support aquaculture in Federal waters. It should

${ }^{3}$ NOAA. 1993. NOAA 1995-2005 Strategic Plan.

4 NMFS. 1994. Report of the Workshop on Aquaculture in the Southeastern United States. January 12, 1994. New Orleans, LA. 
also lead in the investigation of uses of aquaculture for creating habitat in offshore areas.

What remains now is for these recommendations and strategic plans to be put into action. This will require the establishment of a reasonably high priority within NOAA for marine aquaculture and, most importantly, the appropriation or allocation of sufficient funds to make a difference. One of the greatest problems facing marine aquaculture has been a consistent paucity of funding, particularly within the NMFS, to support marine aquaculture. It is now essential that marine aquaculture be given higher priority and funding within the NOAA agencies. Further, the NRC committee recommended a $\$ 12$ million national R \& D initiative for marine aquaculture. Certainly, NOAA would be a good place for at least some of these funds to be appropriated.

Marine aquaculture is an effective tool to restore depleted species, help rebuild and enhance coastal habitats, produce high-quality seafood to meet escalating consumer demand and reduce reliance on imports, protect water quality, and create jobs and economic development opportunities. NOAA is the principal marine agency in the country, and its authorizing legislation should clearly spell out marine aquaculture development as one of its priority missions, one that cuts across its fisheries, habitat, and environmental stewardship responsibilities.

Mr. Chairman and members of the Committee, I again thank you for the opportunity to appear before you today and would be happy to try to answer any questions you may have.

Senator KeRRY. Thank you very much, Dr. Sandifer.

Mr. Garrison, welcome, glad to have you. Sorry to have to drag you out of that beautiful island, but we are glad to have you here.

\section{STATEMIENT OF ROB GARRISON, EXECUTIVE DIRECTOR, NANTUCKET RESEARCH AND EDUCATION FOUNDATION}

Mr. GARRISON. Thanks very much, and I appreciate the opportunity to be able to speak with you today. My name is Rob Garrison. I am the director of NREF, the Nantucket Research and Education Foundation. We operate aquaculture development and marine research and education programs on Nantucket Island. We also operate the Nantucket Marine Laboratory, which is a shellfish hatchery, aquaculture, research, and education facility on Nantucket.

The marine lab is the result of an innovative public-private venture that brought together the town of Nantucket, a private commercial shellfish firm, and our nonprofit. Seed money provided by the town got it started, and combined with private business over a 2-year development period, now the nonprofit runs this facility with very minimal town support. At this facility, shellfish seed are produced for aquaculture development programs, for enhancement of the public fisheries, and also to be sold to private aquaculture businesses. Other programs benefit the public, students, industry, and the environment. Town government has reduced its involvement, but accomplished its original public goals.

With the cooperation of the town, we have developed the Nantucket aquaculture program. This began last year with State-community development funding, and is expanding this year with funds appropriated by Congress and we thank you very much for that, and through NOAA it is operated.

This program provides training in shellfish aquaculture. The trainees, the targeted clientele are commercial fisherman on Nantucket. They are provided training, the necessary materials, and shellfish seed to begin into business. And another component of the program involves enhancement of the natural populations of the shellfish there. One-half of those seed, once they reach a size of 
about 1 inch where they have a good chance of survival over the winter, are released into the waters to increase the natural populations. The other one-half are retained by the trainees to be grown up to market size, sold, and in that way begin their business.

Additionally, there is a research component that is establishing a genetic marker for that particular species of bay scallop so that we can track our enhancement efforts. The final component of the program develops curriculum for other towns and communities, and for high schools who wish to begin aquaculture education programs.

With this program, we are not only expanding the economic base of Nantucket; we are also enhancing the fisheries and establishing shellfishing on Nantucket for as much as 25 percent of the population of Nantucket. Combining the aquaculture development with the fisheries enhancement enlisted the support of the fisherman, the commercial fisherman there, which historically were the most vocal opponents of aquaculture.

Marine aquaculture is capital intensive and site specific. Several years are needed for establishment of a successful project. This program gives fisherman and others the opportunity to start an aquaculture business. It supports the effort with research and development programs, and it is designed to be self-sufficient after several years.

Viewed as a model, the Nantucket aquaculture program can be expanded to other species and communities. There has interest been expressed from the entire east coast, and particular opportunity exists especially to transfer to sea scallop aquaculture with the New Bedford and Gloucester fishing community. NOAA programs could provide seed money for development projects such as this. Combining town and private resources with Federal development moneys benefits all. The initial development risk can be lowered with Federal support, while the project can have the advantage of sound business practices offered by the private industry. Once the development stage is completed, private capital can take over for commercial expansion.

For example, site-specific pilot projects on sea scallop aquaculture could be undertaken concurrently with hatchery technique research and other applied research and enhancement projects, on a small scale, to develop the effectiveness of them. Marine finfish: again it will require facilities to work and develop aquaculture practices for different species and enhancement projects.

As in Nantucket, seed money from Government could combine with private industry to operate development commercialization programs and research new species and methods for aquaculture enhancement. Private industry is willing to invest in the development of aquaculture. NOAA could encourage this private involvement by offering incentives, matching funds, and developing appropriate support services.

Sea Grant must receive funding to develop research and extension programs from marine aquaculture. Additionally, Sea Grant institutions should be encouraged to increase their outreach efforts working with other organizations. Legislatively, marine aquaculture must have a coherent national policy for development. Coordination between all regulatory agencies, State and Federal, is 
mandatory. Permitting must be streamlined. CZM should be encouraged to establish aquaculture as a preferred use for coastal areas. Perhaps even regional zones for aquaculture could be established. States need incentives to develop the necessary policies and procedures to encourage aquaculture.

Thank you very much. [The prepared statement of Mr. Garrison follows:]

\section{PREPARED STATEMENT OF ROB GARRISON}

Good Morning, and thank you for offering me the opportunity to speak with you today.

I am the director of NREF, the Nantucket Research and Education Foundation. We are a non-profit organization involved in aquaculture development and marine research and education programs. The programs are joint efforts with Towns, universities, research institutions, scientists, educators, and private individuals.

NREF operates the Nantucket Marine Laboratory, a shellfish hatchery, aquaculture, research and education facility on Nantucket Island. The Marine Lab is the result of an innovative publiclprivate venture which involved the Town of Nantucket, a private commercial shellfish firm and NREF. Seed money provided by the Town combined with private business to build this facility. After two years of construction and development, the Lab is now operated by NREF with some Town support. Shellfish seed are produced for enhancement of public fisheries, our aquaculture development program, and to be sold to private aquaculture businesses. Other programs benefit the public, students, industry and the environment. Town government has reduced its involvement, but accomplished its original public goals.

With the cooperation of the Town we have designed and implemented the Nantucket Aquaculture Program. This began last year with state community development funding and is expanding this year with funding obtained through NOAA. The Nantucket Program arose out of the need to maintain our commercial shellfisheries, protect natural resources, and develop aquaculture as an environmentally sound business. The program provides training in shellfish hatchery methods, water quality analysis, field grow-out of shellfish, and business start-up. Trainees are provided with deed shellfish, the necessary materials, and space for grow-out. When the shellfish reach the size of approximately 1 inch, 50 percent are returned to the Town to augment natural populations, the remaining 50 percent are ongrown by the trainee to be sold when market ready. A research component investigates establishing a genetic marker for the bay scallop so that enhancement efforts can be tracked in the field to gauge effectiveness. Additionally, curriculum is being developed for other communities and high school aquaculture programs.

This program will expand the economic base of Nantucket, enhance natural sets of shellfish for both recreational and commercial benefit, provide the Town with much needed labor for its propagation and water quality programs, and eventually establish shellfishing on Nantucket as a full-time, viable income for as many persons who choose this career as possible. On Nantucket this could be 200-400 families or 25 percent of the year round population. Commercial bay scallop fishermen are the targeted clientele. Combining aquaculture development with fisheries enhancement enlisted the support of the public as well as the fishermen (previously the most vocal opponents of aquaculture). Marine aquaculture is capital intensive and site specific. Several years are needed for establishment of a successful project. This program gives fishermen and others the opportunity to start an aquaculture business. It supports the effort with research and development programs. And it is designed to be self sufficient after several years. As the aquaculture ventures are commercialized, the initial project is expanded to economically viable levels and thus supports the seed producing and research facility. Enhancement continues as with the original program and can be expanded along with the aquaculture.

Viewed as a model, the Nantucket Aquaculture Program can be expanded to other species and communities. Coastal communities from Maine to the Chesapeake have expressed interest in the program. New Bedford scallopers and the Gloucester community want to establish pilot programs for sea scallop aquaculture and development efforts for groundfish aquaculture and enhancement. We feel the combination of aquaculture and fishenes resource enhancement can play a major role in alleviating the problems resulting from the decline of fisheries in the Northeast.

NOAA programs cas provide seed money for development projects. Projects should be structured to take advantage of both public and private resources. Initial Jevelopment activities can be undertaken jointly and on a small scale. As commer- 
cialization takes place private industry assumes responsibility for expansion. For example, site specific pilot projects on sea scallop aquaculture should be undertaken. Concurrently, hatchery techniques, related applied research, and enhancement projects should be coordinated. Marine finfish will require facilities devoted to the development of aquaculture practices for different species and enhancement projects. We suggest the creation of facilities devoted to aquaculture development and fisheries enhancement. As in Nantucket, seed money from the government can combine with private industry to develop these facilities. The roles of the facilities will be to operate development/commercialization programs and research new species and methods for aquaculture and enhancement. Private industry is willing to invest in the development of aquaculture. NOAA can encourage private involvement by offering incentives, matching funds, and developing appropriate support services. Industry is interested in projects that have direct application. To assure the future Sea Grant needs the funding to develop research and extension programs for marine aquaculture. This support is necessary to the development of aquaculture. Sea Grant institutions should be encouraged to increase their outreach efforts, work with other universities and organizations, and collaborate with private groups in aquaculture development.

We are also looking towards combining aquaculture efforts with other industries to alleviate the normal funding problems encountered by most research and development institutions. We are investigating the development of a facility which will combine income producing activities with $\mathrm{R} \& \mathrm{D}$ efforts in marine aquaculture and fisheries enhancement. The tri-fold goal of the project is to construct a marine museum with associated tourist activities, a water quality testing laboratory, and a marine finfish aquaculture facility all at a common center. Income derived from the laboratory, museum, and tourist related concessions will support the aquaculture efforts. The facility would provide public education, water quality improvement, and development of the necessary technologies to advance marine finfish aquaculture for fisheries enhancement and economic development.

Legislatively, marine aquaculture must have a coherent national policy for development. Coordination between all regulatory agencies, state and federal, is mandatory. Permitting must be streamlined. CZM should be encouraged to establish aquaculture as a preferred use for coastal areas. Perhaps regional zones for aquaculture could be established. States need incentives to develop the necessary policies and procedures to encourage aquaculture. The point is that presently it is extremely difficult for marine aquaculture to exist, let alone grow. We are speaking of the development of an industry that can contribute to the balance of trade, provide jobs, and combine with traditional fisheries to rebuild depleted stocks and keep fishermen employed. Finally, marine aquaculture is, by necessity, an environmentally friendly industry. We need good water quality for a successful project. Water quality monitoring implemented by aquaculture in Nantucket has led to the identification and remediation of pollution problems.

We have an opportunity to lead in the development of aquaculture for fisheries enhancement of traditionally fished species and the creation of a new marine industry. Aquaculture, combined with other enhancement and habitat remediation programs, can help restore the once valuable and productive waters of the Northeast. As in Nantucket, commercial fishermen can continue to earn a living from the ocean while, at the same time, restoring the native stocks.

\section{EXCERPTS FROM A LETTER TO JOHN BULLARD}

The Nantucket Research and Education Foundation (NREF) was formed to conduct scientific research and educational programs in aquaculture, water quality, fisheries, natural resources and computer modeling. Programs begun on Nantucket will be expanded to other communities and eventually impact the entire region. Our goals are to promote and develop aquaculture, revitalize the fishing industry and protect water quality and natural resources. Our educational programs target students, fishermen, the scientific community and the public. We work closely with other communities establishing programs in these areas, assisting in fundraising, and coordinating projects with outside institutions. Presently, projects are underway with Harvard University, University of Connecticut, Duke University, Harbor Branch Oceanographic Institute, and the University of Massachusetts. Since testifying before the Subcommittee on Fisheries and the Environment and presenting our program during an aquaculture conference in South Carolina, Jim McVey of Sea Grant, Hank Parker of JSA, John Burris of MBL and other aquaculture professionals have expressed interest in our program and its potential as a model for a national program. 
Our philosophy is that for aquaculture to obtain increased support and realize its potential for economic development, food production, and fisheries enhancement more people must become involved. Traditionally, a major constraint for marine aquaculture has been conflict of use for the waters and opposition to the private use of public waters. Our program addresses this by involving the habitual opponents and benefiting the public. Fishermen (usually the most vocal opponents) are targeted as clientele for the program. The decline of the fishing industry and fishermen's inherent skills provide a large, easily trained population ready to benefit from aquaculture. The public benefits from increased natural fish populations, a new economic base and improved water quality. (By necessity, marine aquaculture must take place in areas of good water quality. In Nantucket we have improved our water quality and are reclaiming lost habitat. The motivation to do so came from aquaculture and the desire to maintain our fisheries.) In addition, NREF's program allows the private sector to get involved without the huge capital expenses normally involved. Indeed, we are presently working with a large private company that is interested in a joint aquaculture venture with a Town. All in all, everyone is happy.

We are excited about the present outlook for aquaculture. The administration's emphasis on economic development, job training, and biosciences provides an excellent opportunity. By including fisheries enhancement, water quality issues and, of course, the potential for new jobs; NREF's program can lead the way for aquaculture. We would like to see a national program for aquaculture development. Congressman Studds has indicated his interest in using the Nantucket program as a model. Federal funding could be administered to Towns, or several communities together through an application procedure. This would be a one time cost, once up and running the program could support itself. Regional hatcheries could be established. Existing marine science institutions and universities could provide the necessary technical expertise for research and development.

We see a great potential in combining tourism and aquaculture/marine science. NREF is presently proposing a facility for Plymouth, Massachusetts which would combine three objectives: I1 An interactive marine science museum would provide information and education on fisheries and aquaculture for students and the general public; 2) A certified water quality testing laboratory would give the project the necessary analytical ability; and 3) The main focus of the project would be a research and development facility for finfish aquaculture in the Northeast. The museum and laboratory, combined with associated aquacultured seafood restaurant and gift shop, would provide the necessary income to operate the R \& D facility.

We are also excited about the prospects of aquaculture for New Bedford and Gloucester. Both communities are interested in developing aquaculture. Combining town and private resources with federal development monies benefits all. The initial development risks can be lowered with federal support, while the project can have the advantage of sound business practices offered by private industry. Once the development stage is over private capital can take over for commercial expansion.

\section{AQUACULTURE TRAINING PROGRAM}

The objectives of this program are (1) to expand the economic base of Nantucket by allowing more commercial shellfishermen and other underemployed individuals to fully support their families by the shellfish resource; (2) to train such persons in hatchery aquaculture, field grow-out, and water quality analysis; (3) to provide Nantucket with much needed labor for its propagation and water quality programs; (4) to enhance natural sets of shellfish in Nantucket waters for both commercial and recreational use; and (5) to establish aquaculture as a viable industry for Nantucket and other coastal communities.

a) Hatchery Aquaculture Training Session (12 weeks) instructs the participant in all phases of hatchery aquaculture. Topics covered include sterile technique; water filtration and disinfection; growth, culture and nutrition of algae; broodstock collection, acclimation and maturation; spawning; fertilization; larval rearing; setting larvae; post-set incubation; disease.

b) Water Quality Training Session (12 weeks) instructs the participant in all phases of water quality monitoring. Topics covered include sample collection, transport and preservation; microscopy; bacteriology; nutrient analysis; pesticides and contaminants; point and non-point pollution sources; laboratory quality control.

c) Field Aquaculture Training Session (16 weeks) instructs the participant in all phases of field grow-out aquaculture. Topics covered include business start-up and management; site selection; nursery operations; grow-out mechanisms (pens, cages, nets, etc.) and operations; the grow-out environment; biofouling; predators and disease. 
d) Town/Trainee Coop (field grow-out through inch) Trainees receive shellfish seed produced at the Nantucket Marine Laboratory and are responsible for growout to 1 inch in a town specified area. Materials and supplies are provided by the program. In addition, stipends are available to trainees based on need and performance. As the shellfish reach one inch, 50 percent are returned to the town for planting in commercial and recreational areas (enhancement). The remaining 50 percent are the property of the trainee as in-kind payment. The trainee grows these out to market size and sells them. It is anticipated that income from sales of shellfish will allow participants to continue in business.

NREF will assist trainees in the formation of a cooperative style organization for business and marketing purposes; and identify programs offering no or low interest loans and tax incentives to fishermen and others who wish to establish an, aquaculture business. In addition, NREF will complete a course curriculum for the above mentioned sessions to be made available to other communities interested in the program. At least one workshop will be conducted to assist other towns interested in implementing the program. NREF also anticipates developing a genetic marker for shellfish in order to assess the effectiveness of the enhancement portion of the program.

[Other miscellaneous materials may be found in the committee files.]

Senator KERRY. Thank you very much, Mr. Garrison. Mr. Hallerman.

\section{STATEMENT OF DR. ERIC HALLERMAN, ASSISTANT PROFES- SOR, DEPARTMENT OF FISHERIES AND WLDLIFE SCIENCES, VIRGINIA POLYTECHNIC INSTITUTE AND STATE UNIVER- SITY}

Dr. Halierman. Mr. Chairman, my name is Eric Hallerman. I am an assistant professor of fisheries and wildlife sciences at Virginia Tech University, where I carry out research, teaching, and public outreach activities regarding aquaculture. I am honored to offer suggestions on how NOAA authorizing legislation might be framed in order to promote marine aquaculture.

Reauthorization provides a context for discussing unmet needs and new opportunities for NOAA's mariculture programs. The committee chairman has asked me to discuss the environmental effects of marine aquaculture and to address the role of science and technology in promoting environmentally sound marine aquaculture.

With the growth of mariculture, the frequency of new species introductions has grown. In addition to the desired effects of species introductions for mariculture, a growing body of evidence indicates negative effects, including introduction of pathogens and parasites, habitat alterations, heightened competition or predation, gene pool deterioration, and unwanted socioeconomic effects.

Another potential impart of mariculture results from wastes from production operations. In ecosystems where dilution is insufficient, large loadings of soluble nitrogen and phosphorous wastes pose eutrophication programs. Accumulation of solid wastes can change the physical and chemical environment, reducing numbers and diversity of species living near mariculture operations. A mechanism for assuring careful siting of marine aquaculture operations might be embodied in new legislation.

A related problem is posed by solid and liquid waste disposal from processing and packaging plants. Improved waste reduction, reuse, and disposal methods are needed, which could be approached by authorization of targeted research. 
Antibiotics may be added to fish feeds to reduce mortality from bacterial fish diseases. Concerns stem from development of drug-resistant strains of bacteria, accumulation of antibiotics in marine sediments, accumulation of antibiotics in fish and shellfish, and possible impacts on human consumers of antibiotic residues in fish and shellfish. Authorization of research on drug-resistant bacterial strains and on food safety of aquaculture products would be well justified.

Large numbers of individuals escape from certain types of aquaculture systems. In freshwater ecosystems, the ecological impacts of cultured salmonids on wild stocks have become well recognized. In estuarine and marine systems, understanding of ecological interactions among cultured and wild stocks is quite limited. The genetic implications of cultured stocks and wild stocks has become a contentious issue, especially in the Pacific Northwest. Authorization might be provided for the research needed in these areas.

The development of genetically engineered aquatic organisms and their potential use in aquaculture complicate assessment of effects of cultured stocks on wild stocks. Programs encouraging risk assessment while promoting development of genetically modified aquatic organisms will be critical in addressing this gap in knowledge. Suitable language could be incorporated in the NOAA reauthorization bill or in the bill for the Marine Biotechnology Investment Act.

Targeted development of science and technology will pay a key role in promoting environmentally sound marine aquaculture. Areas where targeted R\&D activity will enhance the sustainability of mariculture include the following:

Development of analytical techniques and computer models to simulate the environmental impact of aquaculture operations will allow improved facility siting and operations management;

Advances in aquaculture engineering will offer a greater variety of culture systems in terms of siting possibilities, waste treatment or removal, and water and feed delivery to minimize environmental impacts;

Reformulation of aquaculture feeds to improve digestibility of phosphorus will allow nutritional needs to be met while decreasing total phosphorus content, decreasing nutrient loadings due to aquaculture in sensitive ecosystems;

Development of improved disease diagnostic tools and vaccines will improve yields and decrease risks faced by aquaculture operations, while decreasing possible impacts of aquaculture on wild stocks;

Approval of additional therapeutics for aquaculture species would increase yield and decrease the reliance on particular antibiotics, decreasing concerns about antibiotic resistance;

Development of domesticated aquaculture stocks will improve yield, decrease reliance on collecting seed stock from wild sources, and decrease the attractiveness of culturing exotic species or genetically engineered organisms;

Development and commercialization of improved methods for producing reproductively sterile aquaculture stocks will minimize genetic impacts of cultured stocks, especially genetically engineered stocks, on wild stocks; and 
Environmentally safe testing of genetically engineered organisms will allow assessment of their utility in aquaculture as well as any ecological and genetic risk.

Well-directed R\&D, followed by effective extension activities, will be crucial for realizing environmentally sustainable aquaculture. Through the research and development and extension activities of NMFS and Sea Grant, NOAA has the capability to promote environmentally sound development of marine aquaculture. I urge the committee to regard reauthorization as an opportunity to prioritize environmental concerns in agency goals, and to provide appropriate levels of support for relevant program areas.

Mr. Chairman, I thank you for this opportunity to present my views.

\section{[The prepared statement of Dr. Hallerman follows:]}

\section{Prepared Statement of Dr. Eric M. Hallerman}

Mr. Chairman and members of the Committee, my name is Eric Hallerman. I am an Assistant Professor in the Department of Fisheries and Wildlife Sciences at Virginia Polytechnic Institute and State University, where I carry out research, teaching, and public outreach activities cegarding aquaculture. I have been involved in aquaculture ince the late $1970 \mathrm{~s}$, and have published numerous scientific papers on genetics in aquaculture. I have served as President of the Genetics Section of the American Fisheries Society, on grant proposal review panels, and on research prioritization panels concerning aquaculture. Mr. Chairman and members of the committee, I am honored and pleased to offer suggestions on how NOAA authorizing legislation might be framed in order to promote marine aquaculture. I add that I offer my comments as an individual, and not as a representative of my institution.

\section{REAUTHORIZING LEGISLATION FOR NOAA SHOULD INCLUDE SUPPORT FOR MARICULTURE}

U.S. per capita consumption of seafood products has increased 49 percent since 1960 , and was 14.9 pounds in 1991 (Leahy 1993). However, over half of the most important U.S. fisheries currently are harvested at or above sustainable ;evels (National Marine Fisheries Service 1991). The United States imports 40 percent of its seafood (National Marine Fisheries Service 1993), which contributes over three billion dollars to our annual trade deficit (Leahy 1993). During the early years of this decade, the world harvest of fishery products from the seas peaked at 99 million metric tons, exceeding even a high estimate for sustainable yield (Robinson 1988), and subsequently has declined. These factors give rise to a growing, unmet demand for fishery products.

Aquaculture can contribute significantly to the supply of fishery products. Aquaculture contributes approximately 16 percent by weight of the world's seafood production, although less than 10 percent in the United States (Leahy 1993). In addition to food products, aquaculture products include industrial materials, pharmaceuticals, energy, and bait fish. Aquaculture is a rapidly growing sector of American agriculture. Beyond providing a healthful product, it provides employment and economic base to rural areas. Expansion of aquaculture serves the interests of the American people.

Through the National Oceanic and Atomospheric Administration (NOAA), the Department of Commerce administers programs which support the development of the scientific, technical, and commercial bases of marine aquaculture. NOAA is involved in mariculture through the National Marine Fisheries Service (NMFS) and the National Sea Grant Program (National Research Council 1992). NMFS involvements include the operation of salmon hatcheries, research studies on culture of oysters, salmon, and shrimp, dissemination of aquaculture information, and promotion of international markets for U.S, aquaculture products. Sea Grant, through its system of research grants to universities and the Marine Advisory Service, has been responsible for the support of research and extension activities on biological and technological aspects of production of marine, estuarine, and Great Lakes species. These programs have played an important part in the development of the U.S. aquaculture industry.

Reauthorization of NOAA provides the opportunity to reexamine the efficacy of its marine aquaculture programs for advancing the goals of U.S. ocean policy. Reauthorization provides the forum for discussing unmet needs and new opportunities 
for NOAA's mariculture programs, and it is in this context that I offer my comments today. The committee chairman has asked me to discuss the environmental effects associated with marine aquaculture, and to briefly address the role of science and technology in promoting environmentally sound marine aquaculture.

\section{ENVIRONMENTAL EFFECTS ASSOCIATED WITH MARINE AQUACULTURE}

Aquaculture, like all agriculture, causes environmental impacts. The environmental impacts of aquaculture have received particular scrutiny because mariculture is fairly new in the United States and because it frequently is conducted in public waters (National Research Council 1992). As we consider reauthorization in light of national ocean policies, we must design programs which promote marine aquaculture while protecting the environment. NOAA programs should promote aquaculture development which not only is economically viable, but also enviromentally sustainable. Environmental concerns associated with marine aquaculture are diverse, ranging from introduction of exotic species to impacts of aquaculture effluents to ecological and genetic impacts of escaped aquaculture stocks on wild stocks. I will provide a brief overview of the major concerns posed by aquaculture, providing references to more thorough reviews.

Introduction of exotic species. With the growth of mariculture, the frequency of new species introductions has grown, especially over the past 25 years. The rise of mariculture has led to broad distribution of finfish, especially salmonids (Sindermann 1986), shrimps, and molluscs (Chew 1990). In addition to the desired, positive impacts of species introductions for mariculture, a growing body of evidence indicates negative ecological and socioeconomic effects. These impacts include:

- Introductions of pathogens and parasites. Two cases leading to major economic impacts are: (1) the introduction of the protozoan parasite Bonamia ostreae to Europe with the softshell clam Mya arenaria (Chew 1990), which led directly to the loss of the softshell clam fishery in Europe, and (2) the wide spread of infectious hypodermal and hematopoietic necrosis virus (IHHNV) with the distribution of shrimp from Central and South America (Sindermann 1986).

- Habitat alteration. Through their growth or activities, introduced species can alter the physical habitat characteristics of the receiving ecosystem, negatively impacting indigenous species and human activities. For example, introduced with $\mathrm{Pa}$ cific oysters, the seaweed Sargassum muticum has become a nuisance to boaters and fishermen on the coasts of Vancouver Island (Bourne 1979).

- Heightened competition or predation. For example, prodigious settlements of juvenile Pacific oyster Crassostrea gigas resulted in its colonization of all sites formerly occupied by C. anguiata in France (Maurin and LeDantec 1979), destroying the fishery for the latter.

- Gene pool deterioration. The possibility that an introduced species can hybridize with an indigenous species poses the danger of compromising the fitness or even the genetic integrity of the indigenous species. For example, poor management of tilapia stocks (Oreochromis sp.) has allowed unwanted hybridization of previously pure species by escapes into the wild and vice versa (McAndrew and Majumdar 1983). Interspecific hybridization of tilapia stocks is so widespread that it has become difficult to find pure-species stocks and the performance of many stocks has been compromised (Pullin 1983)

- Unwanted socioeconomic effects. For example, introduction of the exotic Pacific oyster Crassostrea gigas in Australia for mariculture purposes led to decline of the Sydney rock oyster Saccostrea commercial is, which was the object of a commercial fishery (Chew 1990).

Environmental issues posed by exotic aquatic species are treated in depth by the American Fisheries Society (1986), Courtenay and Stauffer (1989), Pollard (1989), DeVoe (1992), Rosenfield and Mann (1992), Sindermann et al. (1992), and the Office of Technology Assessment (1993). A number of protocols for reaching decisions on proposed introductions of non-indigenous species exist (Sindermann 1986, Kohler and Courtenay 1986), and federal policies are being formulated consequent to adoption of the Non-indigenous Aquatic Nuisance Prevention and Control Act of 1990.

Introduction and spread of parasites and diseases. Movements of cultured species consequent to mariculture activity often has caused the simultaneous introduction of parasites and pathogens even in cases where the host was an indigenous species. The most dramatic example may be the monogenean fluke Gyrodactylus salaris, which is believed to have been introduced into Norwegian waters with the import of Atlantic salmon smolts for mariculture in the 1970 s. It has now spread to 32 Norwegian river stocks (Egidius et al. 1990), where it has become one of the primary causes of mortality (Johnson and Jensen 1988). Adoption of a protocol for quarantine of newly-imported aquaculture stocks, such as that outlined by Sindermann 
(1986), should minimize concommitant introductions of parasites and pathogens. Requirement of such precautions might be mandated in legislation.

Concentrations of fish in aquaculture operations create conditions for outbreak of disease. The relative importance of disease transmission from cultured stocks to wild stocks and vice versa is a contentious issue.

Wastes from aquaculture operations. Major soluble end products in the digestion process are ammonia and orthophosphate. Although ammonia is toxic in the milligram per liter range, dilution effects in marine environments keep ammonia toxicity from becoming problematic. However, effluents from aquaculture facilities into freshwaters or into enclosed bays with limited circulation can pose problems of ammonia toxicity. The nitrogen in ammonia and the phosphorus in orthophosphate can be utilized as nutrients by algae, and large loadings can pose eutrophication problems - such as algal blooms, dissolved oxygen depletion, turbidity, and suppression of rooted aquatic plants-in freshwater systems and in enclosed bays where dilution is insufficient.

Cage culture of fishes generates large amounts of solid wastes in the form of feces and uneaten feed. About onefourth of the feed eaten ends up as feces, and from 520 percent remains unutilized (Getchell 1988). The wastes generally are deposited in the immediate area of the culture site. Accumulation of wastes can alter benthic ecology (i.e., that of bottom-dwelling organisms) by changing the physical and chemical environment or by changing or reducing the numbers and species resident beneath net pens or downstream from effluents (National Research Council 1992). If deposition is sufficient, chemical changes in the sediment will favor opportunistic species that can tolerate low dissolved oxygen levels and higher sulfide and ammonia concentrations. Waste tends to accumulate beneath pens in sites of less than 15 meters depth and low current velocities (Weston 1986). Models based on depth, current velocity, loading rates, and other factors are now available to select sites where impacts of aquaculture will be minimal (Weston and Gowen 1988). A mechanism for assuring careful attention to siting of marine aquaculture operations might be embodied in new legislation.

Use of feed additives and antifouling agents. Antibiotics may be added to fish feeds to reduce mortality from bacterial fish diseases such as vibriosis and furunculosis. These antibiotics are used in marine aquaculture as prophylaxis and as therapeutics for disease outbreaks. Concerns about antibiotics stem from three potential environmental effects (Whitely and Johnstone 1990):

- Development of drug-resistant strains of bacteria. Drug resistant bacteria were found in the effluent of an intensive fish culture pond in Japan (Aoki and Kitao 1985). Of further concern, drug resistance was shown to be transferable from a fish pathogen to a human pathogen in vitro (Toranzo et al. 1984).

- Accumulation of antibiotics in sediments and subsequent inhibition of microbial decomposition. Jacobsen (1989) reported oxytetracyclin in the sediments beneath net pens in Norway. Accumulation of an antibiotic is sediment depends on many factors, including its solubility, half-life, and concentration in seawater. Because the most commonly-used antibiotic, oxytetracycline, is highly soluble and has a short shelf life, release of pharmaceutical compounds from fish farms seems unlikely to pose environmental problems (National Research Council 1992).

- Accumulation of antibiotics in fish and shellfish. For salmonids given oxytetracyclin, recommended withdrawal times are 60 to 90 days, depending on water temperature (Jacobson 1989). Little information is available on clearance times in non-salmonid farmed fish (National Research Council 1992).

A fourth, related concern about antibiotics is the possible impact on human consumers of antibiotic residues in fish and shellfish. Many of our fisheries products are imported from other countries, where regulation of antibiotic treatments and withdrawal times are not regulated as stringently (National Research Council 1992). Although cooking destroys most oxytetracline residues in salmonids, little information is availiable about residues in other fishes. Authorization of research targeted toward broadening our understanding of the implications of feed additives on appearance of drug resistant bacterial strains and on on food safety of aquaculture products would be well justified.

Anti-fouling agents have been used to retard the growth of organisms on nets or predator control nets of floating net-pen operations. The antifouling agent tributyltin (TBT) has been shown to be exceptionally toxic to shellfish larve (Minchin et al. 1987, Davies et al. 1988). The National Marine fisheries Service has demonstrated that salmon held in TBT-treated nets accumulated residues of the chemical in their tissues (Getchell 1988). The State of Maine has banned the use of TBT in antifoulant paints and dips for marine use, suggesting consideration of a similar ban at the federal level. 
Ecological and genetic effects of cultured stocks on wild stocks. Different types of marine aquaculture operations offer different degrees of confinement for cultured fishes. Few individuals escape from on-shore tank culture systems. Large numbers of fish escape from sea cage aquaculture operations (citations in Hallerman and Kapuscinski 1992). Sea ranching operations involve deliberate release of entire aquaculture stocks. Because very large numbers of individuals may be cultured, even a small percentage of escapees may be large relative to native populations. Hence, a large proportion of the fish in a given ecosystem may have originated from aquaculture operations. For example, $15-20$ percent of the salmon examined from 54 Norwegian rivers in 1987 were escapees from culture operations, ranging up to 80 percent in one particular river (Egidius et al. 1991).

The importance of ecological impacts of cultured fish on native stocks is a matter of controversy. In freshwater ecosystems, the ecological impacts of cultured salmonids on wild stocks through competition and behavioral interaction (e.g., Vincent 1974, Bachman 1984) have become well recognized. In estuarine and marine systems, understanding of ecological interactions among cultured and wild stocks is quite limited. Concerns center on competition for food resources in the estuarine portion of the life cycle, especially for out-migrating salmonids (Himsworth 1981). The potential for competition among fish of aquaculture and wild origins in the open ocean is debated, with little quantitative information available. Potential ecological effects of cultured aquatic organisms poses particular concern when threatened or endangered species and strains are in the ecosystem at issue. Authorization might be provided in legislation for the research needed in these areas.

The genetic implications of non-indigenous cultured stocks on wild stocks has become a contentious issue, especially in the Pacific Northwest (Hilborn 1992, Stickney 1994). Cultured stocks of a species differ genetically from wild stocks, whether through deliberately practiced selective breeding or passively occuring founder effects, genetic drift, and adaptation to culture conditions. Influx of fish from mariculture operations poses a threat to native gene pools (Waples 1991, Hindar et al. 1991). The array of gene frequencies for fitness-related traits constitutes the native population's adaptation to its ecosystem, and frequently includes combinations of genes which must be expressed together for maximal fitness to be realized. Mixing with an exotic gene pool can shift gene frequencies and disrupt important gene combinations, reducing the fitness of the native population. Major shifts in allele frequencies can happen quickly-assuming that 30 percent of the individuals in a river originate from cultured stocks, over half of the genetic stock structure of the species can be lost in one generation (Mork 1991), i.e., native gene pools can be threatened with extinction. One of the most important factors leading to the decline of over 200 salmon stocks in the Pacific Northwest is interaction with cultured fish (Nehlson et al. 1991).

The development of genetically modified aquatic organisms through gene transfer, chromosome set manipulation, and interspecific hybridization, and their potential use in aquaculture adds further complexity to the issue of ecological and genetic effects of cultured stocks on wild stocks (Kapuscinski and Hallerman 1990a, Hallerman and Kapuscinski 1992). For example, dramatic growth rate increases have been reported for Atlantic salmon expressing an introduced growth hormone gene (Du et al. 1992), yet we have little sense of what impacts such fish might pose were they to escape from a net-pen mariculture operation (Kapuscinski and Hallerman 1990a, Hallerman and Kapuscinski 1992). Programs encouraging risk assessment while promoting development of aquatic GMOs will be critical in addressing this gap in knowledge (Hallerman and Kapuscinski 1993). Suitable language could be incorporated in the bill for the Marine Biotechnology Investment Act, if reintroduced.

Presence of infrastructure associated with aquaculture associated with culture operations in public waters. Many people choose to live near the ocean or its bays in order to enjoy amenities such as natural beauty. Aquaculture facilities, notably floating net-pen operations, are widely held to be unsightly. Conflicts have ensued between landowners and aquaculturists, which sometimes have been taken to the courts. Lawsuits, or threat of lawsuits, have constrained the development or mariculture in the United States, particularly in Puget Sound. Targeted development of submerged aquaculture systems should address aesthetic objections to mariculature facilities in sensitive areas.

A second infrastructure-rclated problem is posed by solid and liquid waste disposal from processing and packing plants on the coast. Improved waste reduction, use, and disposal methods are needed, which could be approached by authorization of targeted research.

Alteration of natural ecosystems. Siting of aquaculture operations sometimes has had major impacts on natural ecosystems. For example, shrimp farms often have 
been built on mangrove swamp areas. This has reduced or eliminated spawning and nursery areas for many marine and estuarine species, in some cases, limiting the availability of seed stock for the shrimp operation itself. Other wetland ecosystems, particularly seagrass areas, also have been impacted. Siting of mariculture operations is a major determinant of the type and magnitude of environmental impacts posed.

\section{THE ROLE OF SCIENCE AND TECHNOLOGY IN PROMOTING ENVIRONMENTALLY SOUND} MARINE AQUACULTURE

Solutions to environmental concerns posed by marine aquaculture will require a mix of approaches, including: wise siting of aquaculture operations, development of appropriate operations management practices, application of new scientific knowledge, and development of new technologies, as well as improved regulatory oversight and improved public acceptance of the value of aquaculture.

Targeted development of science and technology will play a key role in promoting environmentally sound marine aquaculture. Reauthorization of NOAA provides the opportunity to authorize targeted research and development.

Against the background of environmental concerns presented above, areas where targeted R\&D activity will enhance the sustainability of mariculture include the following:

- Development of analytical techniques and computer models to simulate the environmental impact of aquaculture operations (Weston and Gowan 1988, Brune 1990) will allow improve facility siting and operations management.

- Advances in aquaculture engineering will of fer a greater variety of culture systems in terms of siting possibilities, waste treatment or removal, and water and feed delivery to minimize environmental impacts.

- Reformulation of aquaculture feeds to improve digestibility of phosphorus will allow nutritional needs to be met while decreasing total phosphorus content, decreasing nutrient loadings due to aquaculture in sensitive ecosystems.

- Development of improved disease diagnostic tools and vaccines will improve yields and decrease risks faced by aquaculture operations, while decreasing possible impacts of aquaculture on wild stocks.

- Approval of additional therapeutics for aquaculture species would increase yield and decrease the reliance on particular antibiotics, decreasing concerns about antibiotic resistance.

- Development of domesticated aquaculture stocks will improve yield, decrease reliance on collecting seed stock from wild sources, and decrease the attractiveness of culturing exotic species or genetically modified organisms.

- Development and commercialization of improved methods for producing reproductively sterile aquaculture stocks will minimize genetic impacts of cultured stocks, especially genetically modified stocks, on wild stocks.

- Environmentally safe testing of genetically modified organisms will allow assessment of their utility in aquaculture as well as any ec6logical and genetic risk.

I emphasize that this listing of examples is illustrative, but certainly not exhaustive. The key point is that well directed $R \& D$, followed by effective extension activities, will be key to realizing environmentally sustainable aquaculture.

Through the research and development and extension activities of NMFS and Sea Grant, NOAA has the capability to promote environmentally sound development of marine aquaculture. Reauthorization provides the opportunity to prioritize environmental concerns in agency goals and to provide appropriate levels of support for relevant program areas. I urge the committee to take this opportunity to provide NOAA wise direction to promote marine aquaculture while protecting our marine environment.

\section{INTERAGENCY COORDINATION}

Aquaculture is an industry whose activities are overseen not only by the Department of Commerce, but by a variety of federal agencies. Aquaculture development is well served by effective inter-agency coordination. Reauthorization of the National Aquaculture Act is addressed in S. 1288, which recently was reported from the Senate Agriculture Committee. The bill establishes federal leadership for promotion of aquaculture under the U.S. Department of Agriculture (USDA), and authorizes coordination of federal oversight under the Joint Subcommittee on Aquaculture (JSA). A designee of the Secretary of Commerce, through his/her participation in JSA, ensures that federal actions in the aquaculture arena serve the economic development and marine environmental protection interests of Department of Commerce programs, such as Sea Grant, the National Coastal Resources Research Institute, Small Business Innovation Research, and the National Marine Fisheries Service. Because 
reauthorization bills for both NOAA and the National Aquaculture Act are before the Senate this session, I urge you to ensure that mechanisms for coordinating federal development and oversight activities for aquaculture are maintained and enhanced.

\section{CONCLUSIONS}

Well-crafted and coordinated federal policy will promote development of marine aquaculture, a sector of American agriculture of great potential importance. Reauthorization of NOAA provides the opportunity to favorably influence the development of mariculture, enhancing economic development while protecting the marine enviroment. As you craft the reauthorization bill, I unge you to address the environmental concerns that I have put forward to you in my oral and written testimony. Mr. Chairman and members of the committee, I thank you for this opportunity to present my views.

[A list of cited literature may be found in the committee files.]

Senator KERRY. Thank you very, very much. I do not think we have ever had a panel as time conscious and efficient as this panel. It is quite extraordinary.

Let me just pick up with you, Dr. Hallerman, if I can right away. You have been very detailed in your testimony on these various problems ranging from exotic species or parasites, diseases, et cetera. Let me begin here. Is there a sufficient concern for the current oversight and management of these problems, of these programs, or do you think there is something that might be out of control and that presents a danger of some kind?

Dr. HALlERMAN. No, it is not the latter. What I would like to see are targeted research areas within, say, Sea Grant calls for proposals looking at environmental impacts of aquaculture. I would also like to see encouragement of sustainable aquaculture in a more general bill for Commerce-for instance, on the siting of aquaculture operations, which could be part of a permit process overseen by Commerce. I do not see a problem out of control. I would like to tweak the direction just a little bit.

Senator KERRY. Of the various environmental problems that you have cited, are there any dangers to the public from the product that comes out as a consequence of any of those problems in the aquaculture process?

Dr. Hallerman. My concern, and the reason I mentioned antibiotic residues in food, is that a lot of our fisheries products are imported from outside the United States, from places where there may not be any regulations on use of antibiotics or other additives to feed. As far as I know, there is no monitoring of fisheries products from outside in terms of whether there are residues in those foods. It may be worthwhile to have some research just to spot check products coming into America to see if there are residues, and of course the targeted research to see if those residues are meaningful in a food safety sense.

Senator KERRY. So, your basic request would be that NOAA set up some regimen for stronger oversight, in a sense.

Dr. HALLERMAN. Yes.

Senator KERRY. Now let me ask everybody generally, whoever wants to leap in on this, as you sit here, each of you has extolled the virtue of moving in the direction of greater involvement, and each of you has suggested that the Federal Government, and NOAA particularly, ought to be the conduit and be more involved. 
Lay out to the committee in an order of priority if you would the greatest restraints on moving forward. What are the problems and barriers to our really being whole hog involved in this?

Dr. SANDIFER. Mr. Chairman, if I may, that depends on who you speak to. The industry as a whole sees the immediate requirements of today, whereas the technologists, the technicians involved, tend to look a little bit broader. From the standpoint of what the industry seems to see in the marine environment, it would be a confusing, often overlapping, permitting and regulatory process that makes it extremely difficult to get into business in the coastal zone at all.

There are substantive other issues related to the technology base, and specifically to the supply of seed animals. There are valid concerns that the seed be sufficiently free of diseases or parasites associated, and of the correct genetic stock so they pose no danger to wild stocks. But, I think the biggest single concern is how does one get through the regulatory maze to get into business in the first place?

Senator KERRY. Now, are the restraints on aquaculture legitimate, or are they just bureaucratic and sort of ignorant of some of the impacts at this point?

Dr. SANDIFER. Senator, I would have to say it is a combination of the two. Many of the restraints are correct and well meaning. Most of us who have been involved in aquaculture development for some time have had a rude awakening over our careers that aquaculture is not quite as environmentally clean as we thought it was when we started out. And it turns out that aquaculture development has some environmental costs associated with it. However, those costs are generally substantially less than are found in many other kinds of industrial or coastal development. The problem becomes one of correct classification and treatment of those effects.

For example, aquaculture effluents are generally termed to be industrial effluents. They are not industrial effluents. They are the equivalent of agricultural effluents, in most cases without the chemicals or with relatively few chemicals. It is mostly biological oxygen demand, and it needs to be treated in a very different way from individual wastes.

Then there is the whole issue of how do acquaculturists have access, fair access, to use of public resources in the same manner, for example, that commercial and recreational fishermen do, have some protection for the use of those public resources and at the same time allow the public to maintain its right to the use of the resources. That is where it gets to be a very complex issue in the coastal zone.

Senator KERRY. Now, is this mostly as to offshore bay or estuary aquaculture or as to onshore wetlands or both?

Dr. SANDIFER. Both. And in fact, some of the more recent recommendations have been for at least the research community, within NOAA specifically and within other Federal agencies, to look at the options for moving aquaculture operations to higher ground, out of the immediate coastal zone. That was the closed system culture approach that Dr. Baker referred to. But you still have to take in some water and you still have to discharge some water some time. The laws of physics still apply. 
And the second option is to move further offshore. I alluded to this in my testimony that NOAA should take the lead in developing both the policy for leasing water columns and technology for moving into Federal waters 3 miles out and further, perhaps using some interesting combinations of habitat enhancement and aquaculture to produce improved commercial fisheries opportunities and true seafood farming opportunities.

That is a bit longer range, but that is the kind of arenas that NOAA should be planning to look at.

Senator KERRY. Well, I would think that that kind of offshore farming prospect also might be one of the most efficient and rapid ways of guaranteeing stock replenishment.

Dr. SANDIFER. Senator, I will only speak for myself. I think it will be, but I must tell you that a recent discussion amongst some leading scientists in the Southeastern United States indicated that, while this is where we might like to see things head, at least in part for the future, at least over the next decade or two most of us believe that marine aquaculture development is going take place in the coastal zone. That is where the businesses can be now, that is where the technology allows us to be now, that is where the consumers are right now. So, we are going to have to deal with that problem of coastal jurisdiction as well as the opportunities to eventually move further offshore as technology allows.

Senator KERRY. Anybody else want to add to that?

Mr. GaRRISON. I would like to just add that I agree with all the previous comments there, and for NOAA and this committee to be involved in aquaculture development, the one place where there is a problem and it does need to be-you may start from the highest levels of getting the separate agencies that are involved-Commerce, Interior, Agriculture-to define their roles exactly regarding aquaculture and how each one can support private aquaculture development.

And I believe from that point that needs to happen right on down through somehow giving States incentives to go along with policy that is formulated at that level so that we can have a coordinated policy for aquaculture development which includes all of the regulatory and permitting problems that are happening now where some agencies have no policy at all or all of the sudden another agency pops up and says this is going to be our jurisdiction here now.

Senator KERRY. I understand.

Mr. Dill, you cited in your testimony unsafe or unclean farming practices with respect to shrimp and particularly the experience in-was it China where they had 1.2 billion dollars' worth of shrimp damage as a consequence of disease? What are we doing to guarantee that we do not replicate that situation or that it does not occur? Is it sufficient?

Mr. Dill. I think a combination of what Dr. Sandifer refers to in terms of licensing and quarantine capability in terms of the importation of foreign food stock or seed and the development as has been done in the broiler industry and in the swine industry of high health animals are the means of turning a very negative situation into a very positive situation for the United States. 
Senator KERRY. Well, is the industry itself taking steps to guarantee a sustainable shrimp farming capacity?

Mr. DiLl. I believe they are. The institute has been involved along with Dr. Sandifer in the development of SPF or specific pathogen free shrimp stocks, and the economics drive you to it. Consequently, the industry in the United States is exclusively SPF oriented. In other words, they have adopted over the last 3 years the principle that you have to have clean animals to be successful economically, a very simple, commonsensical sort of principle.

Senator KERRY. How would you compare our efforts to develop environmental technologies to promote aquaculture compared to, say, Norway or Japan?

Mr. Dill. I think the advantage that we have as a Nation, particularly in Hawaii, is that the regulations that we work under are very stringent. And so consequently, right from the beginning the sensitivity to the environment has been a major factor. If you are going to speak of sustainability you have to speak of the environmental impact of what you do, and that translates into economic costs and opportunity at the same time.

Senator KERRY. Are we developing sufficient technologies in this country, or does this committee need to try to gear that up?

Mr. DiLL. I think there is a need to develop technologies that are cost effective. I think one of the themes that I was encouraged by Dr. Baker's testimony was the fact that there is now interest, or at least an articulation of interest, in the development of aquaculture in terms of the private sector. And when you start talking about the private sector you are going to have to talk about things that make sense economically and meld those with your environmental concerns.

Senator KERRY. What is the biggest environmental downside of coastal environmental involvement? Is it the effluent? Is it the water?

Mr. DiLl. I think the effluent is the most obvious. Maybe some of the other panel members would comment. But I think there is a real need.

Senator KERRY. Is that not processable through one of these closed water treatment systems?

Dr. Hallerman. If I may, Senator, that is one solution, but the other one is simply paying sufficient attention to siting of the facilities. Effluents will not be a problem.

Senator KERRY. As long as you have sufficient tidal movement or whatever?

Dr. Hallerman. Right. Right, and keep it away from the sensitive areas.

Dr. SANDIFER. Senator, under a variety of programs, including the ones that Mr. Dill referred to that we collaborate in, there is quite a bit of technology development work going on in both the coastal shrimp industry and coastal finfish production industries to eliminate or at least reduce very much the level of discharges going into open waters. With a combination of careful siting, technology to reduce the release of any effluents at all, and good flushing, there essentially will be no measurable impact on the marine environment. 
This is the kind of technology that will be available within the next 5 to 10 years, will be available and be applied in the private sector. It is already being transferred at its experimental stage to the private sector, so it is going to be there and will make the difference in meeting what for the most part are realistic permit requirements on the discharges.

Senator KERRY. Sure.

I think as a panel you have done an outstanding job of outlining the problems that we face and priorities that we have to address, and I think the committee really wants to use every resource at our disposal and every opportunity at our disposal to try to augment people's focus on this industry. This is a farming industry. It is a harvesting growth business with enormous potential, just enormous potential. We are proving already in our catfish farming and other things that we have great markets and great ability to do it.

For obvious reasons of supply and demand, other countries have moved faster than we have to try to develop their skills on it. I think we need to now move equally as fast and pointedly, and we are going to try and do that. We are going to try and build on some of your recommendations.

Clearly, the permitting, one-stop-shop and so forth that you talked about, that is really important. And I think we have developed a body of knowledge that is sufficient now about our coast and the coastal zone management process and so forth that we ought to be able to integrate this kind of effort with the other interests that we are trying to protect, and I think you have well stated that they can be harmonized. There is no reason they cannot be.

So, again, we will leave the record open in the event we want to follow up with some additional questions.

I apologize for truncating this, but I have a noon meeting which I must go to. But I am very grateful to you. This is something the committee began talking about a few years ago, and I think we are really in a position now to begin to launch it in a much more significant way, and we are going to try and do that. So, thank you for being with us today.

We stand adjourned.

[Whereupon, at 12:05 p.m., the hearing was adjourned.] 



\section{APPENDIX}

\section{Prepared Statement of the Environmental, Defense Fund}

The precipitous declines of stocks of wild fish worldwide from overfishing, water pollution, and changes in fish habitat such as dam construction and filling of coastal wetlands are sharply increasing the economic incentives for aquaculture. From 1980-1990, United States aquaculture production grew approximately fourfold and fish farming now accounts for 10-15 percent of United States fish and shellfish har. vests. There is now considerable interest in helping the aquaculture industry, now the fastest growing segment of the United States agricultural industry, continue or even accelerate its current growth. The Environmental Defense Fund (EDF) supports the continued development of the aquaculture industry. We strongly believe, however, that environmental protection must be a key theme in this industry's development, if aquaculture is to enjoy long term economic growth and continuing public support.

In this testimony we will first discuss EDF's vision for aquaculture. We will review the environmental benefits and drawbacks of aquaculture and discuss the importance of developing the aquaculture industry so that it is both environmentally and economically sustainable. We will then discuss four areas in which authorizing legislation concerning aquaculture could promote the development of an environmentally and economically sustainable aquaculture industry.

\section{IMPORTANCE OF DEVELOPING A SUSTAINABLE AQUACULTURE INDUSTRY}

The growth of the aquaculture industry could bring important environmental benefits. By providing an alternative source of fish, aquaculture could help decrease current unsustainable fishing pressures on wild populations. In addition, culture of finfish, shellfish, and aquatic plants could provide an important, alternative source of income for fishermen who have to leave the traditional fishing industry. For example, overfishing of economically valuable fish species in New England has caused fish populations to collapse, leaving many fishermen jobless and small fishing communities devastated. Because of aquaculture's environmental and economic benefits, the development of a New England aquaculture industry has been proposed by NOAA and others as a key component of efforts to aid New England fishing communities and to take fishing pressure off or restore depleted fish populations New England waters.

Culture of some aquatic organisms could even provide solutions to environmental problems. Culture of seaweed and filter-feeding shellfish, such as oysters, can help cleanse water of excess nutrients. Other potentially promising applications of aquaculture include bioenergy production and integrated aquaculture systems which have multiple product outputs.

Aquaculture can also have considerable drawbacks, however, at least if aquaculture facilities are developed with little thought to environmental protection. Ocean net pens, or other enclosures with large numbers of fish, may lead to significant water pollution with fish feces and uneaten fish food. Over time, deposition of these materials on bay bottoms can result in the release from bay sediments of gases such as ammonia and hydrogen sulfide, which are toxic to fish. Similarly, effluent from freshwater ponds or raceways can pollute streams and rivers.

Aquaculture can permanently alter the composition. of wild fish populations and aquatic ecosystems. Fish routinely escape aquaculture facilities, which are notoriously "leaky." Storm damage to net pens may result in the escape of millions of fish. Moreover, some aquaculture operations depend on "ranching" or augmenting stocks of wild fish.

Escape or intentional release of fish from aquaculture facilities can pose several ecological concerns. First, escaped or released fish of nonnative species may establish wild populations, displacing native fish or otherwise harming aquatic ecosystems. Second, large numbers of escaped or released fish of native species may 
breed with wild fish stocks. Cultivated fish often differ substantially from wild stocks, similar to the way that other domestic animals differ from wild ones, and widespread interbreeding between cultivated and wild fish may alter the genetic makeup of wild populations in significant, undesirable ways. Third, releases of cultivated fish may encourage high levels of fishing. Since fishermen cannot easily distinguish wild and cultivated stocks, wild stocks as well as cultivated ones may be depleted. Fourth, escape or released native or nonnative fish may introduce new potentially devastating pathogens and parasites to wild fish populations.

Aquaculture facilities can also be divisive within communities. Fish farms may be regarded as coastline eyesores, particularly if they are not specifically designed to be unobtrusive. Freshwater fish farms may divert large quantities of water from streams and other water supplies. Fish farmers may try to exterminate predatory mammals and birds, which are cherished by many people. In addition large, corporate aquaculture facilities may provide employees low wages and little of the independence to which fishermen are accustomed.

The development of the aquaculture industry thus presents a challenge of reaping this industry's benefits while avoiding environmental problems associated with aquaculture. The Environmental Defense Fund believes strongly that injecting environmental concerns and opportunities early in the development of aquaculture will markedly increase the prospects for an economically and environmentally sustainable industry that enjoys strong public support.

There are a number of ways in which federal aquaculture policy, could promote the development of an environmentally sustainable aquaculture industry. For example, federal support for targeted research to improve aquaculture feeds, so that uneaten feed does not heavily pollute surrounding ecosystems with excess phosphorous, would help reduce the environmental impacts of aquaculture. Development of domesticated aquaculture stocks of native fish species could improve aquaculture yields and simultaneously reduce the temptation to cultivate nonnative fish species, which can be destructive to native ecosystems.

In contrast, if environmental concerns are now ignored, environmentally destructive practices and technologies could become increasingly difficult to alter in the future, as the industry grows and such practices and technologies become increasingly widespread. Further development of the aquaculture industry without regard to environmental protection could lead to an erosion of public support for aquaculture because the industry would come to be viewed as polluting and thus undesirable. Such views could in turn increase public controversy about the siting of aquaculture facilities.

Congress now has an opportunity to pass aquaculture legislation that promotes the development of an economically and environmentally sustainable aquaculture industry. In the rest of this testimony we will discuss elements of aquaculture legislation that would help Congress accomplish this goal. Our comments will refer to the National Aquaculture Act of 1980, 16 U.S.C. 2801 et seq., and the National Aquaculture Development, Research and Promotion Act (S. 1288), now being considered by the Senate.

\section{EMPHASIZING THE IMPORTANCE OF ENVIRONMENTAL PROTECTION}

The importance of developing aquaculture in an environmentally responsible, sustainable manner should be emphasized in all appropriate sections of aquaculture legislation. Unfortunately, the environment is mentioned only infrequently in the National Aquaculture Act of 1980 and in S. 1288. We recommend that language concerning environmental protection be incorporated, at minimum, in the following sections of aquaculture legislation.

\section{Findings}

An additional finding be added to the Finding Section of the 1980 Act, 16 U.S.C. 2801 (a), that "Incorporating environmental concerns in the development of aquaculture will enhance the prospects for an economically and environmentally sustainable industry." Environmental risks associated with aquaculture should also be mentioned explicitly in the report that ultimately accompanies the Committee's bill to the floor.

\section{National Aquaculture Development Plan}

The National Aquaculture Development Plan, 16 U.S.C. 2803, should give greater emphasis to environmental protection and to the development of sustainable aquaculture systems. The 1980 Act stipulates that the Plan should address water quality management and use of waste products, 16 U.S.C. $2803(\mathrm{~b})(3)(B)$ and $(\mathrm{C})$, but does not require the Plan to address directly other environmental concerns. This subsection should be amended to require the Plan to address the full range of environ- 
mental concerns raised by aquaculture. In addition to water quality management and use of waste products the Plan should address the following: (1) conservation of genetic resources, including methods to minimize genetic introgression (mixing) of cultured fish with wild fish stocks; (2) any potential ecological or economic harm from introductions of exotic species resulting from aquaculture activities; (3) freshwater diversion impacts on in-stream flows; (4) visual pollution, and (5) impacts from predator control measures.

The Secretaries of Commerce, Interior, and Agriculture are currently required under the 1980 Act to "undertake a continuing assessment of aquaculture in the United States." 16 U.S.C. 2803(e). Environmental protection is not among the six activities that are named as components of the continuing assessment. The 1980 Act should be amended to add a seventh component, "the identification of steps that could be taken to make aquacultural practices compatible with environmental protection."

\section{Joint Subcommittee on Aquaculture}

The list of purposes and functions of the White House Office of Science and Technology Policy's Joint Subcommittee on Aquaculture, which coordinates national activities regarding aquaculture, does not now refer to the environmental impacts of aquaculture. 16 U.S.C. 2805 . We urge that this list be broadened to include a section stating that, "in each of its other functions and activities, [the Subcommittee shall] include the explicit consideration of the environmental impacts of aquaculture and the need for additional research to better understand and to develop methods for mitigating the environmental impacts of aquaculture."

\section{Aquaculture Education}

The Aquaculture Education section in S. 1288 should be revised to emphasize the importance of education concerning environmentally sound management of aquaculture systems. For example, the bill could include a provision stating that education grants will be given priority if they go to aquaculture learning centers that "foster understanding and awareness of the environmental implications of aquaculture and research into sustainable aquaculture practices."

\section{International Aquaculture Information and Data Collection}

S. 1288 would amend the Agricultural Trade Act of 1978, 7. U.S.C. 5692, to authorize the Secretary of Agriculture to collect, analyze, and disseminate economic information and data concerning international aquaculture. We support this amendment, but urge that it be broadened to include environmental as well as economic information. Some aquaculture facilities abroad have been extremely destructive to the environment. For example, in some tropical areas mangrove swamps have been destroyed to create shrimp farms, resulting in the loss of estuary areas vital to fish reproduction. Collection of environmental as well as economic information would enable a fuller understanding and analysis of the implications of aquaculture abroad and inform the development of environmentally sound aquaculture facilities in the United States.

\section{ROLES OF FEDERAL AGENCIES}

\section{Shared Leadership}

The Secretary of Commerce, Secretary of Interior, and Secretary of Agriculture should continue to share responsibilities for aquaculture. In contrast, S. 1288 would greatly expand the U.S. Department of Agriculture (USDA's) role as a lead agency to include "the development, implementation, promotion, and coordination of national policy and programs for private aquaculture," and responsibility for resolving interagency conflict. Secs. 2(b)(4) and 7(e).

Transferring from the Departments of Commerce and Interior to USDA such broad leadership powers, as provided for in S. 1288, would be a poor idea. We anticipate that environmental protection will be a major focus of policy development for aquaculture. USDA has a poor track record for environmental protection, especially when tradeoffs must be made between agricultural and environmental interests. The Department of Commerce, through the National Oceanic and Atmospheric Administration, and the Department of the Interior, have traditionally shown far stronger interest in integrating environmental protection with economic development. It is vital that these two agencies, "with their considerable, longstanding expertise on fisheries issues, continue to share with USDA leadership in establishing national policies and programs for aquaculture. 
Inclusion of EPA

The U.S. Environmental Protection Agency (EPA) should be given a greater role in developing strategies for aquaculture. EPA's programs and regulations related to the environmental impacts of aquaculture, including impacts on water quality, instream flows and aquatic ecosystems, mean that this agency already has considerable responsibilities concerning aquaculture. Ignoring the importance of EPA's role would be shortsighted, particularly if a major goal of aquaculture legislation is to promote the development of an environmentally sound industry.

One section of S. 1288 where EPA clearly should be included with other agencies is proposed new Section 7, National Policy for Private Aquaculture. As it is now written, this section now mandates that the Secretary of Agriculture, in consultation with the Secretary of Commerce, the Secretary of the Interior, and the heads of other agencies, as appropriate, coordinate and implement a national policy for private aquaculture. EPA should be specifically included in the list of agencies to develop this policy. In addition, for the reasons discussed in the previous section, the responsibility for developing the national policy should be distributed among all four participating agencies, rather than assigned primarily to USDA.

\section{Coordination by the Joint Subcommittee on Aquaculture}

As mentioned above, federal agencies coordinate their aquaculture activities through the Office of Science and Technology Policy's Joint Subcommittee on the Secretary of Agriculture. 16 U.S.C. 2805. The Subcommittee has been highly successful at increasing communication and coordination among those federal agencies which are members of the Subcommittee. In addition, the Subcommittee has even initiated several interagency projects to address pressing problems in aquaculture, such as a lack of available drugs licensed for administration to fish.

Given that a number of federal agencies will continue to have important responsibilities concerning aquaculture, we urge that a major problem of the Subcommittee-the lack of a budget-be remedied. To achieve Subcommittee goals staff from various agencies must now voluntarily assume Subcommittee responsibilities, in addition to their regular duties. The Subcommittee would benefit greatly from an adequate budget that allowed agency staff to be detailed to work on Subcommittee initiatives and allowed the hiring of other necessary experts. Aquaculture legislation should authorize a minimum of several hundred thousand dollars per year to support the Subcommittee's critical functions.

\section{PUBLICLY OWNED FISH AND SHELLFISH STOCKS}

We are troubled by provisions in the National Aquaculture Act of 1980 that encourage use of aquaculture technology in the rehabilitation and enhancement of public fish and shellfish stocks, and in particular, by the Act's encouragement of such efforts by private entities. The Act includes a finding that "the rehabilitation and enhancement of fish and shellfish resources are desirable applications of aquaculture technology." 16 U.S.C. 2801(a)(5). The Act also mandates that the Secretaries of Agriculture, Interior, and Commerce "encourage the implementation of aquaculture technology in the rehabilitation and enhancement of publicly owned fish and shellfish stocks (including rehabilitation and enhancement by private nonprofit enterprises), and in the development of private commercial aquacultural enterprises." 16 U.S.C. $2804(a)(3)$.

As discussed above, the introduction of nonnative fish species and large numbers of cultured native fish can cause serious harm to aquatic ecosystems. 16 U.S.C. $2801(a)(5)$ and 16 U.S.C. $2804(a)(3)$ appear to encourage such harmful introductions. Private involvement in such introductions is especially worrisome because a private enterprise may have interests inconsistent with those of the public. Involvement of private commercial enterprises is the most worrisome. These enterprises by definition are motivated primarily to maximize their own economic profits and are therefore especially likely to take actions inconsistent with the public's interest in pro. tecting natural ecosystems and preserving native fish and shellfish populations.

A specific problem with 16 U.S.C. $2804(\mathrm{a})(3)$ is that it is ambiguous and under one interpretation encourages the involvement of commercial aquaculture enterprises in wild stock enhancement. This section could be read simply to "encourage the implementation of aquacultural technology * * * in the development of private commercial aquacultural enterprises." More troubling, the section can also be read to "encourage the implementation of aquacultural technology in the rehabilitation and enhancement of publicly owned fish and shellfish stocks * * * in the development of private commercial enterprises." The Act should at the very least be amended to remove the ambiguity and eliminate the second possible interpretation. 
Even if this ambiguity in the Act is corrected as we propose, we remain concerned about nonprofit efforts to rehabilitate or enhance publicly owned fish and shellfish stocks, if these efforts are not subject to' comprehensive environmental oversight. As discussed above, any use of aquaculture to enhance wild fish may present significant environmental risks. Furthermore, the 1980 Act should bed amended specifically to require decisions to encourage that the use of aquaculture technology in the rehabilitation and enhancement of aquaculture facilities take into account any associated environmental risks.

Accordingly, we recommend amending 16 U.S.C. 2804 (a)(3) to read as follows:

"(3) encourage the implementation of aquacultural technology-

"(A) in the rehabilitation of publicly owned fish and shellfish stocks by federal or state agencies (including rehabilitation and enhancement by private nonprofit enterprises operating under contract to and the direct supervision of federal or state agencies with responsibility for ecosystem protection), and

"(B) in the development of private commercial aquaculture;

"provided that any such implementation of aquacultural technology is expected not to result in significant ecological risks, such as undesirable changes in the genetic makeup of wild fish and shellfish stocks or the introduction of an exotic species not already present in the ecosystem."

The related finding, 16 U.S.C. $2801(5)$, should be qualified similarly.

\section{DISASTER ASSISTANCE}

S. 1288 would amend the Food, Agriculture, Conservation, and Trade Act of 1990 , 7 U.S.C. 1421 , to specifically make aquaculture producers eligible for federal disaster assistance. As discussed below, this amendment would be both poor fiscal policy and poor environmental policy, and we recommend that, to the extent that Congress decides aquaculture should receive federal protection against weather-related risks, aquaculture should be covered by crop insurance rather than disaster assistance. Moreover, the Senate Committee on Agriculture and Forestry recently passed the Federal Crop Insurance Reform Act of 1994 (S. 2095), which would reform both federal crop insurance and disaster assistance programs for agricultural producers, including, specifically, those engaged in aquaculture. We urge that insurance or assistance for aquaculture be addressed through this comprehensive legislation, rather than ad hoc in general aquaculture legislation.

USDA currently offers farmers both crop insurance and disaster assistance as aid when crops are lost or damaged. Under the Federal Crop Insurance Act of 1980, 7 U.S.C. 1501 et seq., crop insurance is supposed to be the primary form of loss protection for farmers. Crop insurance is fiscally preferable to disaster assistance because under the crop insurance program farmers must pay at least part of the costs of insurance protection (about two-thirds of the costs over the past decade). In contrast, disaster assistance is free to recipients.

Although crop insurance is available for many crops and premiums are heavily subsidized by the federal government, no more than 40 percent of eligible acres have ever been insured under the program. Congress, aware of this low participation rate, has safeguarded farmers against losses by passing ad hoc disaster assistance. legislation most years since 1983. Such disaster assistance has come at enormous cost to the federal government. For example, Congress spent $\$ 7.7$ billion on disaster assistance between 1987 and 1993 , versus $\$ 5.3$ billion on crop insurance.

A number of experts believe that disaster assistance has promoted farming in environmentally sensitive areas where farming otherwise might not be economically justified. For example, floodplain and areas with highly erodible soils may be farmed because producers know they are likely to be indemnified by Congress for losses. Similarly, federal insurance and disaster relief programs for coastal homeowners have promoted extensive coastal development that otherwise would be financially extremely risky for homeowners. Disaster assistance for aquaculture could easily promote similar phenomena, such as the establishment of marine aquaculture facilipromote similar phenomena, such as the establishment of marine aquaculture facili-
ties in storm-prone coastal areas, and also subsequently the construction of related jetties, sea walls, and other protective structures that may directly and indirectly damage natural ecosystems and other property by disrupting normal hydrology. Federal crop insurance for aquaculture producers would be less likely to promote such development than would disaster assistance, because producers relying on crop insurance would at least bear part of the costs of disaster protection.

The proposed Federal Crop Insurance Reform Act of 1994 (S. 2095) is intended to make crop insurance the dominant form of crop loss protection, in part by apparently requiring the approvals of greater than majorities in Congress to pass future ad hoc emergency relief legislation. Under S. 2095, disaster assistance would still 
be given for some crops: those which are ineligible for crop insurance because insufficient actuarial data are now available. Aquaculture "crops" are among those crops that would be covered by such assistance. However, when sufficient actuarial data are gathered, aquaculture crops would become eligible for crop insurance.

Legislation that promotes widespread purchase of crop insurance rather than reliance on disaster assistance is highly desirable for both fiscal and environmental reasons. The Environmental Defense Fund does not now endorse S. 2095, which would provide excessive federal subsidies for crop insurance premiums. However, even this bill would be far preferable to a continued reliance on fiscally irresponsible and environmentally destructive ad hoc disaster assistance, as would be given to aquaculture under S. 1288.

\section{LetTer From P.T. Rampy, CoOrdinator, Treasure Coast Coalition, Inc.}

JUNE 17, 1994.

Senator Hollings

\section{U.S. Senate,}

Washington, DC 20510

DEAR SENATOR Hollings: This letter is in response to actions on behalf of the National Oceanic and Atmospheric Administration's management of the Florida Keys National Marine Sanctuary. Argument is based on the following points:

1. Public law 101-605 designated the Florida Keys National Marine Sanctuary in 1990.

2. Section 7. (a) states that a management plan shall be completed "not later than 30 months after the date of enactment *

3. Section 7. (b) provides for "participation by the general public in development of the comprehensive management plan for the Florida Keys Sanctuary."

4. Section 5 (a) clearly states that the sanctuary shall be managed under title III of the Marine Protection, Research and Sanctuaries Act of 1972.

5. The MPRSA of 72 refers to the National Marine Sanctuary Program Development Plan (PDP) for "policy and administrative framework for continued implementation of the Program." (pg. 9)

6. "Sanctuary designation and implementation of the Management Plan enhances and ensures long-term continuity of resource protection in the area." (pg. 14)

7. Figure 1 clearly shows that implementation of the management plan comes AFTER designation. (pg. 6).

To this date no management plan has been completed. None the less the FKNMS officials are enforcing policy contained within the Draft Management Plan. The result is the taking of private property, the detention of taxpayers, the assessment of exorbitant fines and the possible incarceration of U.S. Citizens. These actions clearly reflect the implementation of rules prior to the completion and implementation of the required management plan. This is a gross violation of our rights, and an obvious breach of procedure established in the laws cited above.

Public participation was mandated in the formation of the Management Plan. The majority of the residents in the Keys voiced their opposition to the very existence of the Sanctuary Program. Their cry fell on deaf ears. Management options are presented to the Advisory Council by NOAA. They are not a product of the taxpayer.

Myself, and the thousands of taxpayers I represent in Florida and through out the nation, associated with the TREASURE COAST COALITION, INC., strongly support proactive steps aimed at the reasonable and responsible management of our natural resources to insure an equitable balance of environmental protection with inevitable growth. However this is not achieved by the creation of a redundant bureaucracy which issues volumes of confusing and conflicting rules and regulations steadily undermining our rights and freedoms.

Currently there exists dozens of formed, staffed and budgeted agencies which have jurisdictional powers in south Florida. We do not feel that it is being a good steward of OUR TAX DOLLARS to create or expand a costly, ineffective and redundant bureaucracy such as the National Marine Sanctuary Program under the auspices of NOAA.

Therefore it is without reservation that we urge congress to refrain from funding a program, which would have been described by John Locke as tyrannical, within NOAA; specifically the Florida Keys National Marine Sanctuary.

Sincerely, 


\section{Questions Asked by Senator Inouye and Answers Thereto by Dr. BaKer}

Question. I was disappointed to learn of the Administration's proposal to eliminate funding for the National Undersea Research Program (NURP). Over the years, this program has successfully enhanced scientific understanding of processes in our oceans and large lakes through undersea research and technology development. What was the basis for the Administration's recommendation to eliminate funding for NURP in Fiscal Year 1995?

Answer. While we believe that NURP is a good program, we had to make some hard decisions, and NURP fell below our cutoff in a year of extremely tight budgets.

Question. Does this recommendation reflect the Administration's position that the goals of the NURP program no longer meet the National Oceanic and Atmospheric Administration's (NOAA) mission? If so, how could NURP be revised to better support NOAA's mission?

Answer. NURP has strong potential to meet NOAA's mission. While it has contributed to some degree in the past, NURP is developing a strategic plan that will be in consonance with NOAA's strategic plan. This may help to make NURP more effective in meeting NOAA's mission.

Question. Are there any other programs within NOAA which you feel will accomplish the same goals as NURP, therefore making NURP duplicative?

Answer. NURP has unique features that are not found in any other NOAA program, e.g., access to submersibles, robotic vehicles, underwater laboratories, in situ observatories, and air and mixed-gas diving. There may be some areas of overlap with more traditional research methods, but these are not very significant.

\section{Question Asked by Senator Pressler and Answer Thereto by Dr. Baker}

Dr. Baker, at last year's hearing, we discussed the National Weather Service's plans implementing its new NEXRAD weather service system. As you know, the Weather Service Modernization Act prohibits closing any weather station unless the Secretary of Commerce certifies that there will be no degradation of service as a result of the closure. The intent of the legislation is to ensure a safe modernization program by examining on a case-by-case basis the effects of new technologies and the effects of the deletion of manpower through automation.

I am concerned that I continue to hear from weather service employees who say the intent of the Act is not being followed. One of my constituents sent me a copy of a recent report prepared by the National Research Council entitled "Toward a New National Weather Service: National Weather Service Employee Feedback." The report makes a number of findings and recommendations. For example, a majority of respondents believe the user community is inadequately prepared for modernization. In addition, field personnel are not yet convinced that the work designs and the human resource plan developed by National Weather Service headquarters will be adequate.

Question. Do you agree with any of the recommendations put forth by the National Research Council? Has the National Weather Service implemented any of the recommendations or does it have plans to do so?

Answer. The attached report on National Weather Service (NWS) Employee Feedback issued by the NWS Modernization Committee of the National Research Council (NRC) in March 1994 was based upon a survey of a sample group of NWS employees conducted in August 1992. While many of the long-awaited findings and recommendations of the NRC Panel's report were pertinent and applicable at the time the survey was conducted, extensive progress has been made in the transition process throughout the NWS since the survey.

The NWS generally agrees with all of the recommendations of the NRC report and has, to a greater or lesser degree, implemented or initiated those recommended actions. The report dealt with such matters as: employee job satisfaction; employee perception of their involvement in planning for the modernization; sources of information about the modernization; employee attitudes about NWS capability to manage the modernization; employee attitudes about the degree of user group preparation for modernization; employee concerns about NWS handling of the modernization; and, overall employee evaluation of the modernization program.

Since August 1992, significant progress has been made in the field installation and commissioning of NWS Doppler weather radar and automated surface weather observing systems. Associated with those visible transitional changes have been significant actions which have affected changes in NWS staffing and human resources policy matters. In 1993, the NWS extensively negotiated human resources management procedures with the National Weather Service Employees Organization (NWSEO), the exclusive representative of NWS employees. 
The negotiations resulted in the December 1993 issuance to employees in all field offices of the attached NWS Human Resources and Position Management Plan which summarized and outlined most of the significant personnel and human resources activities expected to occur throughout the transition. The plan answers the vast majority of the personnel-related NWS modernization questions of field employees at the time they were surveyed by the NRC.

\section{Questions Asked by Senator Kerry and Answers Thereto by Dr. BaKer}

\section{ADVANCED WEATHER INTERACTIVE PROCESSING SYSTEM (AWIPS)}

Question. The centerpiece of National Weather Service (NWS) modernization is the Advanced Weather Interactive Processing System (AWIPS), an information system that will acquire and process information from weather observation systems such as satellites and radars. I understand that there are now problems with the AWIPS procurement. What is the nature of the problems and what steps are you taking to correct them? If there is a delay in the current schedule, what impact will this delay have on the costs and future schedule of AWIPS, and what are the implications for NWS modernization?

Answer. The problems with the AWIPS contract stem from contractor failure to make progress in its detailed design of AWIPS. This problem caused the Government to reject a key design document delivered by the ontractor.

In order to correct these problems, the Government commissioned an independent team of experts to identify any underlying causes of the design problems and to pro. pose corrective action. As a result of the review, the Government plans to restructure the contract to more closely track the contractor's progress by increasing the intervals at which the system is delivered, by redefining the capabilities in the first delivered system, and by requiring an increased use of proven NWS weather forecasting applications. The latter minimizes the overall schedule impact of these contract changes upon the contract and the modernization program and provides the earliest possible delivery of systems to field offices. Management changes have been made both at PRC and NOAA to improve the management of AWIPS acquisition.

A firm schedule for the completion of the Development Phase is not possible at this time. Therefore, cost estimates are not available at this time; however, it should be noted that the major program costs under the current contract are associated with the procurement of systems in the deployment phase. When the restructure is completed, we will be in a better position to estimate the costs to the AWIPS program and associated impacts to the modernization.

\section{ROLES OF NMFS AND SEA GRANT IN AQUACULTURE}

Question. NOAA is responsible for conservation, management and wise use of the Nation's living marine resources, promoting healthy ecosystems, and strengthening coastal economies. Aquaculture has the potential to be an important component of this responsibility. What are the current roles of the National Marine Fisheries Service (NMFS) and the National Sea Grant College Program (Sea Grant) in aquaculture?

Answer. In Fiscal Year 1993 the National Sea Grant College Program supported almost 100 research projects with $\$ 7$ million in Federal and matching funds. Sea Grant addresses aquaculture in three time dimensions-immediate, mid-term, and long-term-through activities in its traditional triad: research, education, and outreach or technology transfer. The research component focuses primarily on systems development, genetics, physiology and endocrinology, nutrition, disease, policy, and economics. Sea Grant research, education, and outreach have led to the establishment or enhancement of scores of businesses.

In Fiscal Year 1993, aquaculture research conducted by NMFS was funded at $\$ 3.2$ million while NMFS provided outside support for research or hatchery operations of almost $\$ 17$ million. NMFS presently funds the operation of 25 major salmon hatcheries in the Columbia River Basin through the 1938 Mitchell Act which was established to mitigate loss of salmon runs because of construction of hydroelectric projects. The Mitchell Act hatchery program is the largest federally-funded marine fisheries enhancement program in the United States.

Several NMFS-administered state/federal and industry grant programs have addressed aquaculture development in response to industry needs and state management priorities. In the last five years, the Saltonstall-Kennedy Grant Program has provided funding for commercial aquaculture projects of between $\$ 500,000$ and $\$ 1.7$ million annually, with a trend to increased funding. In Alaska, since ratification of 
the U.S/Canada Pacific Salmon Treaty in 1985, NMFS has provided over $\$ 20$ million for salmon enhancement projects.

Question. How do you foresee the roles of NMFS and Sea Grant changing or evolving in response to the needs of the marine aquaculture industry and the potential role for aquaculture as an integral component of NOAA's mission?

NMFS and Sea Grant are currently working on an implementation plan to increase support for marine aquaculture activities. NMFS and Sea Grant will review industry needs and reevaluate current funding support to ensure that available funds promote the development of sustainable aquaculture operations.

\section{AQUACULTURE INDUSTRY ASSISTANCE}

Question. The marine aquaculture industry has expressed concerns that the permitting process for aquaculture has been a major constraint on the growth of the industry. I understand that the Army Corps of Engineers currently issues permits for activities in navigable waterways. What role do you see for NOAA in the permitting process and the promotion of responsible development of the aquaculture industry?

Answer. As part of the implementation plan, NOAA may seek to streamline the permit application process which has been repeatedly identified by industry as a major impediment to aquaculture development. A streamlined approach should:

- provide national criteria for aquaculture operations. Such criteria could ensure that aquaculture operations have limited adverse environmental impacts on natural resources under NOAA's trusteeship.

- provide that one federal agency coordinate the permit application process. Single agency coordination will reduce costs to industry and shorten the length of time required to obtain a permit. This approach could also improve cooperation between the Federal government and relevant state agencies and promote consistent regulations governing the operation of aquaculture facilities in both Federal and state waters.

To further facilitate approval of permit applications, NOAA could support an effort to identify specific areas for aquaculture development. Permit applications for aquaculture activities within such areas could be subject to expedited review because the areas would have been predetermined to be environmentally suitable for aquaculture development.

\section{ENVIRONMENTAL SAFEGUARDS FOR AQUACULTURE}

Question. Growth of the aquaculture industry has brought attention to its potential environmental effects. Most questions focus on the potential adverse impacts of disease, loss of genetic diversity, introduction of non-indigenous species and potential habitat degradation. What steps would NOAA or NMFS take to ensure that as the aquaculture industry expands, we still maintain a healthy marine environment?

Answer. NOAA support of aquaculture will be fully integrated with its other stewardship responsibilities. NOAA, having the greatest responsibility amongst all agencies for conservation of marine resources and the environment, is well suited to regulate and oversee aquaculture that affects marine ecosystems. If the U.S. aquaculture industry is to expand, a healthy aquatic environment must be sustained for all users, including the aquaculture industry. NOAA will propose an integrated research, development, and technology program in marine aquaculture to:

- Foster the development of environmentally acceptable, cost-effective intensive commercial aquaculture systems in the coastal zone and offshore. Of high priority are research and development of closed-cycle recirculating systems and offshore systems, waste-control methodologies, and the application of computer and artificial intelligence technologies to aquaculture.

- Advance NOAA's fisheries enhancement programs through the development of new hatchery rearing systems and the tailoring of candidate species for those systems, using biotechnology and other scientific approaches. High priority areas include programs to develop where appropriate technology for culturing currently over-exploited species, and those in danger of over-exploitation, better broodstocks, improved hatchery techniques, enhanced growth of high-value species, improved disease resistance and treatment, improved control of reproduction, techniques for the identification of cultured stocks in the ocean, and understanding better the genetic consequences of enhancement. 


\section{Questions Asked by Senator Dorgan and Answers Thereto by DR. BaKer}

Question. What is the role of the USDA in agricultural weather research and related activities now conducted by NOAA and/or the National Weather Service? Do USDA and NOAANational Weather Service work together on agricultural weather research and activities? Please elaborate.

Answer. The USDA and the National Weather Service have a long history of cooperation. In fact, prior to 1940, the Weather Bureau was a part of the USDA. Agrometeorological research at four NWS Agricultural Weather Service Centers (AWSC) is conducted in cooperation with the USDA through the Cooperative State Research Service and the Cooperative Extension Service.

The USDA and NWS work closely together in both their weather research activities and daily operations. Extensive discussions have been held between the two agencies regarding research and the delivery of agrometeorological information to the farmer. Specifically, the USDA's National Agricultural Weather Information System (authorized in the 1990 Farm Bill but never funded) provides a vehicle by which NWS weather and climate information can be efficiently and effectively distributed to farmers through NWS/USDA/state partnerships.

NOAA is responsible for managing, printing, and distributing the Weekly Weather and Crop Bulletin. This bulletin is prepared jointly by NOAA and USDA and has been published continuously since 1872. The unit that prepares this bulletin consists of NWS and USDA personnel co-located at a USDA facility.

The NWS has plans to take the lead in organizing an Agricultural Weather Advisory Group that will include members from NOAA, USDA, and various user groups. This group will be tasked with strengthening the partnership between NOAA and USDA, in providing agricultural weather services to enhance the Nation's production of food and fiber.

Question. What is NOAA and/or the National Weather Service currently providing to farmers with regard to real-time weather information beyond the fundamental general public forecast?

Answer. The NWS routinely provides specialized agricultural weather forecasts and advisories for agricultural operations directly to the farmer via NOAA Weather Radio and to the print and broadcast media through the Family of Services, a telecommunications system that provides environmental information (near real-time weather and flood data) to external users. Agricultural observations and climatic data specific to agricultural operations are also provided. Areas of the country with crops vulnerable to winter or spring frost are provided with fruit-frost forecasts during certain seasons of the year.

Question. In the context of modernization of the National Weather Service that is currently underway, what is the Service's long-range plan with regard to providing agricultural benefits to farmers? Does the Service plan to incorporate in its delivery of agricultural benefits the emerging technology of Doppler radar, weather satellites and automated surface observing systems?

Answer. With the arrival of new technologies and stable funding for the Agricultural Weather Services Program, the NWS plans to provide agrometeorological information to all agriculturally important areas of the country in a more equitable manner than we are now able to do. Routine agricultural forecasts issued from nearly every Weather Forecast Office (WFO) will be developed using data from each of the new systems. Methods for dissemination of Doppler weather surveillance radar (WSR-88D) output to remote offices such as the AWSCs will be explored. Automated Surface Observing Systems (ASOS) will provide observations in some rural areas that have had limited weather networks in the past.

More specifically, the WSR-88D will provide us with better short-term wind forecasts and much higher resolution rainfall information. This additional information will be useful in water resource and irrigation management, integrated pest management, scheduling of field work, and safe and efficient application of fertilizer and chemical sprays.

Question. What is NOAA's and the National Weather Service's strategy for conducting research into improved agricultural forecasting methodology? I understand that the National Weather Service plans to co-locate several of its weather service forecast offices at universities across the nation in order to utilize heavily the research and technologies currently being developed at those institutions. The decision to co-locate the Grand Forks-Fargo weather service office at the University of North Dakota-literally across the street from the Department of Atmospheric Scienceswas a wise move. The Department is home to the Regional Weather Information Center which has received federal support for the past several years to conduct agricultural weather research. I urge you and your associates to work with this group 
to forge a partnership between those who do the research and those who apply it to real-world situations.

Answer. The NWS and OAR, in accordance with the interagency plan for the U.S. Weather Research Program, are continually improving the resolution and accuracy of its weather forecasting models. Improvements in short-term forecasting are a goal of the NWS modernization and recent successes in longer range climate predictions should directly benefit U.S. agriculture. These improvements along with an increase in agrometeorological training of NWS forecasters will lead to better products and services. The AWSC program will increase the interaction between NWS meteorologists and USDA and land grant university agronomists, thus fostering regionally specific applied research in agrometeorology. Many WFOs will be co-located with universities, and our goal is to have all AWSCs associated with a land grant university. The development of robust NOAAUSDA/state/private partnerships is a key to future services to farmers.

Moreover, the NWS is planning to issue seasonal and annual forecasts of climatic conditions on an operational basis beginning in 1995. These longer-term prediction products could be of significant benefit to the agricultural community when used in conjunction with the improved short-term weather forecasts resulting from the NWS modernization.

\section{Questions Asked by Senator Gorton and Answers Thereto by Dr. Baker}

Question. Last year, NOAA attempted to consolidate the Pacific Hydrographic Section at Sand Point, Washington with the Atlantic Hydragraphic Section in Norfolk, Virginia. Fortunately, Congress rejected the reprogramming request and the office remains open and operational. I was very critical of the proposal to close this office. Can you assure me that NOAA has abandoned all plans to close or consolidate the Sand Point Office?

Answer. A number of factors have changed since the NOAA proposal to consolidate the Pacific and Atlantic Hydrographic Sections in Norfolk, Virginia. Through retirements and other attrition, the staffing at both sections has been substantially reduced. Previously identified opportunities to eliminate redundant administrative and management structure are no longer available to the same extent. The data processing infrastructure has been redesigned to be personal computer based rather than reliant on central Harris computers. Thus the savings identified from the elimination of duplicate computer facilities and the attendant maintenance costs are no longer achievable. Finally, the functions of the two processing centers have been altered, making each specifically responsible for the processing of fundamentally different data sets. For these reasons, the savings achievable through a consolidation to a single facility have greatly diminished. However, mandated personnel reductions and continuing funding difficulties make it necessary that NOAA management continue to have available for consideration all alternatives whereby program responsibilities can be restructured for more efficient and effective operation. Therefore, it is not possible, regardless of how unlikely a consolidation now appears, to assure you that future consideration or proposal of a consolidation of the two processing centers will not occur.

Question. The Department of Commerce has approved a plan to establish Individual Fishery Quotas in the halibut/blackood fishery in the North Pacific. There have been reports that NOAA does not have the financial resources to fully implement the plan. Since every year of delay results in more loss of life, it is imperative to begin the IFQ program as soon as possible. What is the status of the development of the IFQ plan?

Answer. Implementation of the halibut/blackcod individual fishing quota (IFQ) program is proceeding and is on schedule. Based on the Fiscal Year 1995 Appropriations Act, NOAA has sufficient funds to implement the IFQ plan for Alaska. Initial allocations of quota shares are in the process of being issued. An appeals process is in place for those who wish to contest the allocations based on National Marine Fisheries Service records of individual catch history. Three hundred fifty (350) card "swipe" machines have been delivered and the necessary individualized cards, software testing, and installation will be done during November and December. Fishing under the IFQ program will begin in the spring of 1995. 
BOSTON PUBLIC LIBRARY

|| 



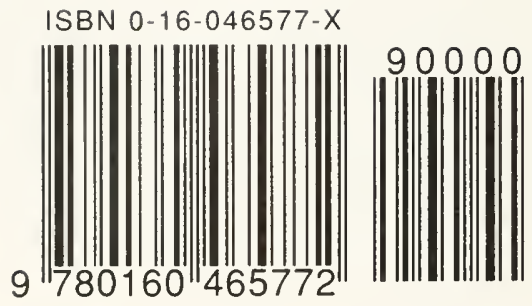

